\title{
Extraction And Analysis Of Pollutant Organics From Contaminated Solids Using Off-Line Supercritical Fluid Extraction (SFE) And On-Line SFE-Infrared Spectroscopy Task 2
}

Semiannual Report

Novem ber 1995 - March 1996

April 1996

Work Performed Under Contract No.: DE-FC21-94MC31388

U.S. Department of Energy Office of Environmental Management Office of Technology Development Washington, DC

By

Energy and Environmental Research Center University of North Dakota

Grand Forks, North Dakota 58202-9018
For

U.S. Department of Energy Office of Fossil Energy Morgantown Energy Technology Center Morgantown, West Virginia 


\section{DISCLAIMER}

Portions of this document may be illegible in electronic image products. Images are produced from the best available original document. 


\section{DISCLAIMER}

This report was prepared as an account of work sponsored by an agency of the United States Government. Neither the United States Government nor any agency thereof, nor any of their employees, makes any warranty, express or implied, or assumes any legal liability or responsibility for the accuracy, completeness, or usefulness of any information, apparatus, product, or process disclosed, or represents that its use would not infringe privately owned rights. Reference herein to any specific commercial product, process, or service by trade name, trademark, manufacturer, or otherwise does not necessarily constitute or imply its endorsement, recommendation, or favoring by the United States Government or any agency thereof. The views and opinions of authors expressed herein do not necessarily state or reflect those of the United States Government or any agency thereof.

Available to the public from the National Technical Information Service, U.S. Department of Commerce, 5285 Port Royal Road, Springfield, VA 22161; phone orders accepted at (703) 487-4650.

This report has been reproduced directly from the best available copy. 


\title{
Environmental Management Technology Demonstration and Commercialization
}

\author{
Semi-Annual Report \\ November 1995 - March 1996
}

Work Performed Under Contract No.: DE-FC21-94MC31388

\author{
For \\ U.S. Department of Energy \\ Office of Fossil Energy \\ Morgantown Energy Technology Center \\ P.O. Box 880 \\ Morgantown, West Virginia 26507-0880 \\ By \\ University of North Dakota \\ Energy and Environmental Research Corp. \\ P.O. Box 9018 \\ Grand Froks, North Dakota 58202-9018
}




\section{TASK 2 - EXTRACTION AND ANALYSIS OF POLLUTANT ORGANICS FROM CONTAMINATED SOLIDS USING OFF- LINE SUPERCRITICAL FLUID EXTRACTION (SFE) AND ON-LINE SFE-INFRARED SPECTROSCOPY}

Semiannual Report

for the period November 1, 1995, to March 31, 1996

Prepared for:

Venkat K. Venkataraman

U.S. Department of Energy

Morgantown Energy Technology Center

3610 Collins Ferry Road

PO Box 880, MS CO5

Morgantown, WV 26507-0880

UND EERC-DOE Environmental Management

Cooperative Agreement No. DE-FC21-94MC31388

Prepared by:

Steven B. Hawthorne

Energy \& Environmental Research Center

University of North Dakota

PO Box 9018

Grand Forks, ND 58202-9018 
TABLE OF CONTENTS

LIST OF FIGURES $\ldots \ldots \ldots \ldots \ldots \ldots \ldots \ldots \ldots \ldots \ldots \ldots \ldots \ldots \ldots \ldots$

1.0 INTRODUCTION/BACKGROUND $\ldots \ldots \ldots \ldots \ldots \ldots \ldots \ldots \ldots \ldots$

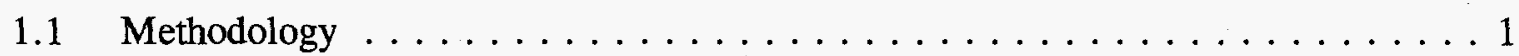

1.2 DOE Environmental Management Focus Areas $\ldots \ldots \ldots \ldots \ldots \ldots \ldots$

1.3 EERC Core Competency $\ldots \ldots \ldots \ldots \ldots \ldots \ldots \ldots \ldots \ldots \ldots \ldots \ldots \ldots \ldots$

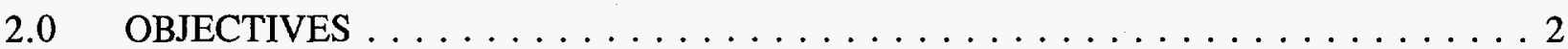

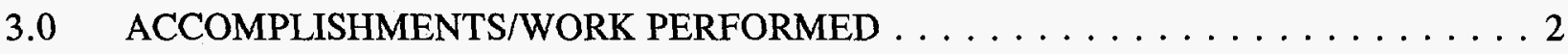

3.1 Development of Commercial Prototype for an SFE-IR Interface . . . . . . . 2

3.1.1 Evaluation of Fiber Optics . . . . . . . . . . . . . . 2

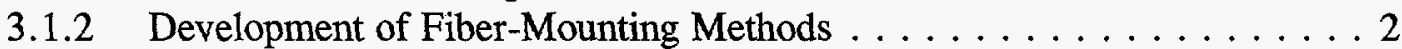

3.1.3 Development of the Prototype Commercial Optical Cell . . . . . . . 3

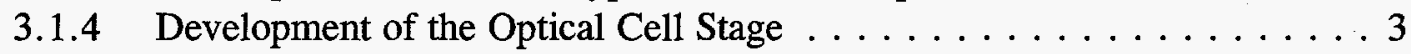

3.1.5 Development of the Cell Heater . . . . . . . . . . . . . 3

3.1.6 Testing the Prototype Commercial Version of the SFE-IR Interface . . . . 3

3.1.7 Additional Modifications of the Interface . . . . . . . . . . 3

3.2 Publications and Presentations . . . . . . . . . . . . . . . 4

\section{LIST OF FIGURES}

1 SFE-FT-IR determination of soil contaminated with PAHs $\ldots \ldots \ldots \ldots \ldots \ldots$

2 SFE-FT-IR determination of soil contaminated with gasoline $\ldots \ldots \ldots \ldots \ldots \ldots$

3 SFE-FT-IR determination of soil contaminated with diesel fuel $\ldots \ldots \ldots \ldots \ldots \ldots$ 


\section{TASK 2 - EXTRACTION AND ANALYSIS OF POLLUTANT ORGANICS FROM CONTAMINATED SOLIDS USING OFF-LINE SUPERCRITICAL FLUID EXTRACTION (SFE) AND ON-LINE SFE-INFRARED SPECTROSCOPY}

\subsection{INTRODUCTION/BACKGROUND}

\subsection{Methodology}

This activity will result in a commercialized version of a field-portable instrument for performing supercritical fluid extraction (SFE) with on-line Fourier transform infrared (FT-IR) detection. The Energy \& Environmental Research Center (EERC) has developed an SFE fieldportable method for quantitatively extracting organic pollutants (e.g., polycyclic aromatic hydrocarbons [PAHs], polychlorinated biphenyls [PCBs], total petroleum hydrocarbons [TPHs]) from soils and sludges under U.S. Environmental Protection Agency (EPA) funding. FT-IR is a detector that can yield quantitative and compound-class information for organic pollutants and is excellent for survey uses, since virtually all organic compound classes can be monitored. A laboratory prototype SFE-FT-IR instrument has been developed at the EERC and the University of North Dakota (UND) Department of Chemistry. The commercial instrument will be field-portable (requiring only generator electricity) and able to extract and measure organic pollutants from soils and sludges, identify the compound classes present, and provide quantitative or semiquantitative results at detection limits relevant to regulatory needs (e.g., parts per million to parts per billion). The SFE-FT-IR approach is particularly advantageous for very hazardous samples (e.g., determination of organics in solids contaminated with radioactive components), since SFE-FT-IR analysis generates no waste solvents. The instrument will also be configured to allow collection of "positive" extracts for analysis by other confirmatory (e.g., gas chromatography-mass spectroscopy [GC-MS]) methods.

\subsection{DOE Environmental Management Focus Areas}

The instrument fulfills the Environmental Management (EM) needs for extracting and measuring organic pollutants ranging from volatiles (e.g., halogenated solvents, benzene, toluene, ethylbenzene, xylenes) to semivolatiles (e.g., PAHs, PCBs, and petroleum hydrocarbons). Relevant samples will be solids and semisolids such as soils and waste sludges. The instrument will be applied in several of the EM Focus Areas, including Contaminated Landfill, Mixed Wastes, Decontamination and Decommissioning and, possibly, for Tank Wastes. Crosscutting areas include Characterization, Monitoring, and Sensor Technology (primary area), with strong applicability to Pollution Prevention.

\subsection{EERC Core Competency}

The EERC and the UND Department of Chemistry jointly developed and constructed the first SFE-IR and SFE-FT-IR interfaces. Both systems have been shown to have excellent analytical characteristics for organic pollutants in soil sludges. Field demonstrations of prototype systems are currently being conducted. Dr. Steven Hawthorne (EERC) is considered a world leader in the use of SFE for the extraction of organic pollutants, and Professor David Tilotta (Department of Chemistry, UND) is known for his development of rapid analysis techniques by coupling solvent- 
free extraction and spectroscopic methods. The commercial partner (Suprex Corporation, Pittsburgh, PA) is widely recognized as a leading supplier of analytical SFE instrumentation.

\subsection{OBJECTIVES}

The major objective is to develop, test, and construct a commercial version of the fiber optic SFE-FT-IR interface in conjunction with Suprex Corporation. The specific objectives for this year are:

- To evaluate optical fibers for optical clarity and chemical inertness to determine the optimal fibers for the commercial interface.

- To develop, construct, and test a prototype of the high-pressure optical cell.

- To produce prototype interfaces for "beta site" testing.

\subsection{ACCOMPLISHMENTS/WORK PERFORMED}

\subsection{Development of Commercial Prototype for an SFE-FT-IR Interface}

An agreement has been reached with Suprex Corporation (Pittsburgh, PA) to commercialize the SFE-FT-IR interface. Suprex is one of the three leading SFE instrument suppliers and has established a worldwide market for its SFE instrumentation. A prototype commercial SFE-FT-IR interface will be produced in the first year. Beta site testing, final development and production of the commercial version, and demonstrations will be performed in the second year.

\subsubsection{Evaluation of Fiber Optics}

Problems in choosing optical fibers for evaluation include 1) reluctance of manufacturers to supply small quantities, 2) large variations in the quality of so-called "identical" fiber materials, and 3) large differences in the materials used for cladding the optical fibers. Fortunately, two suitable fiber optics have been procured: one based on chalcogenide material, and one based on silver halide. Both are suitably clear through the desired IR spectral range. Both have been mounted in the prototype commercial interface and are undergoing continuing evaluation.

\subsubsection{Development of Fiber-Mounting Methods}

Because of the variations in fiber-cladding material, different approaches to fiber mounting are needed. We have developed two approaches that have performed reliably over large pressure ranges (up to $450 \mathrm{~atm}$ ), at least for the short-term tests that have been possible to date. The first approach uses a stainless steel tube that has been drilled to close specifications which allows the fiber to be inserted with a small amount of sealing epoxy resin (used for the chalcogenide fiber). The second approach uses a $15 \%$ graphite/85\% polyimide predrilled ferrule and standard 1/16-inch high-pressure fittings (for the silver halide fiber). This approach has been tested for about 1 month at pressures up to $450 \mathrm{~atm}$ with no failures. 
Both approaches have been designed to be compatible with standard high-pressure fittings to reduce manufacturing costs and increase reliability.

\subsubsection{Development of the Prototype Commercial Optical Cell}

Commercially available low-dead-volume crosses have been found that reduce both the size and the number of connections needed by ca. $1 / 3$ the number needed by the initial prototype version. Only minor modifications (e.g., drilling the optical path through the union) have been needed. The prototype commercial version of the interface has been developed based on these commercial crosses. An additional advantage is their relatively low cost (ca. $\$ 60$ each).

\subsubsection{Development of the Optical Cell Stage}

A prototype commercial version of the optical cell mounting stage has also been developed which incorporates three dimensions of adjustment and provisions for a cell heating chamber. Additional developments to include the focusing lenses are presently being designed.

\subsubsection{Development of the Cell Heater}

Suprex has supplied a prototype heating chamber for the optical cell which is controlled by existing connections and software on its SFE instrumentation. This heater has just been installed and appears to work well.

\subsubsection{Testing the Prototype Commercial Version of the SFE-IR Interface}

Preliminary robustness testing has been performed with the silver halide fiber optics described above. To date, the interface has performed reliably for ca. 1 month over the target pressure range (e.g., up to $450 \mathrm{~atm}$ ). Several real-world samples have been extracted, and the interface appears to have little or no memory (e.g., contaminant carryover) from sample to sample. Examples of SFE-FT-IR determinations of PAHs, diesel fuel, and gasoline on soil are shown in Figures 1-3.

At present, the sensitivity of the interface is not as low as desired for the commercial version (as is expected at this stage of development). Therefore, future work will focus on optimizing the factor controlling sensitivity, including optical alignment of the cell and focusing lenses, optimizing cell path length (i.e., the distance between the optical fibers in the cell interior), and optimizing the transfer of extracted analytes from the extraction cell to the optical cell.

\subsubsection{Additional Modifications of the Interface}

Ray Houck (Suprex) is scheduled to visit our lab in early April to work on integrating and optimizing the use of the prototype commercial interface with the Suprex SFE, system. His suggestions and comments should be very valuable in modifying our present design to make the interface robust and user friendly for the commercial market. 


\subsection{Publications and Presentations}

A manuscript describing the field demonstrations of SFE performed last summer and fall has been submitted for publication in Environmental Science and Technology.

Steve Hawthorne presented an invited keynote lecture (expenses paid) at the Fourth International Symposium on Hyphenated Techniques in Chromatography held in Belgium during February 1996. The lecture included a description of the development of the SFE-FT-IR interface and presented results from SFE-FT-IR analyses of contaminated soils. 


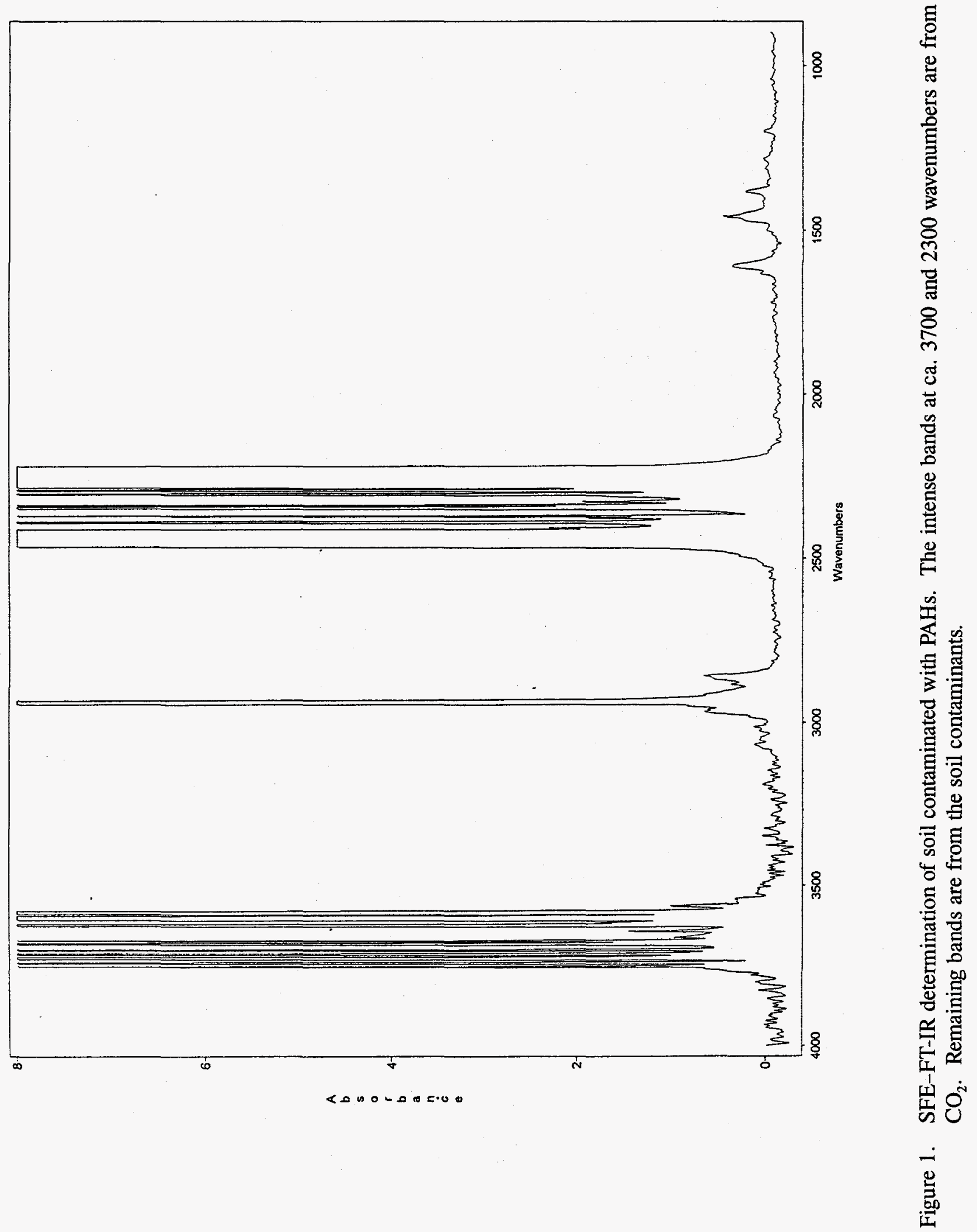




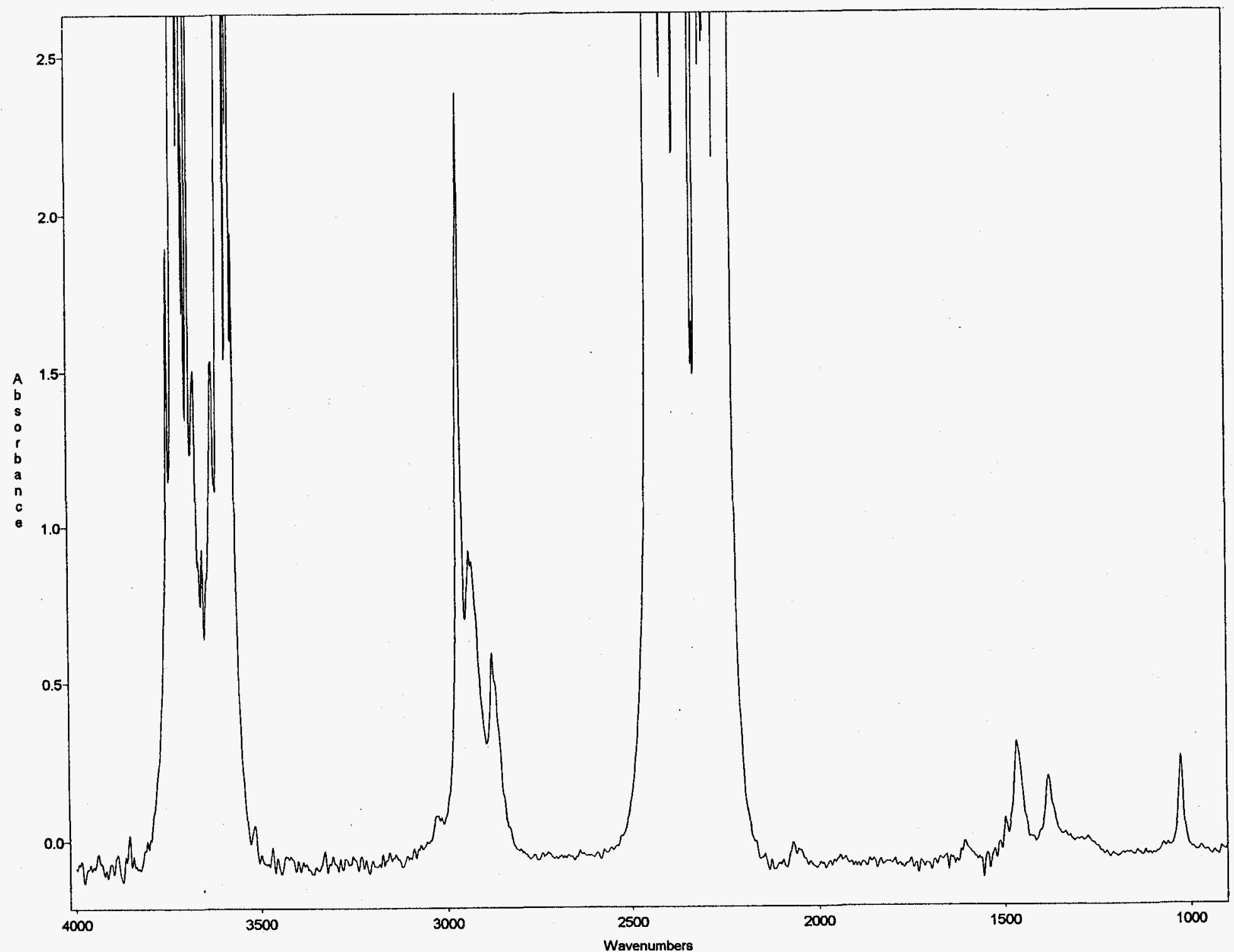

Figure 2. SFE-FT-IR determination of soil contaminated with gasoline. The intense bands at ca. 3700 and 2300 wavenumbers are from $\mathrm{CO}_{2}$. Remaining bands are from the soil contaminants. 


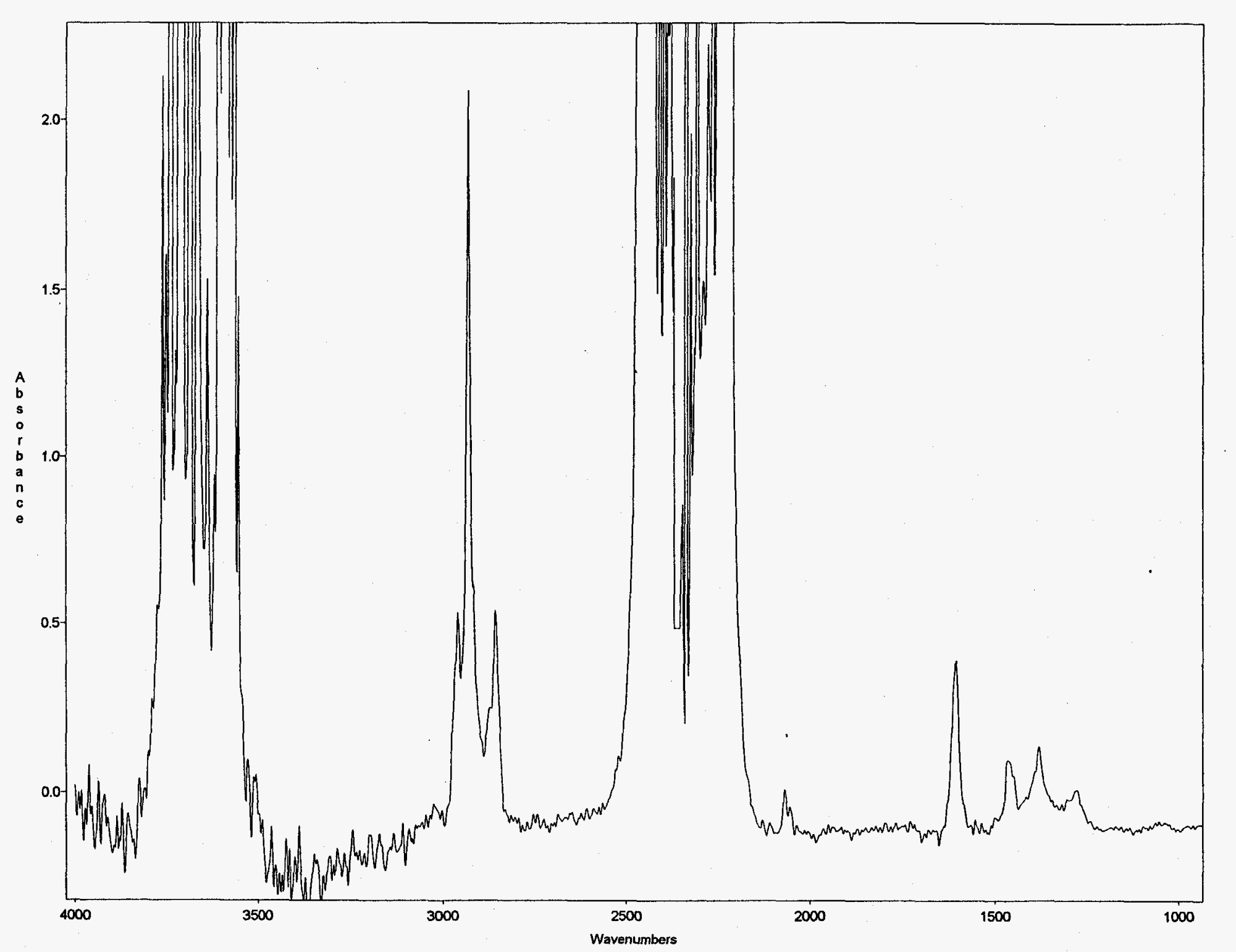

Figure 3. SFE-FT-IR determination of soil contaminated with diesel fuel. The intense bands at ca. 3700 and 2300 wavenumbers are
from $\mathrm{CO}_{2}$. Pemainas bands are 
FORM APPROVED

OMB NO. 19000127

1. Program/Project Identification No. DE-FC21-94MC31388

2. Program/Project Title

EM Task 2 - Extraction and Analysis of Pollutant Organics

4. Name and Address Energy \& Environmental Research Center University of North Dakota

PO Box 9018, Grand Forks, ND 58202-9018
(701) $777-5000$

\section{Reporting Period \\ 1/1/96 through 3/31/96 \\ 5. Program/Project Start Date 9/30/94 \\ 6. Completion Date 9/29/99}

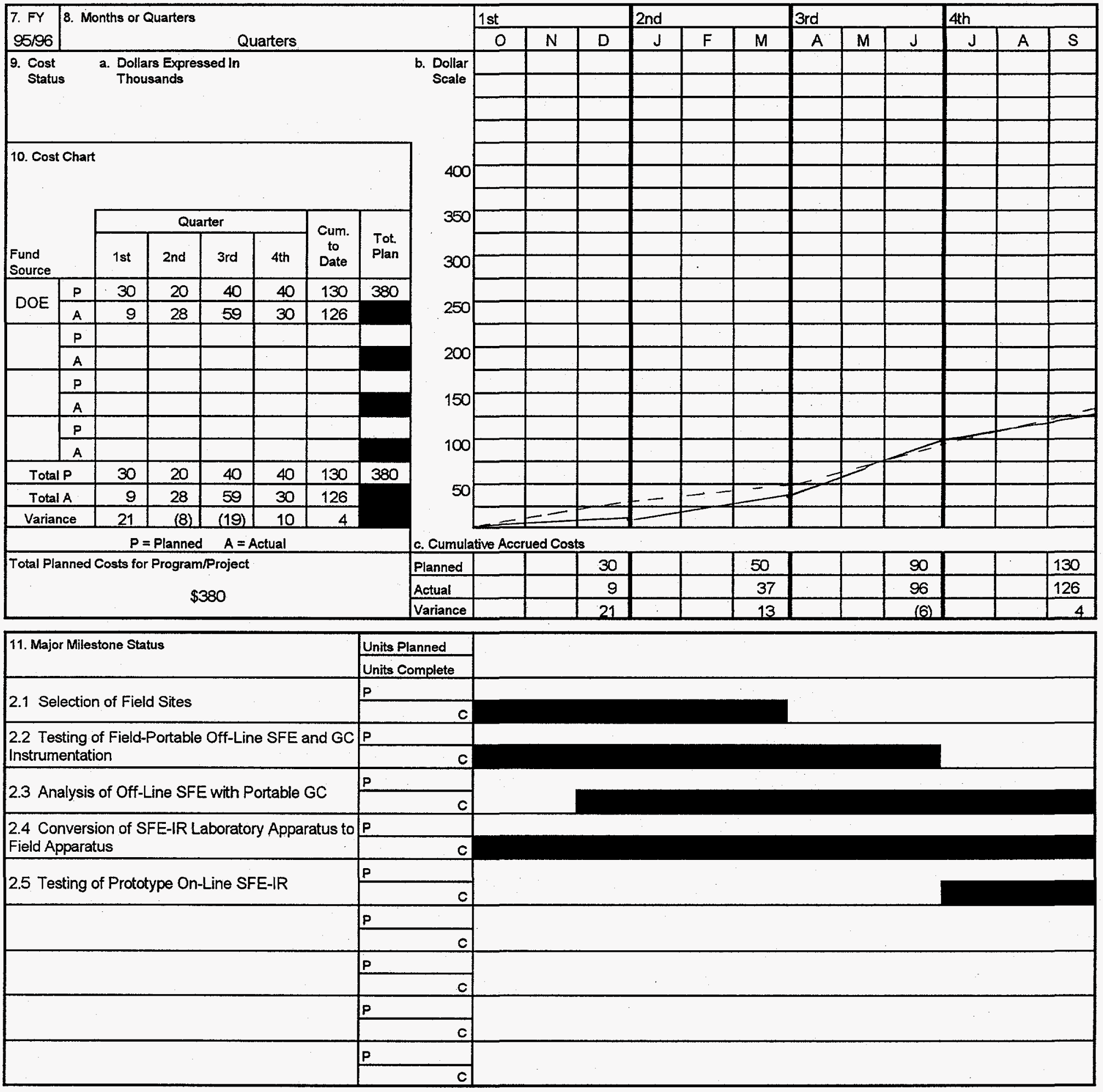

12. Remarks

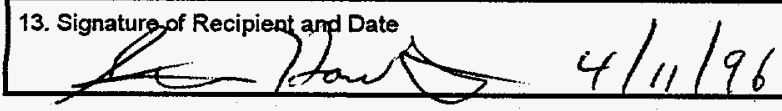


2. Program/Project Title

EM Task 2 - Extraction and Analysis of Pollutant Organics

DE-FC21-94MC31388

4. Name and Address Energy \& Environmental Research Center University of North Dakota

PO Box 9018 , Grand Forks, ND 58202-9018 (701) 777-5000
OMB NO. 19000127

Page 2 of 3

3. Reporting Period

1/1/96 through 3/31/96

5. Program/Project Start Date 9/30/94

6. Completion Date $9 / 29 / 99$

\begin{tabular}{l|l|}
$\begin{array}{l}\text { 7. FY } \\
96 / 97\end{array}$ & 8. Months or Quarters \\
\begin{tabular}{ll} 
9. Cost & Q. Dollars Expressed In \\
Status & Thousands \\
\hline
\end{tabular}
\end{tabular}

10. Cost Chart

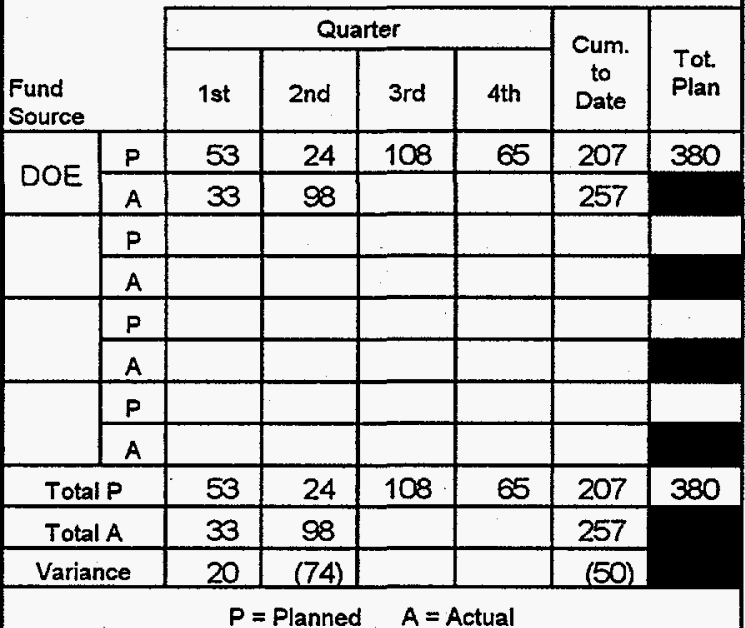

Total Planned Costs for Program/Project

\section{$\$ 380$}

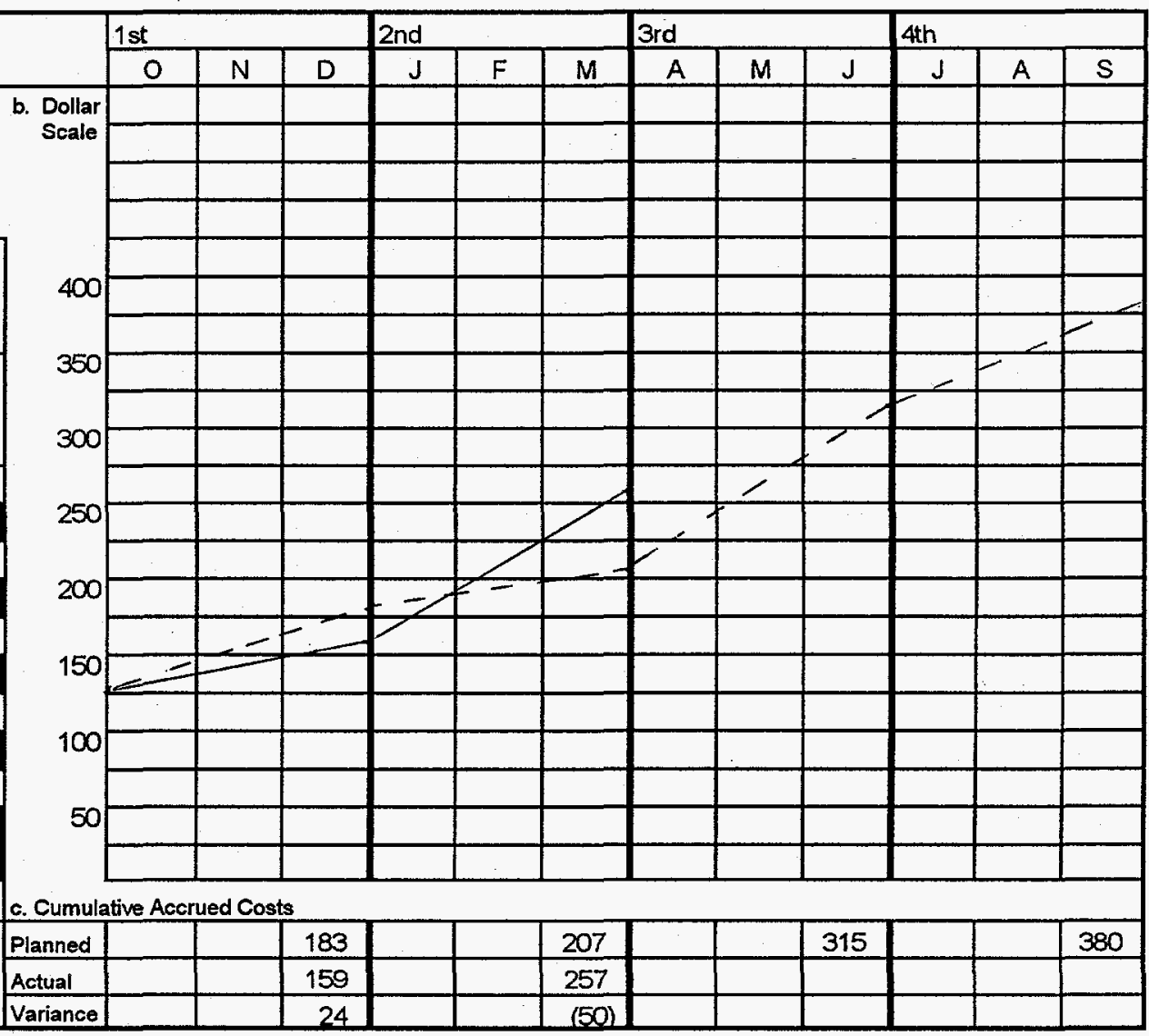

11. Major Milestone Status

2.1 Evaluation of Optical Fibers for Optical Clarity and Chemical Inertness

2.2 Development and Testing of the Prototype High-Pressure Optical Cell

2.3 Producing Prototype Interfaces for "Beta-Site" Testing

13. Signature of Recipient ang Date

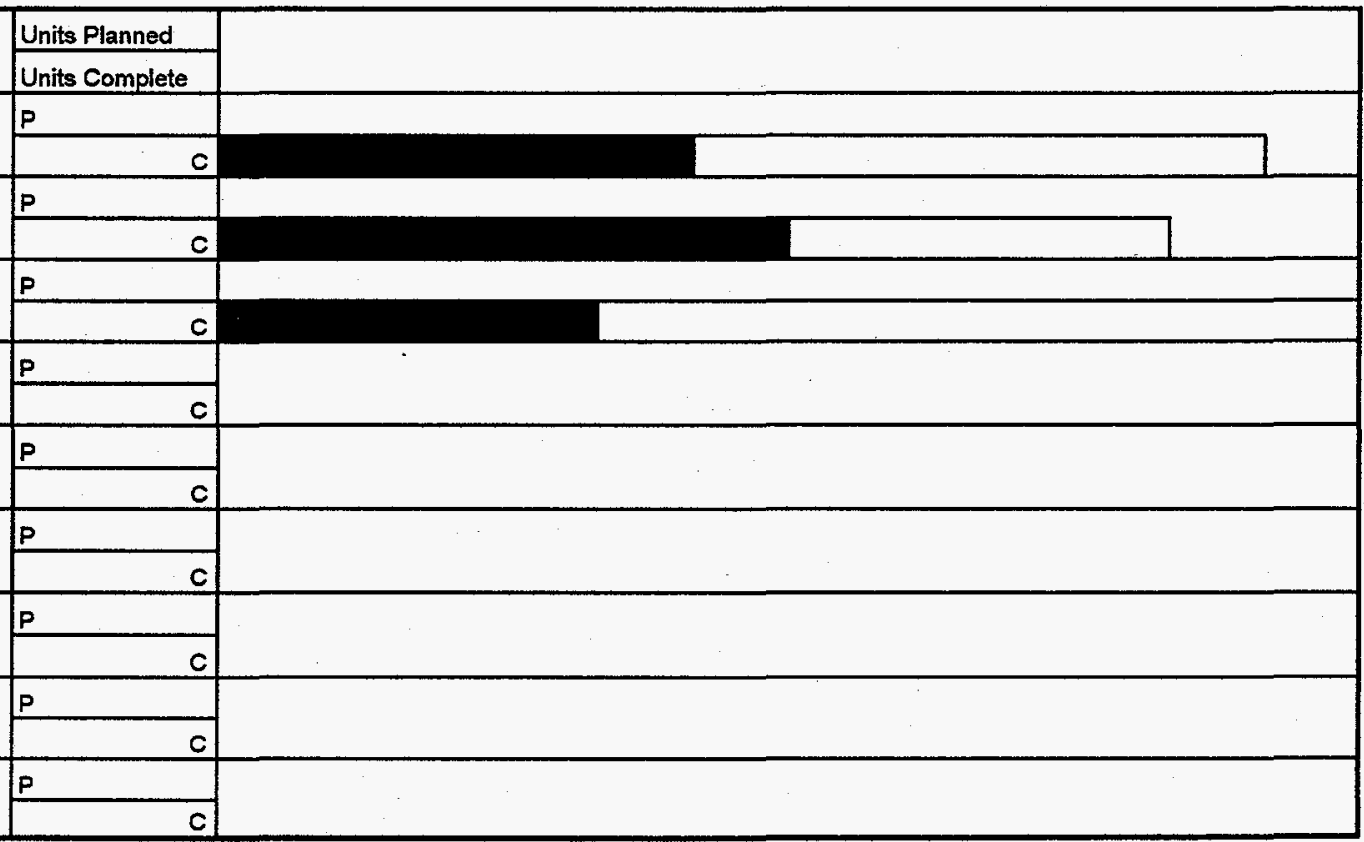

\section{Remarks}


2. Program/Project Title

EM Task 2-Extraction and Analysis of Pollutant Organics from Contaminated Solids Using Off-Line SFE and On-Line SFE-IR

4. Name and Address Energy \& Environmental Research Center University of North Dakota PO Box 9018 Grand Forks, ND 58202-9018 (701) $777-5000$

\begin{tabular}{|c|l|}
\hline $\begin{array}{l}\text { Milestone } \\
\text { ID. No. }\end{array}$ & \multicolumn{1}{|c|}{ Description } \\
\hline Year 1 & \\
2.0 & $\begin{array}{l}\text { Extraction and Analysis of Pollutant Organics from } \\
\text { Contaminated Solids Using Off-Line SFE and On-Line SFE- } \\
\text { IR }\end{array}$ \\
\hline
\end{tabular}

2.1 Selection of Field Sites

2.2 Testing of Field-Portable Off-Line SFE and GC Instrumentation

2.3 Analysis of Off-Line SFE with Portable GC

2.4 Conversion of SFE-IR Laboratory Apparatus to Field Apparatus

2.5 Testing of Prototype On-Line SFE-IR

Year 2

2.1 Evaluation of Optical Fibers for Optical Clarity and Chemical Inertness

2.2 Development and Testing of the Prototype High-Pressure Optical Cell

2.3 Producing Prtotype Interfaces for "Beta-Site" Testing
3. Reporting Period $1 / 1 / 96$ through $3 / 31 / 96$

5. Program/Project Start Date 9/30/94

6. Completion Date 9/29/99

\section{Actual} Completion Date 


\title{
TASK 3 - PYROLYSIS OF PLASTIC WASTE
}

\author{
Semiannual Report
}

for the period November 1, 1995, through March 31, 1996

Prepared for:

Venkat K. Venkataraman

U.S. Department of Energy

Morgantown Energy Technology Center

3610 Collins Ferry Road

PO Box 880, MS C05

Morgantown, WV 26507-0880

EERC-DOE Environmental Management

Cooperative Agreement No. DE-FC21-94MC31388

Prepared by:

Robert O. Ness

Ted R. Aulich

Energy \& Environmental Research Center

University of North Dakota

PO Box 9018

Grand Forks, ND 58202-9018

April 1996 


\section{TABLE OF CONTENTS}

LIST OF TABLES $\ldots \ldots \ldots \ldots \ldots \ldots \ldots \ldots \ldots \ldots \ldots \ldots \ldots \ldots \ldots \ldots$

1.0 INTRODUCTION/BACKGROUND $\ldots \ldots \ldots \ldots \ldots \ldots \ldots \ldots \ldots \ldots$

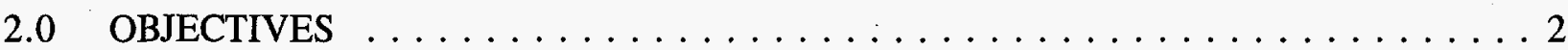

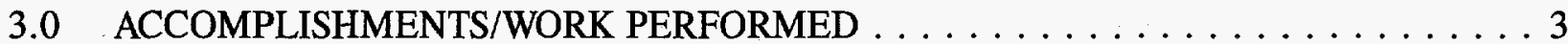

3.1 Initial Test Results $\ldots \ldots \ldots \ldots \ldots \ldots \ldots \ldots \ldots$

3.2 Process Commercialization - Stone \& Webster Participation . . . . . . . . . . . . 5

3.3 Establishment of Minimum Surrogate Detection Limits . . . . . . . . . . . . 6

4.0 WORK PLANNED FOR THE NEXT SIX MONTHS $\ldots \ldots \ldots \ldots \ldots \ldots \ldots$

AN EXAMPLE OF A TECHNOLOGY APPLICATION ANALYSIS . . . . . . . . Appendix A

\section{LIST OF TABLES}

1 Radioactive Waste Generation Volumes $\ldots \ldots \ldots \ldots \ldots \ldots \ldots \ldots$

2 Surrogate Concentrations in Thermal Decomposition Products - General Reactivity Effects $\ldots \ldots \ldots \ldots \ldots \ldots \ldots \ldots \ldots \ldots \ldots \ldots \ldots \ldots \ldots \ldots$

3 Surrogate Concentrations in Thermal Decomposition Products - Actinides Simulation . . . . 4

4 Surrogate Concentrations in Thermal Decomposition Products - Reactor Waste Simulation . . 4

5 Radionuclide Surrogate Detection Limits $\ldots \ldots \ldots \ldots \ldots \ldots \ldots$ 


\section{TASK 3 - PYROLYSIS OF PLASTIC WASTE}

\subsection{INTRODUCTION/BACKGROUND}

Over the last 50 years, the U.S. Department of Energy (DOE) has produced a wide variety of radioactive wastes from activities associated with nuclear defense and nuclear power generation. These wastes include low-level radioactive solid wastes, mixed wastes, and transuranic (TRU) wastes. A portion of these wastes consists of high-organic-content materials, such as plastics and other polymers, synthetic and natural rubbers, resins, and cellulosic-based materials, as well as oils, organic solvents, and chlorinated organic solvents. Many of these wastes contain hazardous materials in addition to radioactive species. Physical forms of the waste include ion-exchange resins used to remove radioactive elements from water at nuclear energy facilities, lab equipment and tools (e.g., measurement and containment vessels, hoses, wrappings, equipment coverings and components, and countertops), oil products (e.g., vacuum pump and lubrication oils), bags and other storage containers (for liquids, solids, and gases), solvents, gloves, lab coats and anticontamination clothing, and other items. Major polymer and chemical groups found in highorganic-content radioactive wastes include polyvinyl chloride (PVC), low-density polyethylene (LDPE), polypropylene (PP), Teflon ${ }^{\mathrm{TM}}$, polystyrene (PS), nylon, latex, polyethylene terephthalate (PET), vinyl, high-density polyethylene (HDPE), polycarbonate, nitriles, Tygon ${ }^{\circledR}$, butyl, and Tyvec $^{\circledR}$.

Costs associated with the accumulation, storage, and disposal of high-organic-content radioactive wastes are high because of irregularities in shape, volume, and composition. Storage of combinations of these contaminated materials in sealed barrels and other containers can cause degradation reactions that yield a wide range of radioactive products (many of which have some degree of volatility and/or environmental mobility) and other hazardous materials, including hydrogen gas. Options for dealing with high-organic-content radioactive waste include volume reduction and storage. Large quantities of these wastes are currently being stored in barrels and casks. One waste reduction option involves separating wastes into combustibles and noncombustibles and then incinerating the combustibles to yield ash and gas. The radioactive component of the waste is reduced in volume and can be stored more easily. Difficulties associated with this approach include the potential for entrainment of radioactive species in the product gas stream and volatilization of radioactive species during the high-temperature combustion process. On-line and full-stream gas analysis systems are being developed to monitor emissions more accurately, but controlling volatile emissions is limited by physical constraints and statistical probabilities.

The University of North Dakota Energy \& Environmental Research Center (EERC) is developing a process for efficient, complete separation of radionuclides from high-organic-content radioactive waste. The process is a low-temperature thermal decomposition-separation technology that will yield a small volume of particulate solids product containing radioactive species, a nonradioactive organic condensate (liquid) product, and a nonradioactive hydrocarbon-rich gas product. By controlling process conditions, the yield of organic condensate product can be varied from 20 to $80 \mathrm{wt} \%$ of the feed material, with the remaining organic content of the feed material converted to gas. Processing at a low reactor temperature $\left(600^{\circ} \mathrm{C}\right.$ or below) ensures against radionuclide volatilization and results in a high condensate yield versus a high gas yield. 
The EERC thermal decomposition-separation process for radionuclide separation is not a combustion process. The process will accomplish the following:

- Decompose, volatilize, and recover the condensable organic content of a waste

- Volatilize and capture chlorine (which may be present in the waste as either organic or inorganic materials)

- Concentrate radionuclide species in a dry particulate solids product

The process will be applicable to the separation of radionuclides from the following waste streams:

- Low-level radioactive solid waste, defined as solid radioactive waste that is not classified as high-level waste, TRU waste, or spent nuclear fuel as defined in DOE Order 5820.2A. This category is generally used to refer to wastes that are radioactive but do not contain components classified as hazardous.

- Mixed wastes, defined as wastes that contain both radioactive and hazardous components as defined by the Atomic Energy Act and the Resource Conservation and Recovery Act (RCRA), including solvents, pyrophoric substances, and other chemically contaminated items. Wastes under this category are of special importance 1) because no current plan for their treatment has been accepted and 2) because of their chemical diversity, these wastes could react during containment to yield a wide variety of products, many of which may be volatile, reactive, ignitable, toxic, or otherwise hazardous.

- TRU waste, defined as waste that has a radioactivity greater than 100 nanocuries per gram ( $\mathrm{nCi} / \mathrm{g}$ ) and is contaminated with alpha-emitting radionuclides that have an atomic number greater than 92 and a half-life of greater than 20 years.

Inventories of low-level, mixed, and TRU wastes accumulated throughout the United States as of 1993 have been compiled and are detailed in a report prepared by Oak Ridge National Laboratory entitled "Integrated Data Base Report - 1993: U.S. Spent Nuclear Fuel and Radioactive Waste Inventories, Projections, and Characteristics" (DOE/RW-0006, Rev. 10, December, 1994). Table 1 compares data from the report with data from Los Alamos National Laboratory (LANL) on radioactive waste generation through 1993 and with data for LANL radioactive waste generation in 1994. A significant portion of annually generated radioactive organic waste is made up of spent (radionuclide-loaded) ion-exchange resins from nuclear power facilities, and in addition to nuclear defense and power generation activities, large volumes of lowlevel radioactive wastes are generated by hospitals and medical research facilities. The EERC technology is being developed for application to these and other waste streams.

\subsection{OBJECTIVES}

The EERC is developing a technology for the thermal decomposition of high-organic-content, radionuclide-contaminated mixed wastes that will enable the separation and concentration of radionuclides as dry particulate solids and the generation of nonradioactive condensate (liquid) and 


\section{TABLE 1}

Radioactive Waste Generation Volumes, $\mathrm{m}^{3}$

\begin{tabular}{lccc}
\hline & DOE Volume & LANL Volume & LANL Volume \\
Waste Type & Through 1993 & Through 1993 & 1994 \\
\hline Low-Level & $2,911,000$ & 220,700 & 2963 \\
Low-Level/Mixed & 173,900 & 665 & 76 \\
TRU & 104,100 & 10,810 & 67 \\
TRU/Mixed & 5187 & 619 & 17 \\
\hline
\end{tabular}

gas products. Successful application of the technology will enable a significant volume reduction of radioactive waste and the production of a nonradioactive organic product that is easily disposed or, ideally, will have value as an oil refinery or chemical feedstock. The objective of the proposed effort is to develop and demonstrate the commercial viability of a continuous thermal decomposition process that can fulfill the following requirements:

- Separate radionuclides from a variety of radioactive waste streams containing a variety of types and levels of polymers, chlorinated species, and other organics, including rubber, oils, resins, and cellulosic-based materials.

- Concentrate radionuclides in a homogeneous, dry particulate product that can be recovered, handled, and disposed of efficiently and safely.

- Separate and recover any chlorine present (as PVC, chlorinated solvents, or inorganic chlorine) in the contaminated mixed-waste stream.

- Yield a nonradioactive, low-chlorine-content, organic condensate product that can be economically disposed of or, ideally, is acceptable to a refinery as a petroleum product or chemical feedstock.

\subsection{ACCOMPLISHMENTS/WORK PERFORMED}

\subsection{Initial Test Results}

Using the continuous fluid-bed reactor (CFBR) system described in the previous semiannual report (April-October 1995), nine CFBR tests were performed at a reactor feed rate of about 1 $\mathrm{kg} / \mathrm{hr}$ of mixed polymers with added alkaline chlorine sorbent and selected radionuclide surrogates. Information regarding radionuclide surrogates, test feedstock compositions, reaction conditions, analytical procedures, and preliminary data reduction is provided in the April-October report. The objective of these preliminary screening tests was to investigate the effectiveness of the EERC thermal decomposition process in concentrating radionuclide surrogates in a solid product while yielding a surrogate-free condensate product, based on per surrogate liquid detection limits of about $5 \mu \mathrm{g} / \mathrm{g}$. The test results shown in Tables 2-4 indicate that even at a decomposition temperature of $600^{\circ} \mathrm{C}$, the surrogates (most of which were added to the feedstocks as highly reactive chlorides and nitrates) do not react to form volatile species, but either react to yield nonvolatile solids or remain 
TABLE 2

Surrogate Concentrations in Thermal Decomposition Products - General Reactivity Effects ${ }^{1}$

\begin{tabular}{lrcrrrrc}
\hline Test No.: & M526 & M526 & M524 & M524 & M525 & M525 & $\begin{array}{c}\text { M525 } \\
\text { Temp, }{ }^{\circ} \mathrm{C}:\end{array}$ \\
& 451 & 451 & 494 & 494 & 588 & 588 & $\begin{array}{c}588 \\
\text { Filtered } \\
\text { Condensate }\end{array}$ \\
Product & Solids & Condensate & Solids & Condensate & Solids & Condensate & $<5$ \\
\hline $\mathrm{Ca}, \mu \mathrm{g} / \mathrm{g}$ & 126,200 & 627 & 322,200 & 1660 & 275,600 & $<5$ & $<5$ \\
$\mathrm{~V}, \mu \mathrm{g} / \mathrm{g}$ & 6469 & 16 & 19,340 & 22 & 15,490 & $<5$ & $<5$ \\
$\mathrm{Sn}, \mu \mathrm{g} / \mathrm{g}$ & 3593 & 910 & 10,089 & 229 & 10,020 & 4 & $<5$ \\
$\mathrm{Sb}, \mu \mathrm{g} / \mathrm{g}$ & 11,710 & 124 & 13,440 & 102 & 25,160 & 8 & $<5$ \\
$\mathrm{Cu}, \mu \mathrm{g} / \mathrm{g}$ & 10,300 & 43 & 13,170 & 5 & 8120 & $<5$ & $<5$ \\
$\mathrm{Ti}, \mu \mathrm{g} / \mathrm{g}$ & 2063 & 59 & 3620 & 157 & 2931 & 7 & $<5$ \\
\hline
\end{tabular}

${ }^{1}$ All concentration values are averages of duplicate analyses.

TẢBLE 3

Surrogate Concentrations in Thermal Decomposition Products - Actinides Simulation ${ }^{1}$

\begin{tabular}{|c|c|c|c|c|c|c|c|}
\hline Test No.: & M527 & M527 & M528 & M528 & M529 & M529 & M529 \\
\hline Temp, ${ }^{\circ} \mathrm{C}:$ & 451 & 451 & 495 & 495 & 602 & 602 & $\begin{array}{c}602 \\
\text { Filtered }\end{array}$ \\
\hline Product & Solids & Condensate & Solids & Condensate & Solids & Condensate & Condensate \\
\hline $\mathrm{Ca}, \mu \mathrm{g} / \mathrm{g}$ & 285,200 & 7950 & 173,300 & 3840 & 194,800 & 11,240 & $<5$ \\
\hline $\mathrm{V}, \mu \mathrm{g} / \mathrm{g}$ & 14,970 & 344 & 10,450 & 153 & 17,670 & 537 & $<5$ \\
\hline $\mathrm{Sn}, \mu \mathrm{g} / \mathrm{g}$ & 11,840 & 687 & 14,590 & 450 & 22,640 & 1570 & $<5$ \\
\hline $\mathrm{Sb}, \mu \mathrm{g} / \mathrm{g}$ & 15,550 & 646 & 23,460 & 359 & 28,340 & 2450 & $<5$ \\
\hline $\mathrm{Cu}, \mu \mathrm{g} / \mathrm{g}$ & 28,960 & 18 & 5435 & 10 & 12,060 & 115 & $<5$ \\
\hline $\mathrm{Zr}, \mu \mathrm{g} / \mathrm{g}$ & 5386 & 240 & 7262 & 159 & 8079 & 744 & $<5$ \\
\hline $\mathrm{Ce}, \mu \mathrm{g} / \mathrm{g}$ & 5699 & 82 & 5816 & 56 & 7313 & 231 & $<5$ \\
\hline $\mathrm{Nd}, \mu \mathrm{g} / \mathrm{g}$ & 4648 & 33 & 2576 & 21 & 4289 & 97 & $<5$ \\
\hline
\end{tabular}

${ }^{1}$ All concentration values are averages of duplicate analyses.

TABLE 4

Surrogate Concentrations in Thermal Decomposition Products - Reactor Waste Simulation ${ }^{1}$

\begin{tabular}{|c|c|c|c|c|c|c|c|}
\hline Test No.: & M532 & M32 & M530 & M530 & M531 & M531 & M531 \\
\hline Temp, ${ }^{\circ} \mathrm{C}:$ & 447 & 447 & 497 & 497 & 583 & 583 & 583 \\
\hline Product & Solids & Condensate & Solids & Condensate & Solids & Condensate & $\begin{array}{c}\text { Filtered } \\
\text { Condensate }\end{array}$ \\
\hline $\mathrm{Ca}, \mu \mathrm{g} / \mathrm{g}$ & 200,400 & 1120 & 256,400 & 4970 & 244,400 & $<5$ & $<5$ \\
\hline $\mathrm{V}, \mu \mathrm{g} / \mathrm{g}$ & 19,820 & 42 & 24,110 & 153 & 21,850 & $<5$ & $<5$ \\
\hline Cs, $\mu \mathrm{g} / \mathrm{g}$ & 15,630 & 130 & 19,940 & 252 & 22,240 & $<50$ & $<50$ \\
\hline $\mathrm{Ru}, \mu \mathrm{g} / \mathrm{g}$ & 1990 & $<5$ & 66 & 6 & 2400 & $<5$ & $<5$ \\
\hline $\operatorname{Re}, \mu \mathrm{g} / \mathrm{g}$ & 1498 & 8 & 1067 & 19 & 1220 & $<5$ & $<5$ \\
\hline $\mathrm{K}, \mu \mathrm{g} / \mathrm{g}$ & 5815 & 85 & 5714 & 109 & 11,170 & $<50$ & $<50$ \\
\hline $\mathrm{I}, \mu \mathrm{g} / \mathrm{g}$ & 16,200 & 55 & 14,300 & 130 & 31,500 & 42 & $\mathrm{NA}^{2}$ \\
\hline $\mathrm{Sr}, \mu \mathrm{g} / \mathrm{g}$ & 4843 & 14 & 12,950 & 33 & 10,990 & $<5$ & $<5$ \\
\hline $\mathrm{Cl}, \mu \mathrm{g} / \mathrm{g}$ & 78,600 & 650 & 55,200 & 1650 & 75,600 & $<20$ & NA \\
\hline
\end{tabular}

${ }^{1}$ All concentration values are averages of duplicate analyses.

${ }^{2}$ Not analyzed. 
inert to enable their concentration and recovery as nonvolatile solids. The fact that all condensate surrogate concentrations were either below detection limits or were reduced to levels below detection limits by filtration (with an $8-\mu \mathrm{m}$ filter) indicates that the surrogates detected in the unfiltered liquids were not present as volatile species, but were probably present as a result of entrainment in the process gas stream and nonremoval by the less-than-adequate particulate control system. Resizing of the product gas stream cyclone will be done to increase particulate removal effectiveness; the use of a postreactor sorbent bed (primarily for chlorine capture) would also reduce particulate carryover. It is recognized that demonstration of "zero" radioactive emissions will be required of any technology being seriously evaluated for commercial-scale volume reduction of radioactive wastes.

The preliminary tests reported here were technical feasibility studies and were not conducted to demonstrate zero radioactive emissions.

\subsection{Process Commercialization - Stone \& Webster Participation}

The EERC contracted Stone \& Webster Environmental Technology \& Services (S\&W) to evaluate the commercial potential and assist in the development of the EERC waste plastics thermal decomposition process as applied to separation of radionuclides from high-organic-content nuclear facility wastes. Dr. Joe Cardito of S\&W spent two days at the EERC inspecting facilities and equipment, reviewing technical information, and discussing process commercialization and marketing strategies. Dr. Cardito will submit a formal report to the EERC as a contract deliverable; a summary of his preliminary assessments and recommendations is provided below.

\section{Process Applicability/Market Niche}

Efforts should be focused on application of the EERC process to spent (fully loaded) ionexchange resins used to remove radionuclides from aqueous solution at nuclear power facilities. Demonstration of process economics and technical viability with resins should facilitate its marketing to commercialization entities, either as a stand-alone technology or as a component of a larger process, and should enable further applications testing with more varied waste streams. Consideration should be given to developing and marketing a skid-mounted version of the process, which may provide significant economic advantage.

\section{Development Needs}

- A series of process demonstration tests should be performed at the EERC in which Amberlite IRN-150/nuclear-grade resin loaded with (nonradioactive) cesium is used as feedstock. The resin should be loaded with at least 0.64 grams of cesium per cubic foot of resin (a calculated maximum value for spent resin from operating nuclear power facilities) at the EERC prior to test performance. A primary test objective will be to demonstrate (to the extent possible without the use of radioactive material) that the process residual would qualify as a Class A waste, according to Department of Transportation and Nuclear Regulatory Commission Regulations in Title 49 and Title 10 of the Code of Federal Regulations.

- A series of process demonstration tests should be performed at the EERC in which a wellcharacterized postconsumer plastics mixture with added polymers (to represent nuclear facility organic waste materials) and several radionuclide surrogates is used as feedstock. 
- A complete material balance should be performed around the EERC process as applied to 1) the cesium-loaded Amberlite resin and 2) the postconsumer plastics mixture, into which has been added several polymers representative of nuclear facility lab waste, including recycled Tyvec ${ }^{\circledR}$ and polycarbonate, virgin nylon and acrylonitrile butadiene styrene (ABS), and several radionuclide surrogates. The material balance data will be used to assess process economics.

\section{Marketing/Commercialization Needs}

- Work should be initiated on preparation of a "technology application analysis" for marketing the EERC process to commercialization entities. An example of a technology application analysis prepared by S\&W is provided as Appendix A.

- Contact should be made with representatives of Scientific Ecology Group, Inc. (Oak Ridge, Tennessee), M4 Environmental L.P. (Oak Ridge, Tennessee), and Chem-Nuclear Systems, Inc. (GTS Duratech) (Columbia, South Carolina) to initiate discussions on possible commercial application of the EERC process and to set up site visits.

\subsection{Establishment of Minimum Surrogate Detection Limits}

A series of investigations was performed to determine minimum analytical detection limits for radionuclide surrogates in plastics decomposition condensate products. While the first process evaluation tests employed per surrogate detection limits of about $5 \mu \mathrm{g} / \mathrm{g}$, the objective for the upcoming test series is a per surrogate detection limit of about 5 to $50 \mathrm{ng} / \mathrm{g}$. Earlier detection limit estimates (as listed in the April-October report) were based on the commercial availability of a more powerful detector for the EERC inductively coupled argon plasma (ICAP) spectrometer. Because the detector is still under development and unavailable for purchase, it was necessary to achieve lower detection limits through optimization of analytical procedures for use with the ICAP as currently configured. The investigations involved the addition of known quantities of surrogates to condensate products from prior work for use in analytical procedures optimization tests. The resulting optimized detection limits are listed in Table 5.

\section{TABLE 5}

Radionuclide Surrogate Detection Limits

\begin{tabular}{lcc}
\hline Surrogate & Chemical Symbol & Detection Limit, $\mathbf{n g} / \mathrm{g}$ \\
\hline Vanadium & $\mathrm{V}$ & $50-100$ \\
Tin & $\mathrm{Sn}$ & $50-100$ \\
Antimony & $\mathrm{Sb}$ & $50-100$ \\
Copper & $\mathrm{Cu}$ & $5-50$ \\
Titanium & $\mathrm{Ti}$ & $50-100$ \\
Strontium & $\mathrm{Sr}$ & $50-100$ \\
Cerium & $\mathrm{Ce}$ & $100-500$ \\
Zirconium & $\mathrm{Zr}$ & $50-100$ \\
Cesium & $\mathrm{Cs}$ & $5-50$ \\
Iodine & $\mathrm{I}$ & $100-1000$ \\
\hline
\end{tabular}




\subsection{WORK PLANNED FOR THE NEXT SIX MONTHS}

Work was initiated on preparing for performance of a series of 12 CFBR tests in which four different feedstocks will be reacted at three different temperatures. Reactor system preparation includes work on optimization of the particulate control device (which will consist of a "cyclone in a cyclone") for more effective removal of entrained solids from the process gas stream prior to entry of the gas stream into the condensation system. The four feedstocks being prepared include the following:

Feedstock A: Rohm and Haas Amberlite ${ }^{\circledR}$ IRN-150 nuclear-grade resin, into which approximately $30 \mathrm{~g} / \mathrm{ft}^{3}$ of cesium will be ion-exchanged, according to procedures provided by Stone \& Webster.

Feedstock B: Postconsumer plastics, into which will be added 1000 to $5000 \mu \mathrm{g} / \mathrm{g}$ of each of the radionuclide surrogates listed in Table 5.

Feedstock C: A mixture of $90 \mathrm{wt} \%$ postconsumer plastics, $5 \mathrm{wt} \%$ shredded Tyvec ${ }^{\circledR}$ chemical protection suits, and $5 \mathrm{wt} \%$ virgin ABS, to which will be added 1000 to $5000 \mu \mathrm{g} / \mathrm{g}$ of each of the radionuclide surrogates listed in Table 5.

Feedstock D: A mixture of $90 \mathrm{wt} \%$ postconsumer plastics, $5 \mathrm{wt} \%$ recycled polycarbonate, and $5 \mathrm{wt} \%$ virgin nylon, to which will be added 1000 to $5000 \mu \mathrm{g} / \mathrm{g}$ of each of the radionuclide surrogates listed in Table 5.

All tests will employ a nominal $1-\mathrm{kg} / \mathrm{hr}$ feedrate, and all condensate surrogate analyses will be performed (in duplicate) using procedures required to ensure accurate quantitation down to the detection limits listed in Table 2. Data from these tests will be crucial to evaluating the overall effectiveness and economic viability of the process in volume reduction of high-organic-content radioactive waste. Success in these tests will facilitate marketing the process to a commercialization entity and should result in an arrangement for process demonstration with radioactive materials at a nuclear facility. 
APPENDIX A

\section{AN EXAMPLE OF A TECHNOLOGY APPLICATION ANALYSIS}




\section{TEEHNOLOGY APPLICATION ANALYSIS}

Pump \& Treat of Contaminated Groundwater

Twin Cities Army Ammunition Plant

New Brighton, Minnesota

prepared for

US Army
Environmental Center

December 1993 FINAL 


\section{SITE}

Twin Cities Army Ammunition

Plant (TCAAP)

A CERCLA Site

New Brighton, Minnesota
TECHNOLOGY APPLICATION

Page 1 of $12=$

This analysis covers an effort to pump and treat groundwater contaminated with volatile organic compounds (VOCs) by above ground air stripping. The treatment began in October 1987 and is currently ongoing. This analysis covers performance through September 1992.

\section{SITE CHARACTERISTICS}

\section{Site History/Release Characteristics}

- TCAAP is an approximately 4 square mile facility established in 1941 which primarily produced and stored munitions during the periods of 1941 to 1957 and 1966 to 1976 . The site includes 7 major production buildings and over 300 auxiliary buildings. Most of the site is now in caretaker status, however, current lessees manufacture ammunition and other products.

- A series of hydrogeological investigations which began in 1981 revealed elevated levels of VoCs in groundwater.

Fourteen separate source areas have been the focus of detailed site characterization and various remediation efforts.

- Contamination resulted from a variety of past waste disposal practices such as sewer disposal, dumping and burning which released process wastes, oil and grease, heavy metals and solvents to the environment.

- In October 1987 a Boundary Groundwater Recovery System (BGRS) started operation. An expanded system, the TCAAP Groundwater Recovery System (TGRS), began operation in January 1989. Additional smaller scale groundwater remediation efforts were implemented at the plant. Remedial actions were also conducted outside of the plant boundaries. This analysis will focus upon the pertormance of the BGRS and TGRS up through September 1992.

\section{Contaminants of Concern}

Contaminants of greatest concern in the groundwater are:

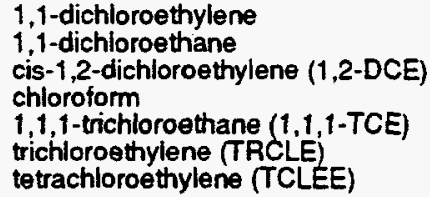

TRCLE, the most prevalent VOC on site, is the target compound used to measure system performance.

\section{Contaminant Properties}

Properties of contaminants focused upon during remediation are:

\begin{tabular}{|c|c|c|c|c|c|}
\hline Property at STP* & Units & TRCLE & TCLEE & 120CE & 1,1,1TCE \\
\hline Empirical Formula & 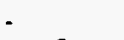 & $\mathrm{CCH}=\mathrm{CCH}_{2}$ & $\mathrm{C}_{2} \mathrm{C}=\mathrm{CO}_{2}$ & CHCLOHO & $\mathrm{CH}_{3} \mathrm{CO}_{3}$ \\
\hline Density & $\mathrm{g} / \mathrm{cm}^{3}$ & 1.46 & 1.62 & - & 1.31 \\
\hline Vapor Pressure & $\mathrm{mmHg}$ & 73 & 19 & 208 & 124 \\
\hline $\begin{array}{l}\text { Henry's Law } \\
\text { Constant }\end{array}$ & \multicolumn{2}{|c|}{ am $\mathrm{m}^{3} / \mathrm{mole} 9.9 \mathrm{E}-3$} & $2.9 E-3$ & - & $1.6 \mathrm{E}-2$ \\
\hline Water Solubility & $\mathrm{mg} / \mathrm{L}$ & $1000-1470$ & $150-485$ & 3500 & $300-1334$ \\
\hline $\begin{array}{l}\text { Octanof-Water } \\
\text { Partition } \\
\text { Coefficient; } K_{\text {ow }}\end{array}$ & - & 195 & 126 & 5 & 148 \\
\hline $\begin{array}{l}\text { Organic Carbon } \\
\text { Parition } \\
\text { Coetticient: } K_{o c}\end{array}$ & - & 66 & 209 & - & 105 \\
\hline 'STP $=$ Standard $T_{t}$ & 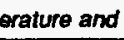 & & $n, 25^{\circ} \mathrm{C}$ & & \\
\hline
\end{tabular}

\section{Nature \& Extent of Contamination}

- Characterization of the nature and extent of contamination at TCAAP slowly evolved over several years of monitoring and treatment. In the mid 1980s it was known that a plume beneath the site had TRCLE concentrations as high as 3600 $\mathrm{ppb}$ (later analyses revealed leveis over $10,000 \mathrm{ppb}$ ) as well as 1,2-DCE and 1,1,1-TCE levels of 160 and 950 ppb respectively. After installation of the BGRS, TGRS and associated monitoring wells more detailed plume delineation became possible.

- A plume extends over six miles downgradient (southwest) of the site; no contamination has been detected immediately upgradient of the site.

- Contaminants have been found to be fairly mobile in most geologic strata. 
Remedial investigation field activities at the site have included:

- soil gas surveys

- surface soil sampling

- soil trenching and sampling

- soil boring installation and sampling

- groundwater well installation and sampling

- geophysical investigations (electromagnetic induction and ground penetrating radar)

Data from hundreds of soil borings and groundwater monitoring wells has allowed the development of numerous two-dimensional contour diagrams illustrating the upper and lower surface areas, groundwater elevations, and contaminant concentration profiles for various geologic units. Portions of some of these diagrams have been included here to provide a general conceptual understanding of site conditions.

Recent (1992) data is used in these diagrams. Earlier plume delineation efforts were based upon less complete data sets. It is currently assumed that the plume outline has not changed significantly over the past several years.

\section{IRCLE Plume (Side View)}

Groundwater monitoring data from Spring 1992 along cross-section A-A' shown in top view

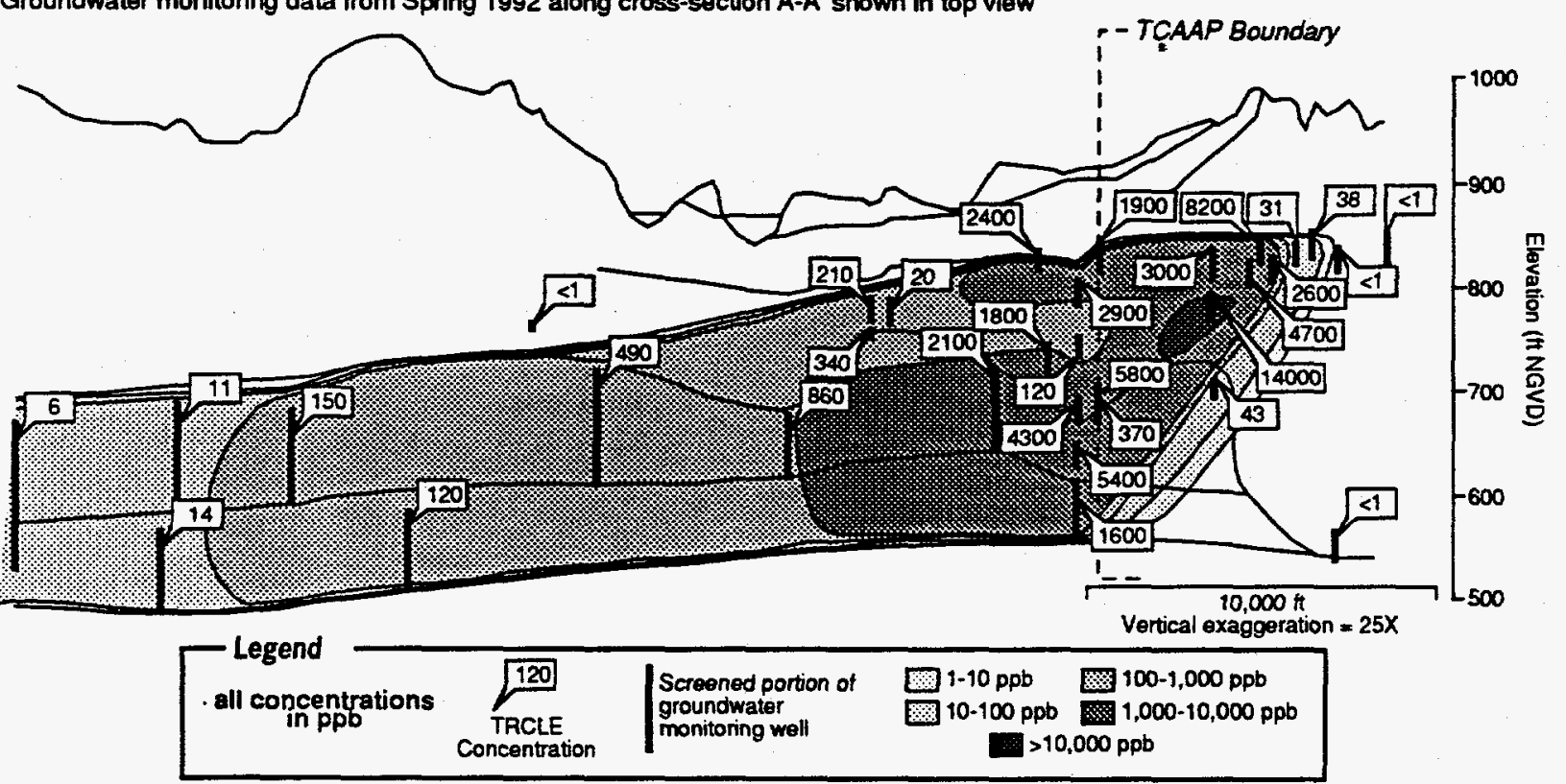

\section{Hydrogeologic Units}

Four distinct hydrogeologic units have been identified beneath TCAAP and the surrounding regions:

Unit 1 New Brighton \& Fridley Formations

Unit 2 Twin Cities Formation

Unit 3 Hillside Sand

Unit 4 Prairie du Chien 8 Jordan Sandstone

Discontinuous recent alluvium and lacustrine deposits; discontinuous local water table equiter: $0-50 \mathrm{ft}$ thick

Discontinuous glacial till; acts as gquitard with some water bearing sand and gravel tenses: $0-150$ tt thick

Overlain by Arsenal sand which forms kame in center of TCAAP; aquifer arbitrarily subdivided into upper middle and lower parts for monitoring: 25-450 $\mathrm{Ht}$ thick

Dolomite bedrock aquiler; $0-250 \mathrm{th}$ thick

Sandstone bedrock aquifer; $0-100 \mathrm{ft}$ thick

TRCLE Plume (Unit 4 View)

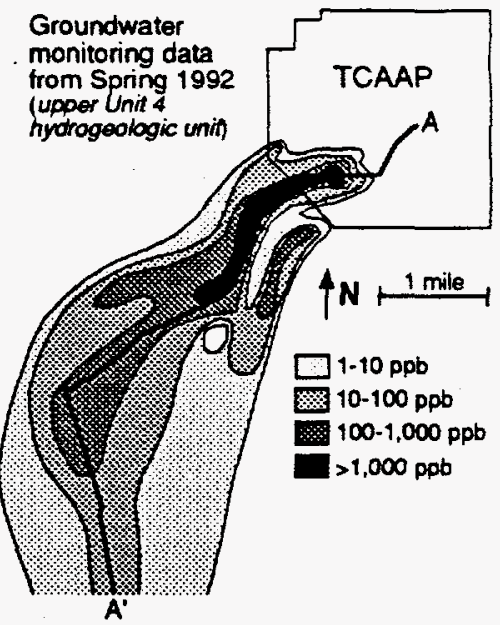

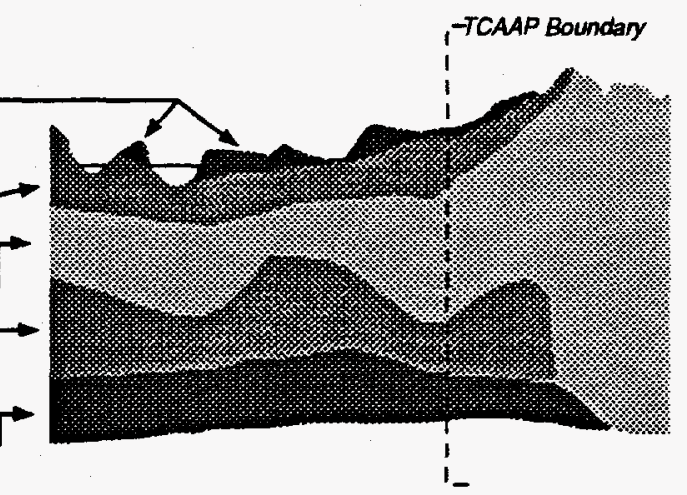




\section{Site Conditions}

- Surrounding region characterized by a continental climate with average yearly temperature of $440 \mathrm{~F}$, rainfall of 25 inches, and snowiall of 40 inches.

- Topography at TCAAP ranges from $880 \mathrm{ft}$ MSL at Rice Creek on the western edge to 1,000 $\mathrm{ft}$ MSL at the kame in the center of the site.

- Groundwater flow is generally to the west and southwest.

- The site possesses a complex hydrogeology arising from heterogeneities in the multilayer aquifer system, fractured bedrock, and discontinuous sand, clay and till layers.

\section{Key Aquifer Characteristics}

Aquifer parameters along the southwest TCAAP boundary have been estimated as:

\begin{tabular}{|c|c|c|c|c|c|}
\hline \multicolumn{2}{|l|}{ Unit } & $\begin{array}{c}\text { Approximate } \\
\text { Thickness } \\
{[\mathrm{ft}]}\end{array}$ & $\begin{array}{c}\begin{array}{c}\text { Hydraulic } \\
\text { Conductivity }\end{array} \\
\text { [ft/day] }\end{array}$ & $\frac{\text { Transmissivity }}{\left[\mathrm{ft}^{2} / \text { day }\right]}$ & Flow Direction \\
\hline Unit 1 & $\begin{array}{l}\text { New Brighton and } \\
\text { Fridley Formations }\end{array}$ & 10 & $0.007-22$ & - & Recent alluvium. Reflects surface topography \\
\hline Unit 2 & Twin Cities Formation & 63 & $0.001-0.01$ & - & $\begin{array}{l}\text { Low conductivity aquitard; groundwater moves slowly } \\
\text { downward to Unit } 3\end{array}$ \\
\hline Unit 3 & Hillside Sand & 156 & 137 & 21,424 & $\begin{array}{l}\text { Generally horizontal and directed southwest and west; } \\
\text { vertical gradient is downward and is }<0.005\end{array}$ \\
\hline Unit 4 & Prairie du Chien & 37 & 85 . & 3,160 & Generally horizontal and directed southwest and west \\
\hline Unit 4 & Jordan Sandstone & 90 & 46 & 4,140 & Generally horizontal and directed southwest and west \\
\hline Bulk FI & ow for Units 3 and 4 & 283 & - & 28,724 & \\
\hline
\end{tabular}

- A wide range of values has been used to describe regional aquifer characteristics. Uncertainties stem from difficulties in aquifer testing and interpretation methods applied to the hydrogeological complexities noted above under Site Conditions.

- Groundwater along the southwest TCAAP boundary is unconfined but becomes confined to the west and north. The confining boundary may change throughout the year due to seasonal groundwater table fluctuations. 
TREATMENT SYSTEM

\section{Overall Process Schematic}

Extraction Well Network

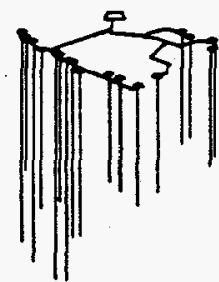

12 Boundary recovery wells and 5 source area recovery wells installed in two stages (first BGRS. then TGRS) [detailed below]
Treatment Plant

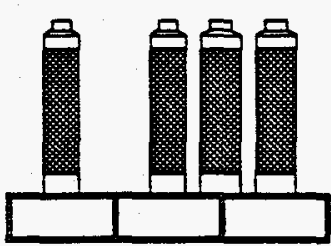

Air stripping plant treating 2900 GPM

[detailed on next page]
Forcemain \& Discharge

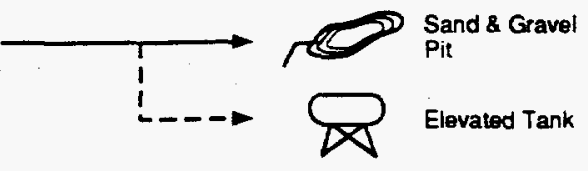

16 " cement lined 150 psi pressure tested ductile iron pipe buried 7-10 ft below grade. Primary discharge point is a

sand and gravel pit having extensive erosion protection.

Alternate discharge to an elevated tank.

\section{Extraction Well Network}

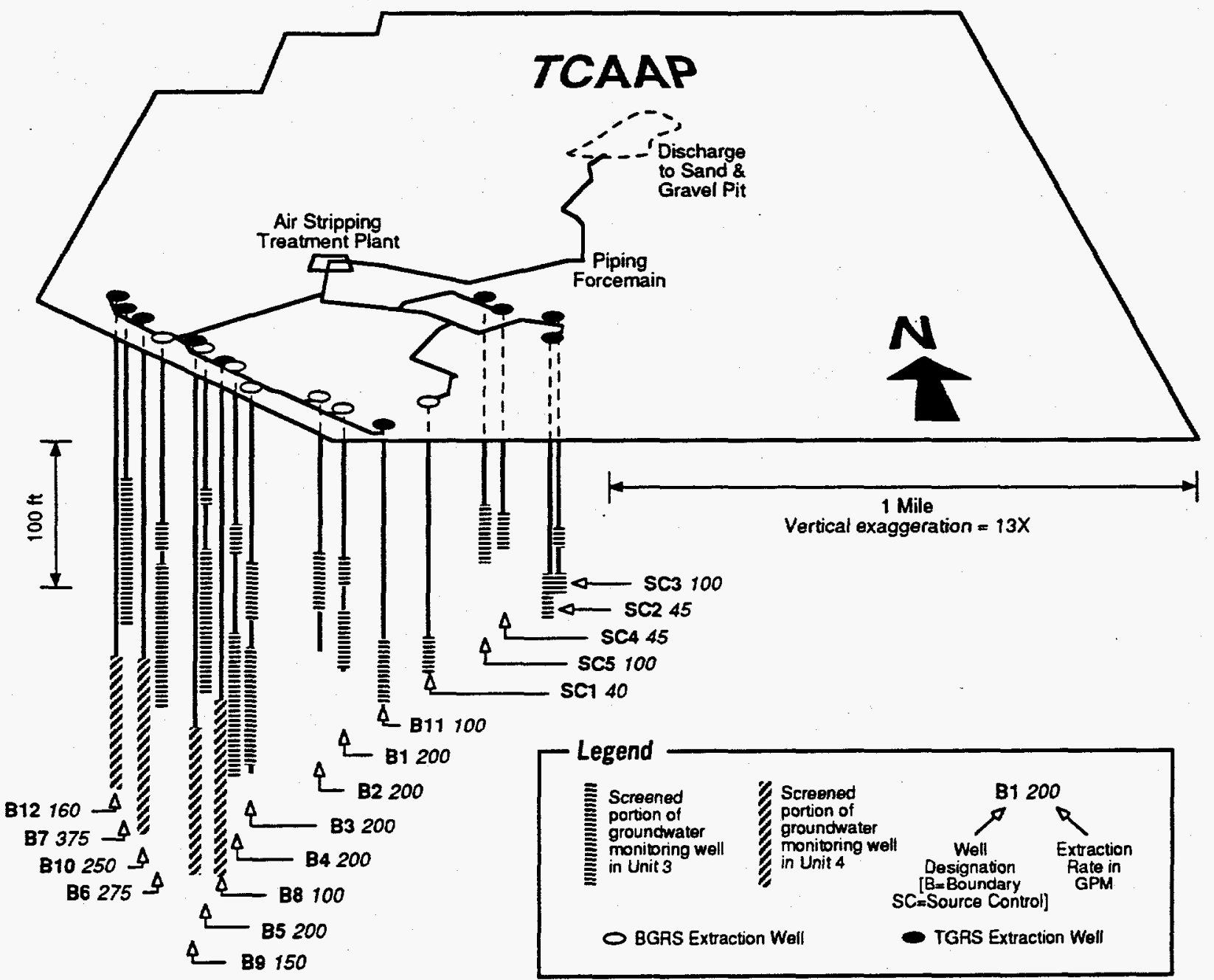




\section{Extraction Well Close-Up}

Typical Unit 3 Extraction Well (Well Shown is B1)

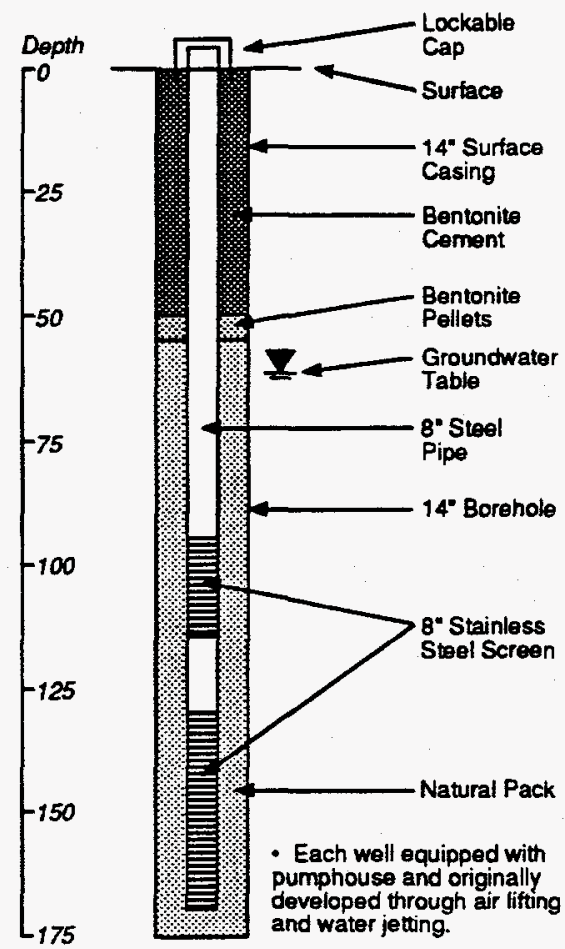

\section{Key Design Criteria}

- Operating life of 30 years (estimated remediation time).

- Handle maximum flow rates throughout system.

- Discharge to multiple points.

- Handle chanaes in flow rates.

- Operate with portions of system shut down.

- Minimal operating labor requirements.

\section{Key Monitored Operating Parameters}

- Water flows

- Air fiows

- Pump discharge pressures

- Automated processes

- Groundwater levels

(to assess zone of capture)

- Contaminant concentrations in treatment plant influent \& effluent (to assess treatment effectiveness)

- Contaminant concentrations in groundwater (to assess achievement of remediation goals)

\section{Air Stripper System Schematic}

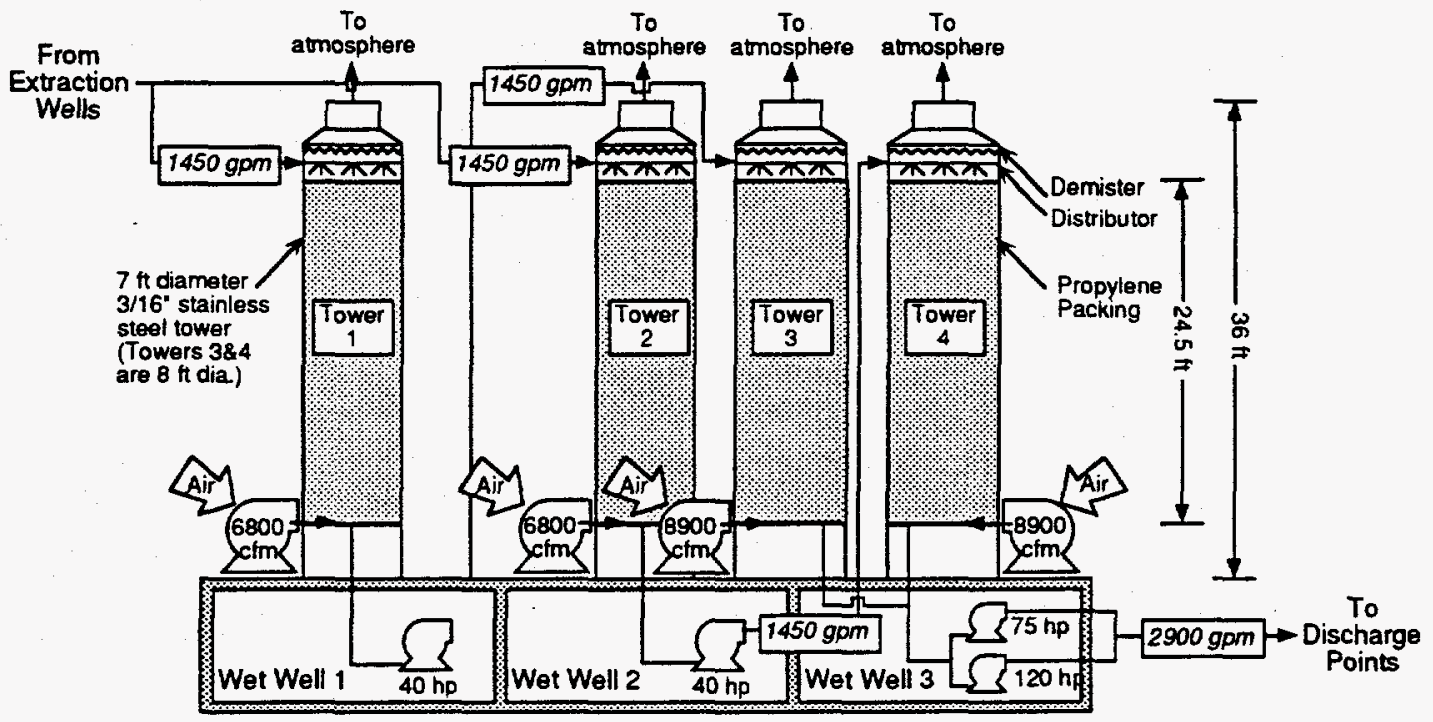

- Tower 4 was added for the TGRS arrangement. Previously, the BGRS system split $1200 \mathrm{gpm}$ between Towers 1 and 2 with discharge from both going to Tower 3 .

- Air compressor ratings represent minimum operating levels.

- Drawing not to scale. 
PERFORMANCE

Performance Objectives

- Achieve cleanup goals including TRCLE concentrations of $5 \mathrm{ppb}$ in groundwater (other criteria detailed within Regulatory/Institutional section).

- Prevent migration of contaminants off the TCAAP site.

- Design and operate treatment system such that its zone of capture contains the plume within the TCAAP boundary.

\section{Treatment Plan}

A phased approach was utilized to implement an overall TCAAP groundwater remediation program:

- Installation of BGRS

- Execution of a Performance Assessment Review (PAR) evaluating the first 90 days of BGRS operation.

- Recommendations from the PAR used to develop criteria for the TGRS.

- Installation of the TGRS.

- Further modifications to the system identified through yearly monitoring and performance assessment reports.

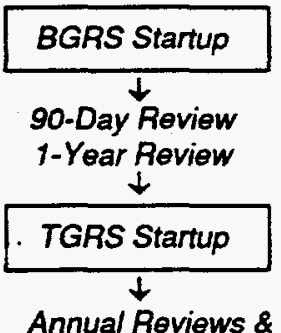

System Modifications

\section{Initial Process Optimization Efforts}

\section{BRGS Performance Assessment}

Conclusions drawn after 90 days of BGRS operation and confirmed by 1 year of operating experience included:

- A substantial portion of Unit 3 \& 4 groundwater and VOC plumes were captured based upon observed drawdowns.

- The treatment system processed an average of $23 \mathrm{lbs}$ of VOCs/day (range of 17 to $29 \mathrm{lbs} / \mathrm{day}$ ).

- VOC plumes showed little variation during treatment.

- Treated effluent satisfied contaminant specific requirements established in the Record of Decision (ROD) for interim measures.

- Air emissions met ROD requirements and were not detected upwind or downwind of the BGRS.

- The TGRS expansion should include four Unit 4 and two Unit 3 boundary extraction wells and four Unit 3 source control extraction wells and corresponding increases in flow handling and treatment facility capacities.

\section{-TGRS Performance Assessment}

Conclusions drawn after 1 year of TGRS operation included:

- Hydraulic capture extended beyond the 5 ppb TRCLE contour at the TCAAP boundary in both Units $3 \& 4$.

- The TGRS extracted and treated 19,510 lbs of VOCs.

- VOC plumes showed little variation during treatment.

- Treated effluent satisfied contaminant specific requirements established in the ROD for interim measures.

\section{Operational Performance}

\section{Volume of Water Pumped}

- From Oct 1991 through Sept 1992 over 1.4 billion gallons of water were pumped from the 17 different extraction wells; monthly flow rates ranged from 112 to 123 million gallons.

- During this period $112 \%$ more water was pumped than was previously determined to be necessary to maintain a capture zone encompassing the VOC plume.

\section{System Downtime}

- The TGRS was operational $98 \%$ of the year ending Sept "92; this performance represented a slight improvement over ' 90 and ' 91 and a significant improvement over ' 89 .

- A preventive maintenance program was instrumental in reducing system downtime.
Causes of downtime 10/91 to 9/92:

Repair to pumphouse $1.0 \mathrm{day}$

Repair to treatment plant $\quad 0.9$

Preventive maintenance 0.1

TCAAP power system faitures 4.2

Total 6.2 days 


\section{Hydrodynamic Performance}

- The zone of capture created by the TGRS extends beyond the $5 \mathrm{ppb}$ TRCLE contour along the entire southwest TCAAP boundary. There is some ongoing debate among parties at TCAAP concerning the extent to which any part of the onsite contaminant plume may be breaking through the system of boundary extraction wells.

- The horizontal extent of capture is nearly identical throughout Units $3 \& 4$.

- Groundwater contours were manually constructed due to the complexities of the flow field and were based upon elevation measurements, pumping test analyses, drawdown analyses and vertical gradient analyses.
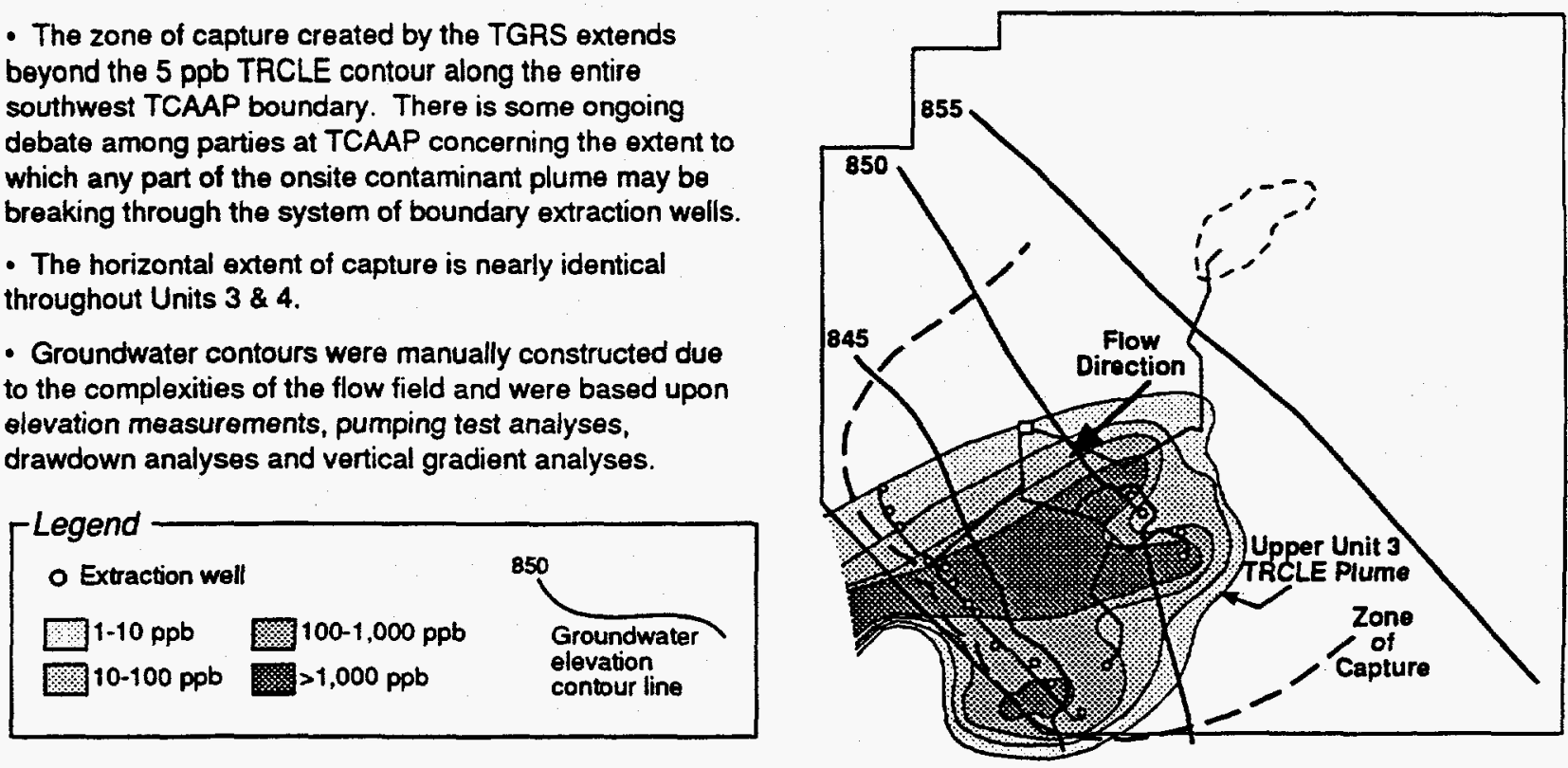

\section{Treatment Performance}

Effects on Plume - VOC leveis appear to have been
reduced near source areas. Interim
measures on soil may be the cause.
- Overall, VOC plumes have changed
little. The plume configurations identified
in 1992 are similar to those identified
earlier. Original estimates of a 30 year
remediation time have been revised and
project achievement of 17 ppm TERCLE
concentrations in 50 to 70 years.

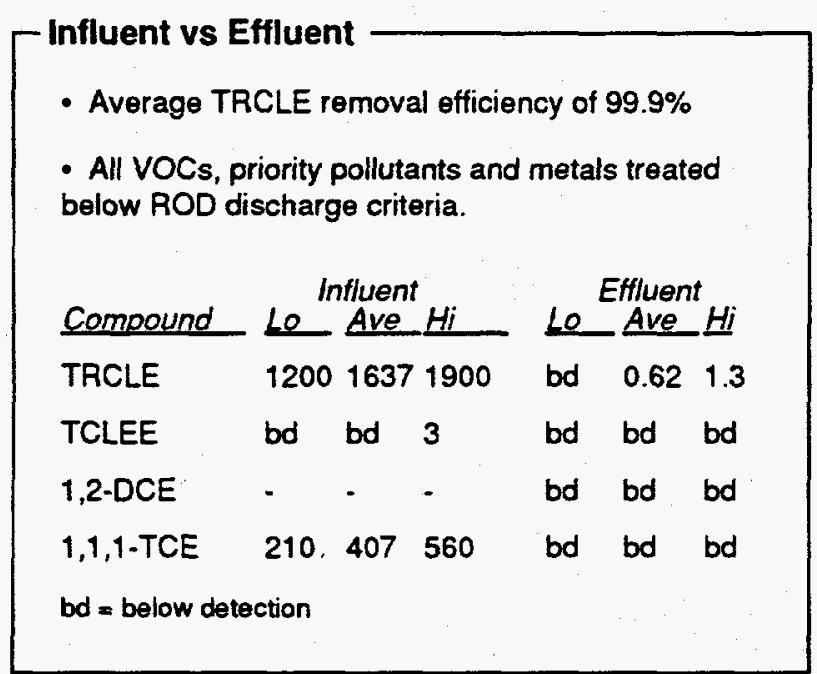

\section{TRCLE vs Time at Influent}

- The concentration of TACLE in groundwater extracted from each well and sent as influent to the air stripping plant:

has decreased over time for wells B1, B2, B7, B10, B12, SC1, SC2 and $\mathrm{SC} 3$

has increased over time for wells $\mathrm{B5}, \mathrm{SC} 4$ and SC5

has shown no clear trend for wells B3, B4, B6, B8, B9 and B11

- The trends may indicate plume redistribution and may also represent a decline in plume strength.

- There has been no clear reduction in overall contaminant concentrations sent to the treatment plant.

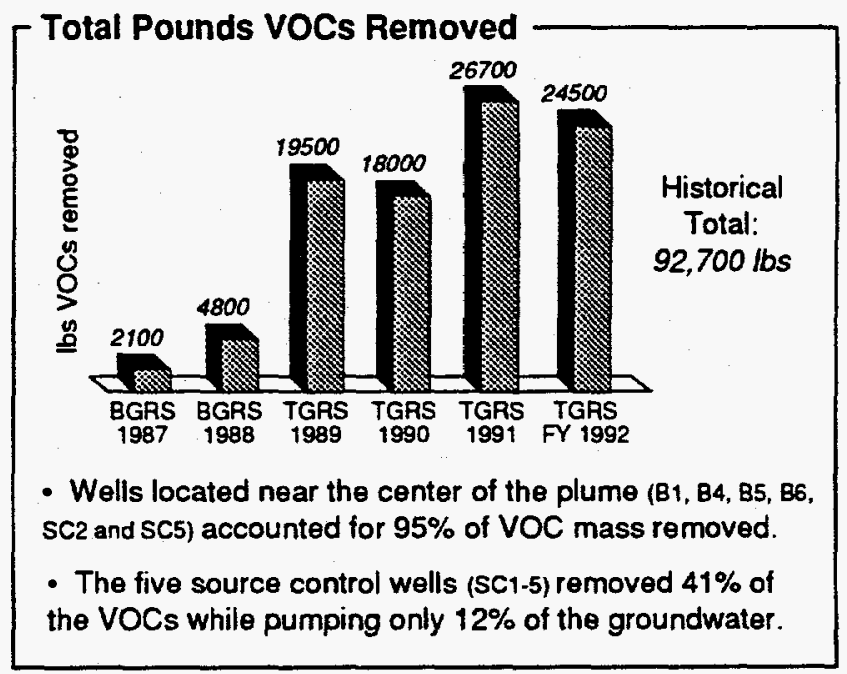


An economic evaluation of the TCAAP air stripping facility was performed in 1990. The evaluation focused on determining (1) total capital cost, (2) operating costs and (3) significant cost elements.

In addition, the installed cost of the TCAAP facility was compared to two other groundwater air stripping facilities using total life cycle costing (TLCC) analysis based upon treatment of 1,000 gallons of water over the life of each plant. The TCAAP facility compared favorably based on the TLCC approach, however, the TCAAP system handled flow rates one order of magnitude larger than the other facilities. The TLCC at TCAAP was estimated to be $\$ 0.30$ per 1,000 gallons of water treated. The total cost of operation and maintenance was calculated to be $\$ 0.12$ per 1,000 gallons.

Other results of the evaluation are summarized below in 1990 dollars.

\section{Capital Costs}

Construction of Treatment Plant

Construction of Wells (16 extraction, 48 monitoring and 17 retum wells)

Construction of Forcemain \& Pumphouses

(17,800 th buried pipe, 16 pumphouses)

Startup

Health \& Safety (Medical monitoring of employees)

Engineering

Project Management

Overhead \& Profit

\section{Operating Costs}

$\begin{array}{lr}\text { Power (@ \$0.04/Kwhr) } & \$ 148,846 \\ \text { Operating Labor } & 219,502 \\ \text { Maintenance Labqr \& Parts } & 150,054 \\ \text { Laboratory Charges } & 25,175 \\ \text { Other O\&M Charges } & 39,518\end{array}$

358,220

110,125

$1,575,710$

Replacement of Tower Packing

5,504

$(\$ 20,865$ occurring every 5 years. annualized at $10 \%$ interest)

928,267

874,257

Total $\$ 8,034,454$

\section{Cost Sensitivities}

Significant cost elements were:

\section{Capital}

- Pumphouses (16)

- Extraction, monitoring \& return well drilling (81)

- Stripping towers

- Extraction, monitoring \& return well casings (81)

- Wet wells at base of stripping towers (3)
$\$ 775,964$

399,633

296,821

241,095

142,740

\section{Operating}

- Operating Labor

$\$ 219,502$

- Maintenance labor \& parts 150,054

- Electricity 
REGULATORY/NSTITUTIONAL ISSUES

- BGRS construction was completed in April 1987 but startup was delayed until October 1987 due to administrative delays in obtaining regulatory approval to operate.

- Extraction well B1 was relocated from the original design since access to private property adjacent to TCAAP was denied.

- Groundwater in the New BrightonArden Hills area near TCAAP has led to abandonment of some municipal water supplies and private wells and necessitated the provision of bottled water in some instances. Municipal wells near TCAAP have added granular activated carbon treatment to meet water supply and remediation objectives.

- It is likely that the contaminant plume emanating from TCAAP has mixed offsite with plumes from other sources complicating allocation of responsibility and coordination of remedial response plans. More evaluation is needed.

- Various responsible parties at TCAAP have hired different consultants to manage aspects of the remedial response. In some cases, parties and their consultants have disagreed in their interpretations of environmental conditions and the performace of treatment systems. Responsible parties are bound by past lawsuits by the City of New Brighton, the City of St. Anthony, and 96 other plaintiffs.

- Regulatory oversight requires reporting any shutdowns or operational problems over 24 hours in duration and rapid development of accompanying plans for correction.

Cleanup Criteria

Several Records of Decision (RODs) apply to the overall TCAAP remedial program. Target cleanup criteria applicable to the BGRS and TGRS systems focus upon 1) residual levels of contamination in the groundwater and 2) containment of existing plumes.

Applicable target deanup levels for major contaminants include:

$\begin{array}{cccc}\text { Comoound } & \text { Criteria Level [opb] } & \text { Compound } & \text { Criteria Level [opb] } \\ \text { TRCLE } & 5 & 1,2 \text {-DCE } & 70 \\ \text { TCLEE } & 6.9 & 1,1,1 \text {-TCE } & 200\end{array}$

\section{SCHEDULE}

\section{BGRS \& TGRS Installation History}

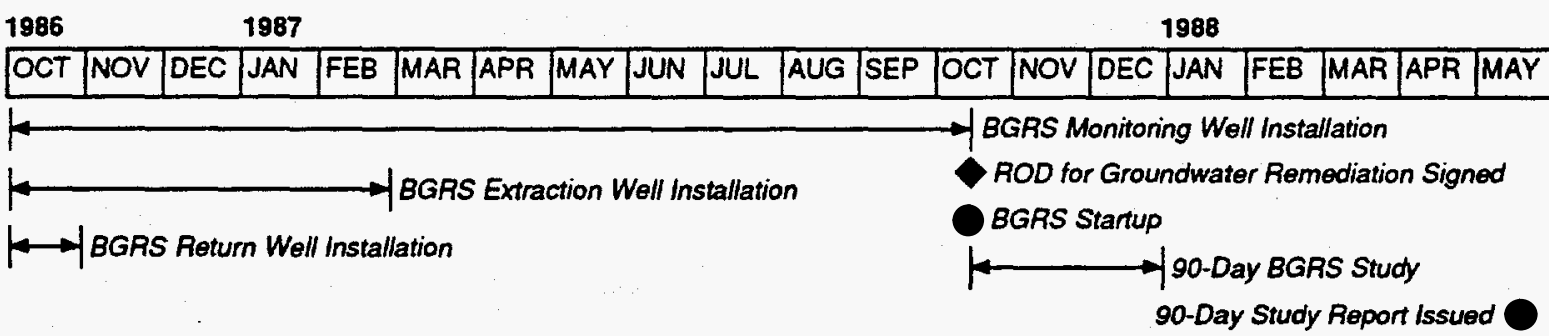

\begin{tabular}{|l|l|l|l|l|l|l|l|l|l|l|l|l|l|l|l|l|l|l|l|}
\hline JUN & JUL & AUG & SEP & OCT & NOV & DEC & JAN & FEB & MAR & APR & MAY & JUN & JUL & AUG & SEP & OCT & NOV & DEC & JAN \\
\hline
\end{tabular}

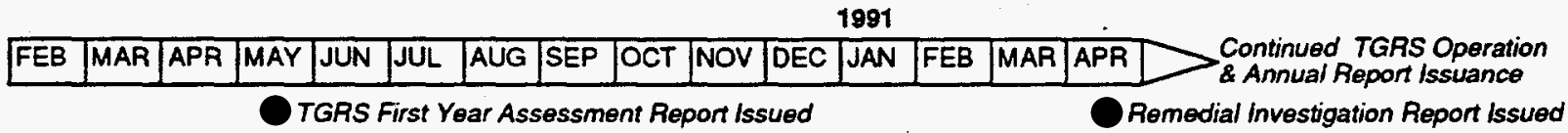




\section{Key Operating Parameters}

\section{Implementation Considerations}

- An understanding of the nature and extent of contamination at the site evolved over several years of monitoring and treatment. Phased design of the treatment system helped insure its proper sizing and effectiveness.

- Extensive efforts to quantify and model aquifer properties were of limited utility due to the presence of many hydrogeological complexities.

- A preventive maintenance program was instrumental in increasing the operational performance of the treatment facility.

\section{Technology Limitations}

- Original estimates of a 30 year treatment period have been extended. Minimum concentrations of target contaminants are projected to be achieved after $50-70$ years of treatment. Perpetual operation of the system will be necessary to ensure continued containment of the VOC plume.

- As anticipated earlier, the technology is not expected to achieve the $5 \mathrm{ppb}$ target cleanup level for TRCLE. It is projected that levels of 17 ppb may be achieved after 50 to 70 years of operation. No alternative technology or system enhancements have been identified to improve upon this performance to date.

- While plume containment appears to be successful, overall VOC plumes appear to have changed little after several years of treatment. Influent concentrations of contaminants to the the treatment plant have exhibited no clear downward trend. Extraction wells have experienced both increases and decreases in TRCLE concentrations from extracted groundwater. However, only interim measures have been taken thus far to clean up source areas. Permanent solutions are scheduled to be implemented in the 1995-1997 time frame.

\section{Future Technology Selection Considerations}

- The zone of capture created by the treatment system encompasses the entire contaminant plume of concern. There is some ongoing debate among parties at TCAAP concerning the extent to which any part of the onsite contaminant plume may be breaking through the system of boundary extraction wells.

- Operation of the treatment system in conjunction with surface remediation of soils has been effective at reducing VOC plume strengths near source areas.

- Bioremediation is being considered by regulators as a viable long-term solution to restore the aquifer to $\leq 5 \mathrm{ppb}$ TRCLE. While selection of bioremediation is not currently anticipated, some technology must be implemented over the next $20-50$ years to go below 17 ppb TRCLE.

- The above ground air stripping system has been effective at removing all VOCs, priority pollutants and metals to concentrations below discharge criteria. However, the air strippers simply transfer contaminants from the groundwater to the air. Granular activated carbon or other emission control technology may be needed in 1995 when new Clean Air Act requirements take effect.

- Groundwater treated by the air stripping systems is used as drinking water at TCAAP following posttreatment by granular activated carbon. Identification of long-term drinking water used for treated effluent will be part of future planning efforts.

- The system has been effective at containing further migration of the VOC plume off of the TCAAP site while treatment of groundwater within subsurface aquifers to drinking water levels has not and is not expected to be achieved. 
ANALYSIS PREPARATION

This analysis was prepared by:

Stone \& Webster Environmental

Technology \& Services

245 Summer Street

Boston, MA 02210

Contact: Bruno Brodfeld (617) 589-2767

CERTIFICATION

This analysis accurately reflects the performance and costs of the remediation:

$\underline{x}$

NAME HERE

Remedial Project Manager

Twin Cities Army

Ammunition Plant
$\underline{\mathbf{X}}$

NAME HERE

Project Manager

Minnesota Pollution Control Agency $\underline{x}$

NAME HERE

Remedial Project Manager

U.S. Environmental Protection Agency

Region V 
SOURCES

\section{Major Sources For Each Section}

Site Characteristics:

Treatment System:

Pertormance:

Cost:

Regulatory/nstitutional issues:

Schedule:

Lessons Leamed:
Source \#s (from list below) 1,3 and 8

Source 5,7 and 8

Source \# 1, 4, 6 and 8

Source \# 2

Source \#s 1,2, 3, 4, 5, 6 and 8

Source \#s 1,3,5 and 7

Source \#s 1,2, 3, 4, 6,8 and personal communications with Marty McCleary. Project Manager, TCAAP (612) 633-2301 ext. 651.

\section{Chronological List of Sources and Additional References}

1. Fiscal Year 1992 Annual Monitoring Report; Installation Restoration Program Twin Cities Army Ammunition Plant, prepared for Commander of Twin Cities Army Ammunition Plant and Commander of U.S. Army Toxic and Hazardous Materials Agency, prepared by Federal Cartridge Company, Wenck Associates, Inc., Alliant Techsystems, Inc., and Conestoga-Rovers \& Associates, Lid., July 1993.

2. Technical and Economic Evaluation of Air Stripping for Volatile Organic Compound (VOC) Removal from Contaminated Groundwater at Selected Army Sites, CETHA-TE-91023, prepared for U.S. Army Toxic and Hazardous Materials Agency, prepared by Tennessee Valley Authority National Fertilizer and Environmental Research Center, July 1991.

3. Installation Restoration Program: Remedial Investigation Report for the Twin Cities Amy Ammunition Plant, (4 volumes). prepared for the U.S. Army Toxic and Hazardous Materials Agency (USATHAMA), prepared by the Environmental Assessment and Information Sciences Division, Argonne National Laboratory, April 1991.

4. IRA-TGRS 1990 Annual Monitoring Report Installation Restoration Program Twin Cities Army Ammunition Plant, (2 volumes). prepared for Commander of Twin Cities Army Ammunition Plant and Commander of U.S. Army Toxic and Hazardous Materials Agency, prepared by Alliant Techsystems, Inc., and Conestoga-Rovers \& Associates, Lid., February 1991.

5. Final Engineering Report: Boundary Groundwater Recovery System (BGRS), prepared by Conestoga-Rovers \& Associates, January 1991.

6. IRA-TGRS 1989 Annual Monitoring Report Installation Restoration Program Twin Cities Army Ammunition Plant, (2 volumes), prepared for Commander of Twin Cities Army Ammunition Plant and Commander of U.S. Army Toxic and Hazardous Materials Agency, prepared by Honeywell, Inc., and Conestoga-Rovers \& Associates, Ltd., May 1990.

7. TGRS Operations and Maintenance Manual: Installation Restoration Program Twin Cities Amy Ammunition Plant, (5 volumes), prepared for Commander of Twin Cities Army Ammunition Plant and Commander of U.S. Army Toxic and Hazardous Materials Agency, prepared by Honeywell, Inc., and Conestoga-Rovers \& Associates, Ltd., October 1989.

8. SMCTC-EV Review Comments on the Technology Application Analysis Dratt Report, prepared by U.S. Army Environmental Center, September 1993. 
FORM APPROVED OMB NO. 19000127 Page 1 of 3

\begin{tabular}{|l|l}
\hline $\begin{array}{l}\text { 1. Program/Project Identification No. } \\
\text { DE-FC21-94MC31388 }\end{array}$ & $\begin{array}{l}\text { 2. Program/Project Title } \\
\text { EM Task 3 - Pyrolysis of Plastic Waste }\end{array}$ \\
\hline
\end{tabular}

4. Name and Address Energy \& Environmental Research Center University of North Dakota

PO Box 9018, Grand Forks, ND 58202-9018

(701) $777-5000$
3. Reporting Period $1 / 1 / 96$ through 3/31/96
5. Program/Project Start Date 9/30/94
6. Completion Date 9/29/39

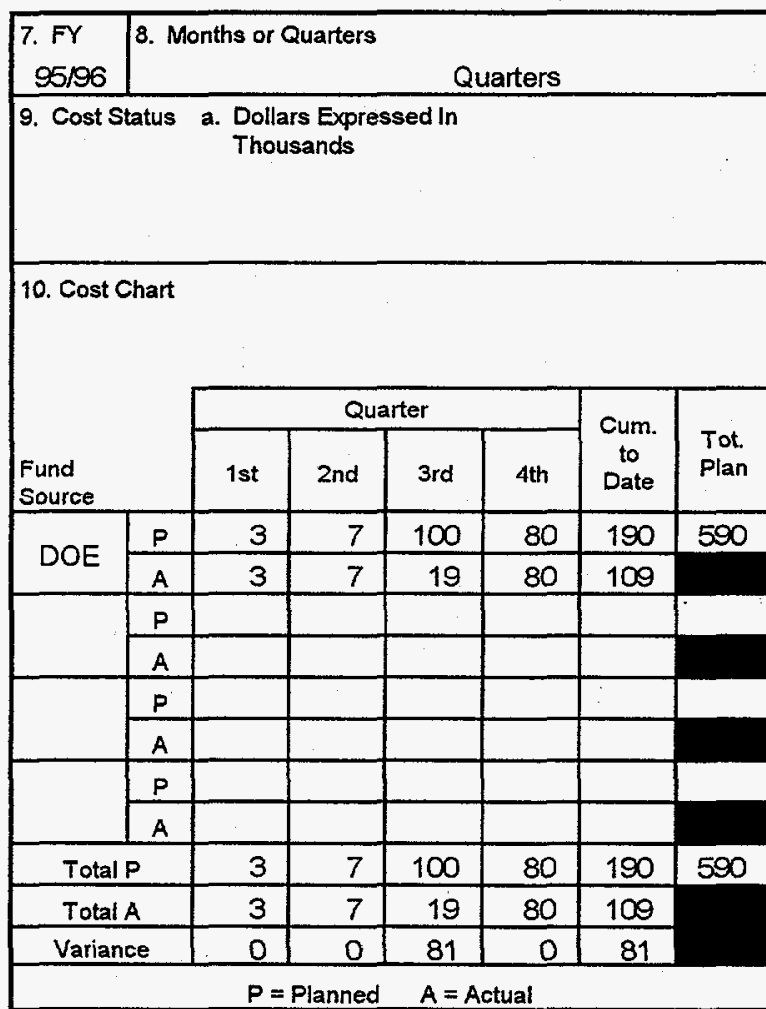

Total Planned Costs for Program/Project

$\$ 500$

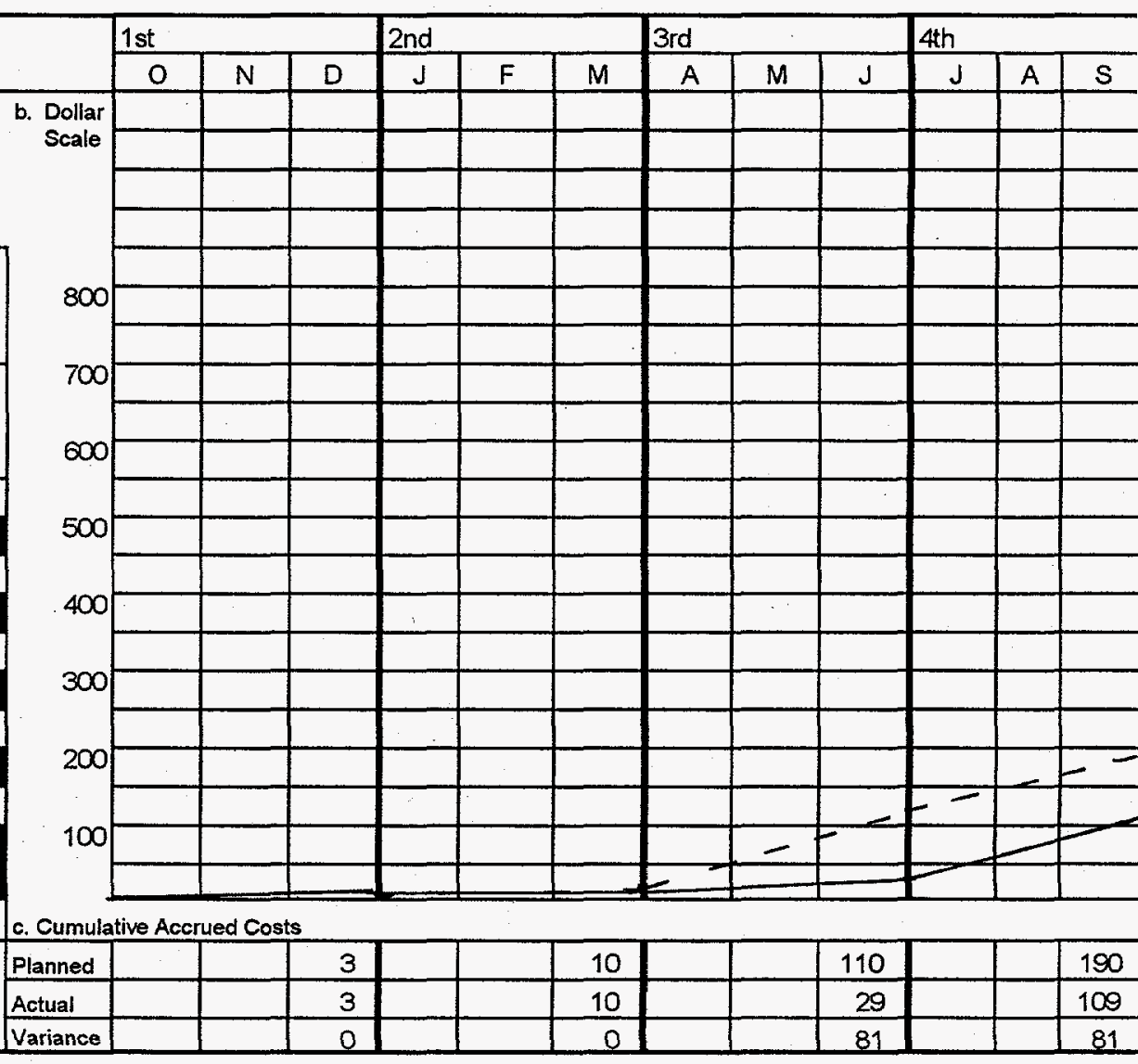

Units Planned Units Complete

3.2 Single-Component CFBR Testing

\begin{tabular}{|l|l|}
\hline$P$ & $C$ \\
\hline$P$ & $C$ \\
\hline$P$ & $C$ \\
\hline$P$ & $C$ \\
\hline$P$ & $C$ \\
\hline$P$ & $C$ \\
\hline$P$ & $C$ \\
\hline$P$ & $C$ \\
\hline
\end{tabular}

12. Remarks 


\begin{tabular}{|l|l|}
\hline $\begin{array}{l}\text { 1. Program/Project Identification No. } \\
\text { DE-FC21-84MC31388 }\end{array}$ & $\begin{array}{l}\text { 2. Program/Project Title } \\
\text { EM Task 3 - Pyrolysis of Plastic Waste }\end{array}$ \\
\hline
\end{tabular}

Page 2 of 3

4. Name and Address Energy \& Environmental Research Center

University of North Dakota

PO Box 9018 , Grand Forks, ND 58202-9018 (701) 777-5000

3. Reporting Period

1-1-96 through 3-31-96

5. Program/Project Start Date 9/30194

6. Completion Date 9/29/99 \begin{tabular}{|l|l|}
\hline $\begin{array}{l}\text { 7. FY } \\
96 / 97\end{array}$ & 8. Months or Quarters \\
\hline 9. Cost & a. Dollars Expressed in \\
\hline
\end{tabular}

Status Thousands

10. Cost Chart

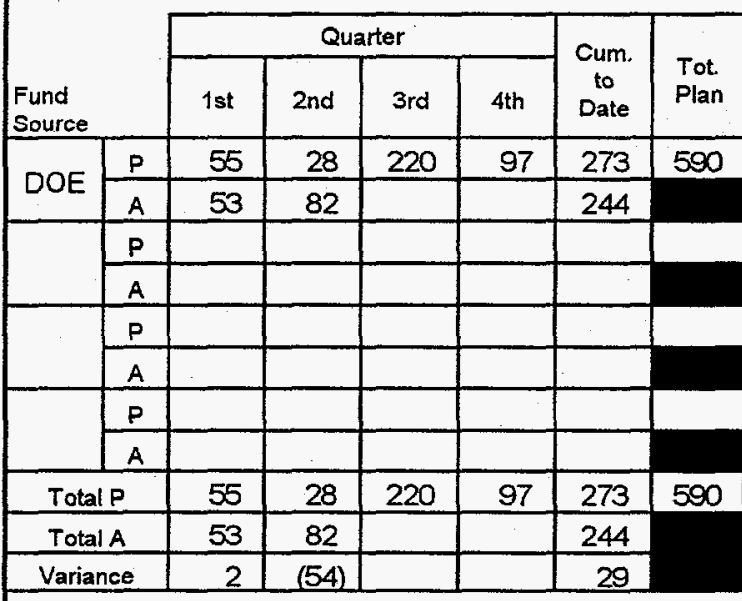

$P=$ Planned $A=$ Actual

Total Planned Costs for Program/Project

$\$ 590$

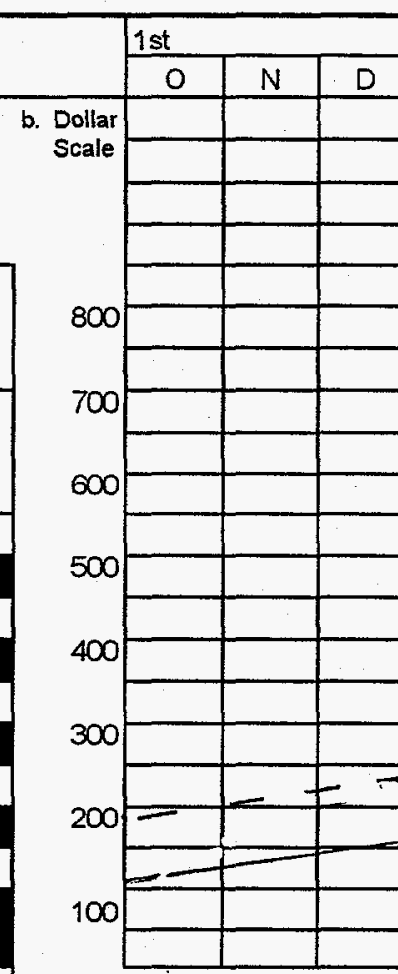

c. Cumulative Accrued Costs

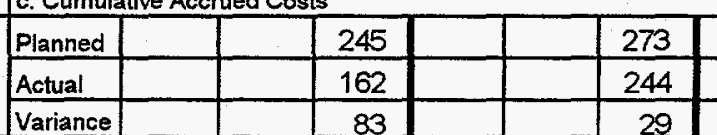

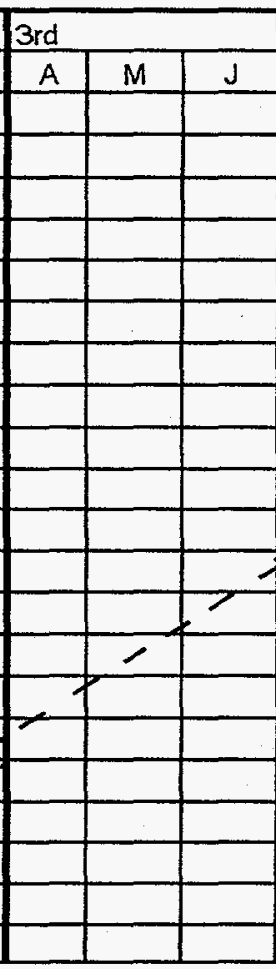
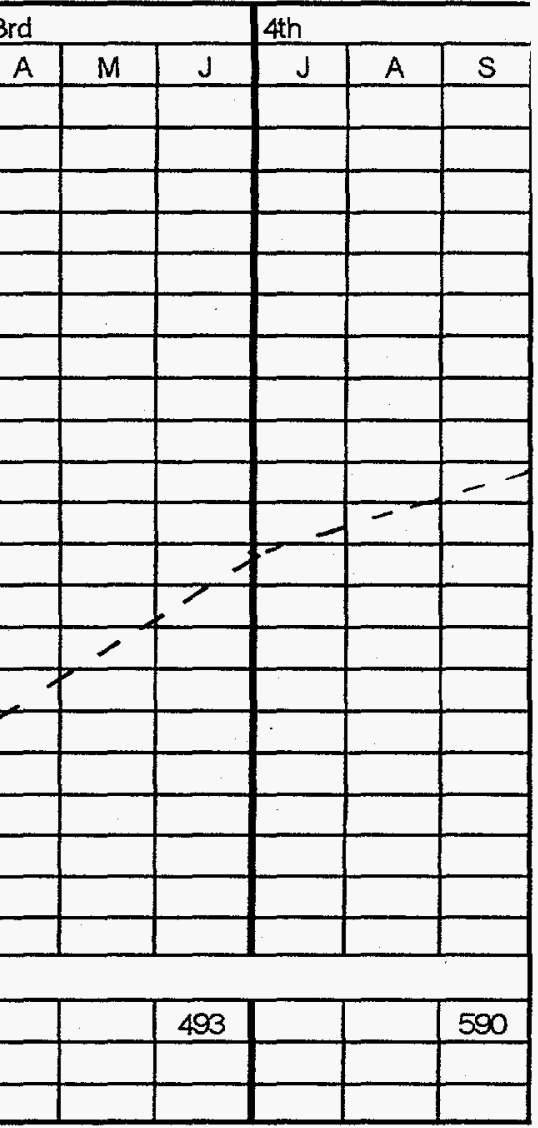

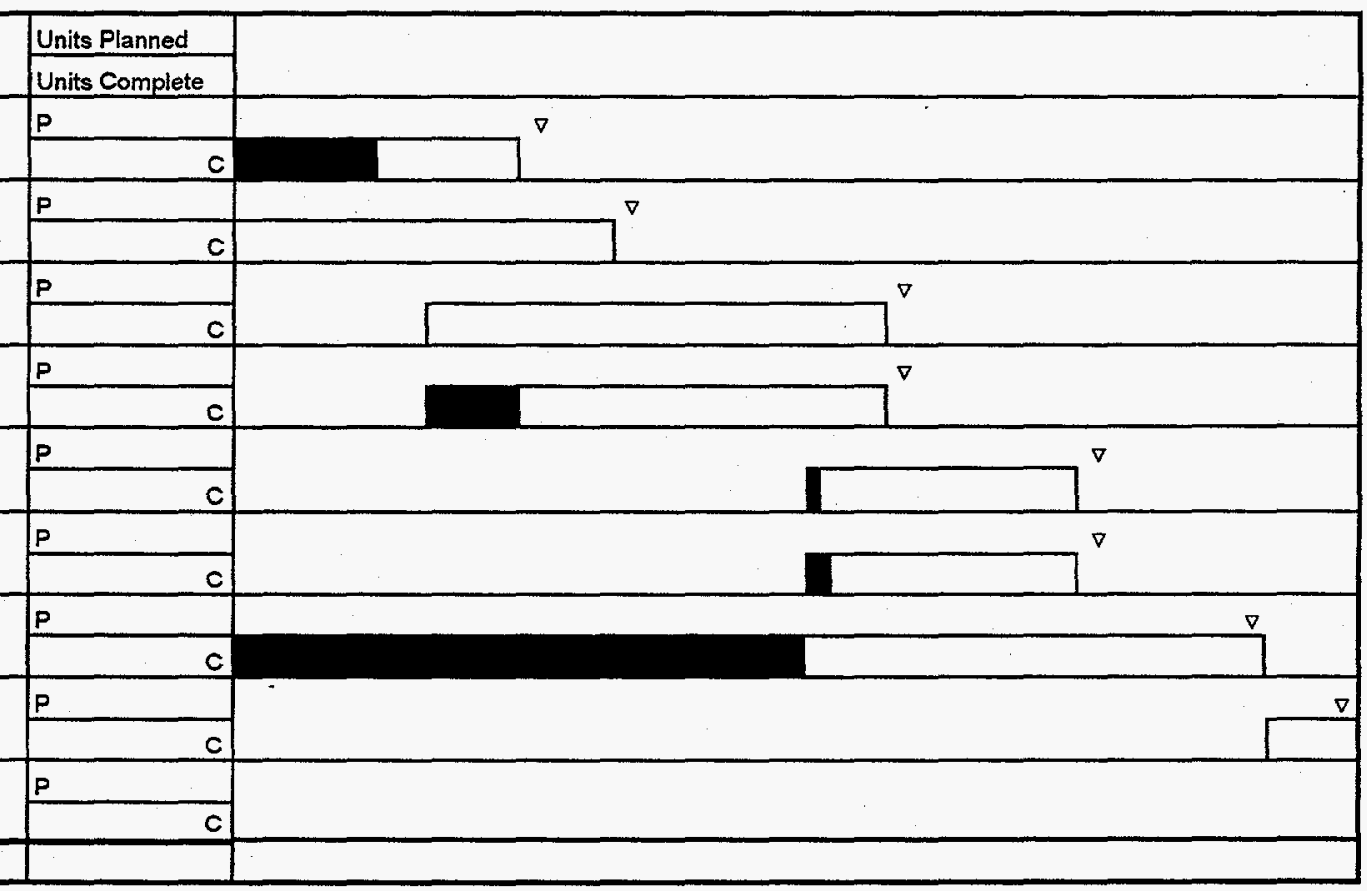

12. Remarks 


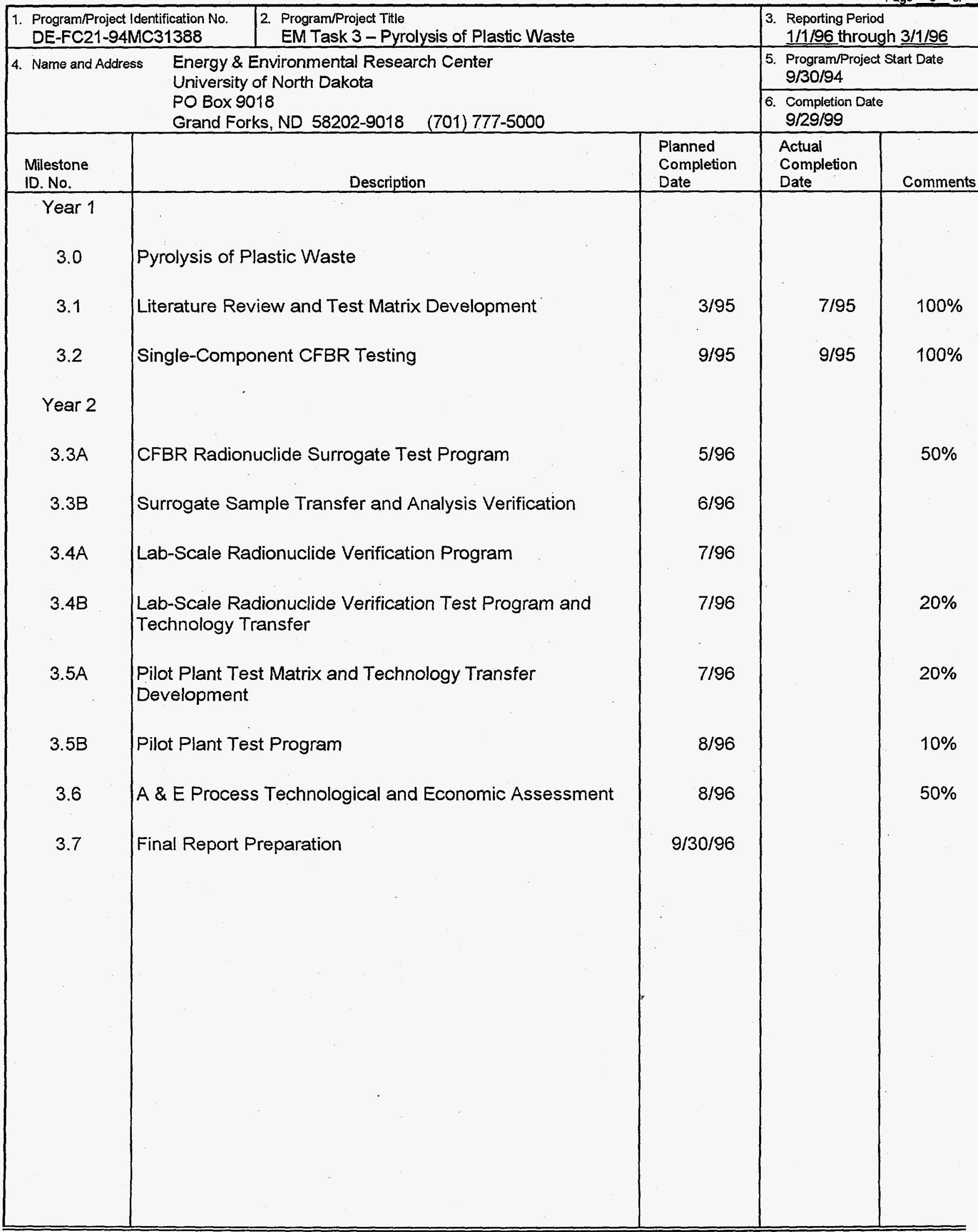




\title{
TASK 8 - MANAGEMENT AND REPORTING
}

\author{
Semiannual Report
}

for the period November 1, 1995, through March 31, 1996

Prepared for:

Venkat K. Venkataraman

U.S. Department of Energy

Morgantown Energy Technology Center

3610 Collins Ferry Road

PO Box 880, MS C05

Morgantown, WV 26507-0880

UND EERC-DOE Environmental Management

Cooperative Agreement No. DE-FC21-94MC31388

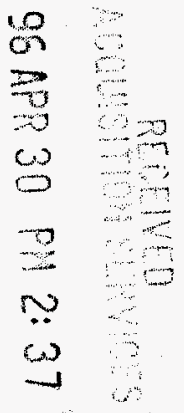

Prepared by:

Daniel J. Daly Edward N. Steadman

Energy \& Environmental Research Center University of North Dakota

PO Box 9018

Grand Forks, ND 58202-9018 


\section{TABLE OF CONTENTS}

LIST OF TABLES $\ldots \ldots \ldots \ldots \ldots \ldots \ldots \ldots \ldots \ldots \ldots \ldots \ldots \ldots \ldots \ldots$

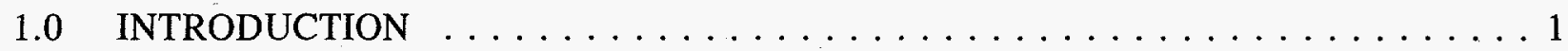

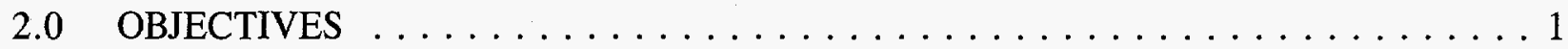

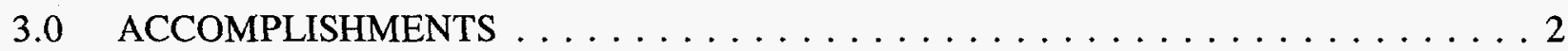

4.0 WORK PLANNED FOR NEXT 6 MONTHS $\ldots \ldots \ldots \ldots \ldots \ldots$

\section{LIST OF TABLES}

1 Profile of Year 2 EMCA Program Areas $\ldots \ldots \ldots \ldots \ldots \ldots \ldots \ldots$

2 Year 2 Technology Commercialization Activities for the METC-EM Cooperative

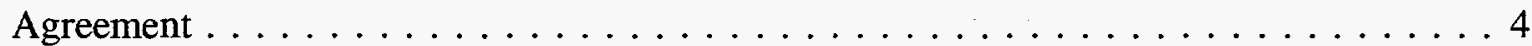

3 Matrix of EERC Core Expertise and EM Technology Needs $\ldots \ldots \ldots \ldots$ 


\section{TASK 8 - MANAGEMENT AND REPORTING}

\subsection{INTRODUCTION}

The task of restoring nuclear defense complex sites under the U.S. Department of Energy (DOE) Environmental Management (EM) program presents an unprecedented challenge to the environmental restoration community. Effective and efficient cleanup requires the timely development or modification of novel cleanup technologies applicable to radioactive wastes. Fostering the commercialization of these innovative technologies is the mission of EM-50, the EM Program Office of Science and Technology. DOE's Morgantown Energy Technology Center (METC) pursues activities integral to the EM-50 mission through a cooperative agreement with the EM Office of Science and Technology.

The advancement of innovative technologies is often arrested at the "valley of death," the general term for barriers to demonstration and commercialization. Alternatively, commercialization and deployment are impacted by a lack of clear choices among competing technologies. The Energy \& Environmental Research Center (EERC), a not-for-profit, contractsupported organization focused on research, development, demonstration, and commercialization (RDD\&C) of energy and environmental technologies is in the second year of a cooperative agreement with METC designed 1) to deliver EM technologies into the commercial marketplace through a unique combination of technical support, real-world demonstrations, and brokering; 2) to facilitate decisions regarding deployment and support for commercialization by providing comparitive performance data through systems analysis; and 3) to support the integration and deployment of "winner" technologies at EM sites. These activities, along with program management, comprise the four program areas of the METC-EERC EM Cooperative Agreement (EMCA): Technology Commercialization, Systems Engineering, Technology Integration, and Management and Reporting. These areas are profiled on Table 1.

This report is focused on the Management and Reporting program area, which corresponds to Task 8 under EMCA.

\subsection{OBJECTIVES}

The primary objective of Task 8 is to ensure the effectiveness of EMCA. This is accomplished through 1) the coodination of internal EMCA activities and coordination with the METC contractors representative, 2) the coordination and expansion of EMCA, and 3) effective technical transfer. 
TABLE 1

Profile of Year 2 EMCA Program Areas

\begin{tabular}{|c|c|c|}
\hline Program Area & Description & EMCA Tasks \\
\hline $\begin{array}{l}\text { 1. Technology } \\
\text { Commercialization }\end{array}$ & $\begin{array}{l}\text { Facilitate the commercialization } \\
\text { and deployment of innovative } \\
\text { cleanup technologies through a } \\
\text { hands-on process of technical } \\
\text { support, brokering, and } \\
\text { performance testing termed } \\
\text { "Dynamic Partnership." }\end{array}$ & $\begin{array}{l}\text { Year } 2 \text { Technologies (see } \\
\text { Table 2) } \\
\\
\text { - Task } 2 \text { (SFE/FT-IR) } \\
\text { - Task } 3 \text { (Thermal Treatment } \\
\text { of Organics) } \\
\text { - Task } 12 \text { (Laser Surface } \\
\text { Cleaning) } \\
\text { - Task } 9 \text { (Centrifugal } \\
\text { Membrane Filtration) }\end{array}$ \\
\hline 2. Systems Engineering ${ }^{1}$ & $\begin{array}{l}\text { Provide a basis for technology } \\
\text { development and deployment by } \\
\text { evaluating candidate EM cleanup } \\
\text { technologies }\end{array}$ & Task 11 \\
\hline 3. Technology Integration & $\begin{array}{l}\text { Provide support for the } \\
\text { appropriate deployment of } \\
\text { cleanup technologies at EM sites }\end{array}$ & $\begin{array}{l}\text { Task } 10 \text { (subcontract to } \\
\text { Waste Policy Institute) }\end{array}$ \\
\hline $\begin{array}{l}\text { 4. Management and } \\
\text { Reporting }\end{array}$ & $\begin{array}{l}\text { - Internal coordination of EMCA } \\
\text { and liason with METC } \\
\text { - Coordination with other } \\
\text { programs, partnership } \\
\text { development, and program } \\
\text { development } \\
\text { - Effective technology transfer }\end{array}$ & Task 8 \\
\hline
\end{tabular}

${ }^{1}$ Added during this reporting period.

\subsection{ACCOMPLISHMENTS}

Specific activities under Task 8, Management and Reporting, are summarized below.

- The Environmental Technology Development Through Industry Partnership Review meeting at the Morgantown Energy Technology Center (METC), October 1995. A paper was prepared that profiles EMCA technology development, demonstration, and commercialization activities. The paper was submitted in November for the meeting proceedings.

- Sixth SPECTRUM International Conference on Hazardous Waste Management, Seattle, Washington, August 18-23, 1996. An extended summary (approximately 1500 words) of a presentation on EMCA activities was submitted November 10. The presentation 
portrayed EMCA as a model for facilitating the rapid commercialization of innovative EM technologies. The paper was accepted and a final draft, due April 12, was initiated.

- Draft Technology Development Data Sheets (TDDS) were completed for each of the five technologies under EMCA as well as for the overall EMCA program. The draft TDDS were forwarded to Mr. Roger Wetzel of Energetics for review. A revised draft of the F2 TDDS was submitted to Mr. Wetzel, based on his initial comments. After a review of the draft TDDS, the EERC was directed to complete only the TDDS on EMCA. A draft of this TDDS was forwarded to METC in March for review.

- METC-EERC EM Cooperative Agreement Program Review Meeting

- Held December 18-19 at the EERC, Grand Forks, North Dakota

- Attendees included Thomas Bechtel, Venkat Venkataraman, Madav Ghate, and Robert Bedick of METC; John Wilson, Donald Oakley and Sheila Cleary of the Waste Policy Institute (WPI); and Patricia Kirk of SpinTek.

- A package of presentation materials was prepared and distributed at the meeting.

- A poster display profiling EMCA was prepared and displayed at the meeting.

- As a result of discussions during the December EMCA program review meeting at the EERC, it was decided to develop a Systems Engineering program area and to discontinue the Fluid-Bed Waste Calcining task under the Technology Commercialization area. The resulting four tasks for Technology Commercialization are outlined on Table 2. A Systems Engineering task proposal was initiated, with Tom Erickson designated as the lead.

- The unique hands-on approach for activities under the Technology Commercialization area was designated "Dynamic Partnership," and this terminology was applied in the TDDS and in the contribution for the SPECTRUM meeting.

- An evaluation of EERC core expertise with respect to EM technology needs was completed. Results of this evaluation are shown in Table 3. This evaluation will be used to guide the development of opportunities under the Technology Commercialization area (Dynamic Partnership) and for the Systems Engineering area.

- Internal program coordination

- Initiation of a personal computer-based listing of EM-related contacts in support of technology development activities

- Initiation of a technology and site characterization activity to support technical demonstration and marketing 


\section{TABLE 2}

Year 2 Technology Commercialization Activities for the METC-EM Cooperative Agreement

\begin{tabular}{|c|c|c|c|c|c|}
\hline Focus Area & Technology & $\begin{array}{l}\text { Commercial } \\
\text { Partner }\end{array}$ & $\begin{array}{c}\text { EERC } \\
\text { Manager }\end{array}$ & $\begin{array}{c}\text { METC } \\
\$ K\end{array}$ & Description \\
\hline \multirow[t]{2}{*}{$\begin{array}{l}\text { Mixed Waste } \\
\text { Characterization, } \\
\text { Treatment, and Disposal }\end{array}$} & $\begin{array}{l}\text { Supercritical fluid } \\
\text { extraction infrared/ } \\
\text { Fourier transform } \\
\text { infrared (SFE-IR/ } \\
\text { FT-IR) analysis }\end{array}$ & $\begin{array}{l}\text { Suprex } \\
\text { Corporation }\end{array}$ & Hawthorne & 250 & $\begin{array}{l}\text { EERC technology for extraction and analysis of } \\
\text { organic pollutants by SFE in } \mathrm{CO}_{2} \text { and IR/FT-IR } \\
\text { analysis. }\end{array}$ \\
\hline & $\begin{array}{l}\text { Thermal treatment } \\
\text { (organics) }\end{array}$ & - & Ness & 400 & $\begin{array}{l}\text { EERC technology for thermal conversion and } \\
\text { destruction of organic substances and separation } \\
\text { of inorganics based on pyrolysis of mixed } \\
\text { organic wastes and staged low-severity } \\
\text { depolymerization, hydrolysis, and } \\
\text { hydrogenation. }\end{array}$ \\
\hline $\begin{array}{l}\text { Facility Stabilization, } \\
\text { Decommissioning, and } \\
\text { Final Disposition }\end{array}$ & Laser surface cleaning & F2 Associates & Grisanti & 110 & $\begin{array}{l}\text { Technical support for development of on-line } \\
\text { analytical systems for trace metals; economic } \\
\text { assessment; laser cleaning unit decontamination } \\
\text { design. }\end{array}$ \\
\hline $\begin{array}{l}\text { Radioactive Tank Waste } \\
\text { Remediation }\end{array}$ & $\begin{array}{l}\text { Centrifugal membrane } \\
\text { filtration }\end{array}$ & $\begin{array}{l}\text { SpinTek } \\
\text { Membrane } \\
\text { Systems Inc. }\end{array}$ & Stepan & 120 & $\begin{array}{l}\text { Technical support for optimizing separation of } \\
\text { organics and inorganics from liquid waste } \\
\text { streams using selective self-cleaning membranes. }\end{array}$ \\
\hline
\end{tabular}


TABLE 3

Matrix of EERC Core Expertise and EM Technology Needs

\begin{tabular}{|c|c|c|c|c|}
\hline \multirow{2}{*}{$\begin{array}{l}\text { ERe Bora } \\
\text { Expertise }\end{array}$} & \multicolumn{4}{|c|}{ Dil Focus argas } \\
\hline & 2 & 3 & 4 & 5 \\
\hline Extraction/Analysis & B & & & A \\
\hline Cementation & bes & & & \\
\hline Vitrification & 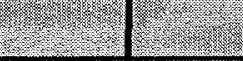 & & & 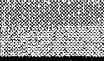 \\
\hline Leaching Assessment & 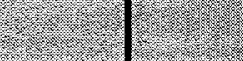 & & & \\
\hline Catalysis & 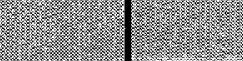 & & & \\
\hline $\begin{array}{l}\text { Thermal Conversions } \\
\text { (liquefaction, pyrolysis, FBC) }\end{array}$ & C & & & \\
\hline Plasma & & & & \\
\hline Biotreatment & & & & \\
\hline Carbon Sorbents & 28 & & & \\
\hline Separations & & D & & \\
\hline
\end{tabular}

\begin{tabular}{|ll|}
\hline & $\begin{array}{l}\text { Active Program } \\
\text { Potential Match } \\
\text { No Current Match }\end{array}$ \\
\hline 1 & $\begin{array}{l}\text { Plume Containment and } \\
\text { Remediation }\end{array}$ \\
\hline $\mathbf{2}$ & $\begin{array}{l}\text { Mixed-Waste Characterization, } \\
\text { Treatment, and Disposal }\end{array}$ \\
\hline $\mathbf{3}$ & $\begin{array}{l}\text { Radioactive Tank } \\
\text { Waste Remediation }\end{array}$ \\
\hline $\mathbf{4}$ & Landfill Stabilization \\
\hline $\mathbf{5}$ & $\begin{array}{l}\text { Facility Stabilization, } \\
\text { Decommissioning, and }\end{array}$ \\
\hline A & Laser Surface Cleaning \\
B & SFE/FT-IR \\
C & $\begin{array}{l}\text { Thermal Treatment Organic } \\
\text { Mixed Waste }\end{array}$ \\
D & Centrifugal Membrane Filtration \\
\hline &
\end{tabular}

\subsection{WORK PLANNED FOR NEXT 6 MONTHS}

Efforts during the period April 1, 1996, through October 31, 1996, will focus on the following: 1) complete TDDS; 2) submit paper and continue preparations for SPECTRUM meeting; 3) continue to identify commercial partners, promising technologies, and outreach opportunities; 4) continue efforts to team with EM sites to match needs with technologies and provide demonstration venues; and 5) continue enhancement of Task 8 effectiveness. 


\section{Program/Project Identification No.}

2. Program/Project Title DE-FC21-94MC31388

EM Task 8 - Management and Reporting

4. Name and Address Energy \& Environmental Research Center University of North Dakota

PO Box 9018 , Grand Forks, ND 58202-9018 (701) $777-5000$

$1 / 1 / 96$ through 3/31/96

5. Program/Project Start Date $9 / 30 / 94$

6. Completion Date 9/29/99

\section{\begin{tabular}{l|l}
\hline 7. FY & 8. Months or Quarters
\end{tabular} \\ \$5/96 \\ 9. Cost \\ Quarters}

Status

a. Dollars Expressed In

Thousands

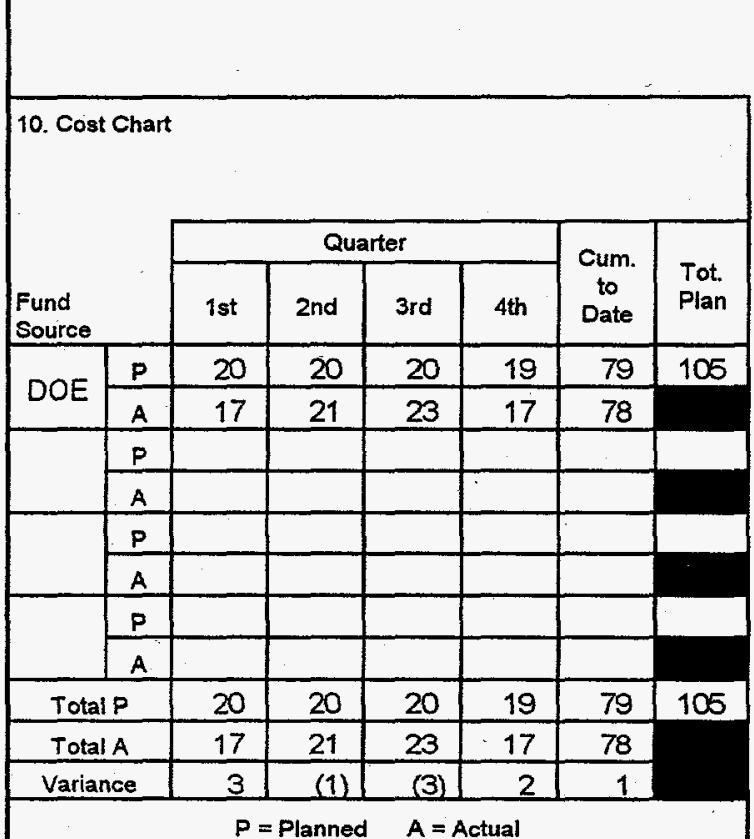

Total Planned Costs for Program/Project

$\$ 105$

11. Major Milestone Status

8.2 Provide Overall Management and Coordination of the Proposed Effort b. Dollar

Scale

\begin{tabular}{|c|c|c|c|c|c|c|c|c|}
\hline \multicolumn{3}{|l|}{1 st } & \multicolumn{3}{|c|}{ 2nd } & \multicolumn{3}{|c|}{ 3rd } \\
\hline 0 & $\mathrm{~N}$ & $D$ & $\mathrm{~J}$ & $F$ & $M$ & $\mathrm{~A}$ & $M$ & $J$ \\
\hline & & & & & & & & \\
\hline & & & & & & & & \\
\hline
\end{tabular}

\section{4 th}

ge 1 of 3 . 
2. Program/Project Title

EM Task 8 - Management and Reporting

DE-FC21-94MC31388

4. Name and Address Energy \& Environmental Research Center

University of North Dakota

PO Box 9018, Grand Forks, ND 58202-9018 (701) 777-5000
3. Reporting Period
1-1-96 through 3-31-96
5. Program/Project Start Date $9 / 30 / 94$
6. Completion Date 9/29/99

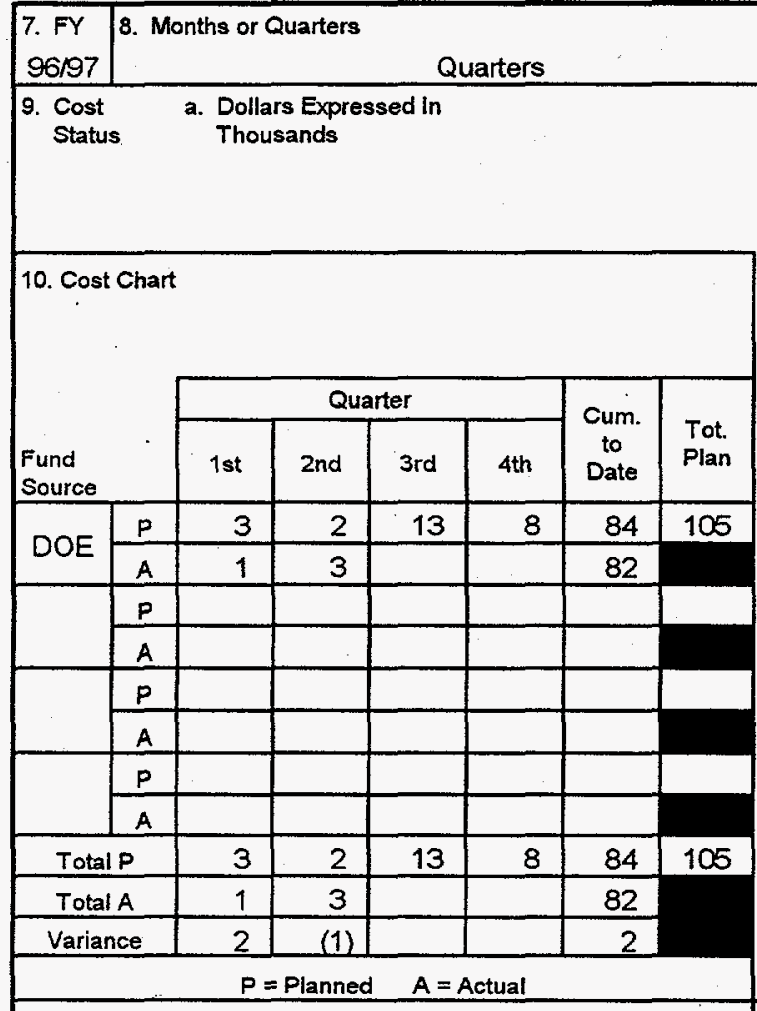

Total Planned Costs for Program/Project

$\$ 105$ b. Dollar Scale

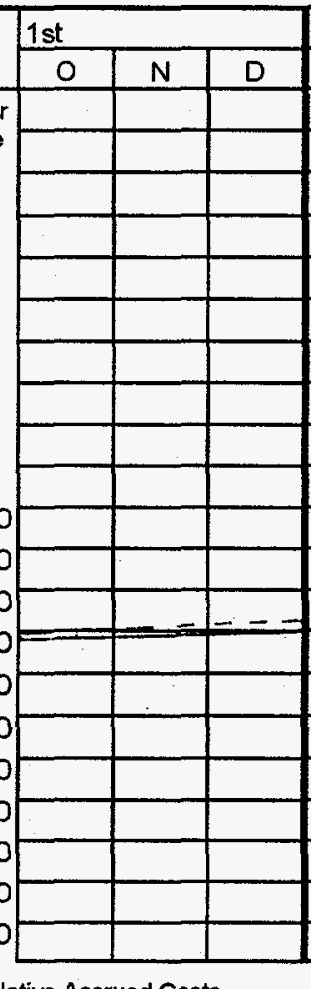

c. Cumulative Accrued Costs

\begin{tabular}{|l|r|r|r|}
\hline Planned & & & 82 \\
\hline Actual & & & 79 \\
\hline Variance & & & 3 \\
\hline
\end{tabular}

2nd 3 3rd 1 4th 
1. Program/Project Identification No. DE-FC21-94MC31388

2. Program/Project Title EM Task 8 - Management and Reporting

Energy \& Environmental Research Center University of North Dakota PO Box 9018 Grand Forks, ND 58202-9018
4. Name and Address

Page 3 of 3

3. Reporting Period 1-1-96 through 3/31/96

5. Program/Project Start Date 9/30/94

6. Completion Date 9/29/99

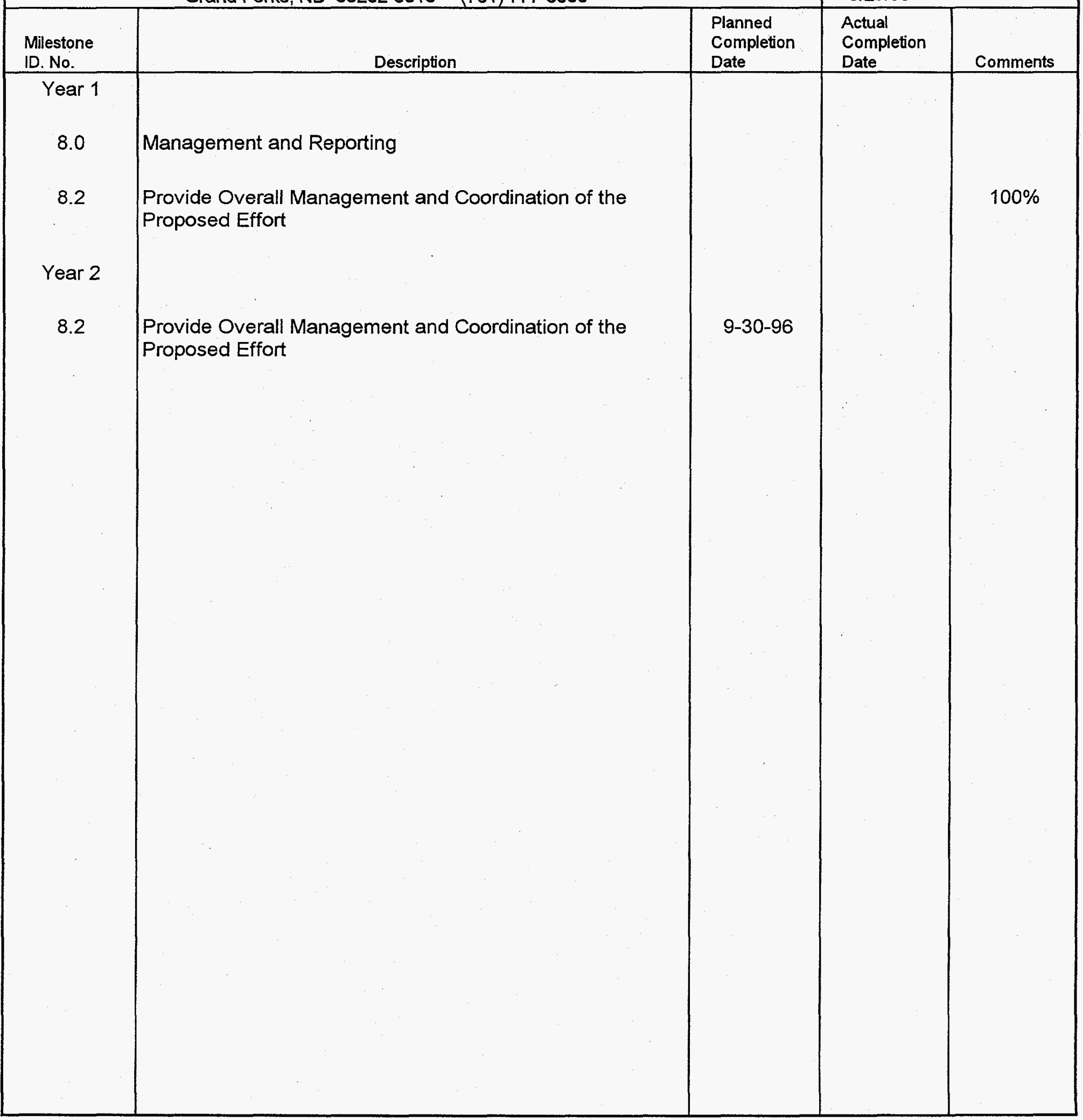




\title{
TASK 9 - CENTRIFUGAL MEMBRANE FILTRATION
}

\author{
Semiannual Report
}

for the period November 1, 1995, through March 31, 1996

Prepared for:

Venkat K. Venkataraman

U.S. Department of Energy

Morgantown Energy Technology Center

3610 Collins Ferry Road

PO Box 880, MS C05

Morgantown, WV 26507-0880

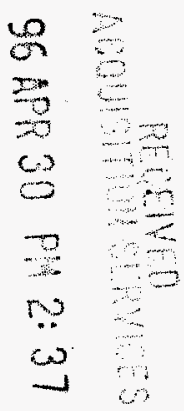

EERC-DOE Environmental Management

Cooperative Agreement No. DE-FC21-94MC31388

Prepared by:

Daniel J. Stepan

Marc D. Kurz

Energy \& Environmental Research Center University of North Dakota

PO Box 9018

Grand Forks, ND 58202-9018 
TABLE OF CONTENTS

LIST OF FIGURES $\ldots \ldots \ldots \ldots \ldots \ldots \ldots \ldots \ldots \ldots \ldots \ldots \ldots \ldots$

LIST OF TABLES $\ldots \ldots \ldots \ldots \ldots \ldots \ldots \ldots \ldots \ldots \ldots \ldots \ldots \ldots \ldots \ldots$

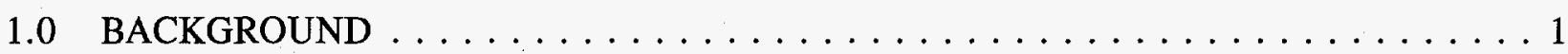

2.0 OBJECTIVES $\ldots \ldots \ldots \ldots \ldots \ldots \ldots \ldots \ldots \ldots \ldots \ldots \ldots \ldots \ldots \ldots \ldots \ldots \ldots \ldots$

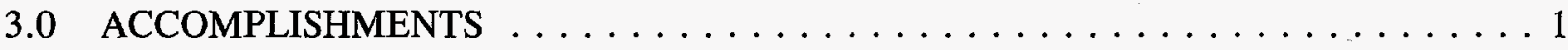

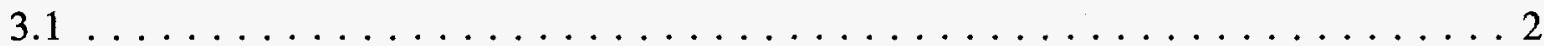

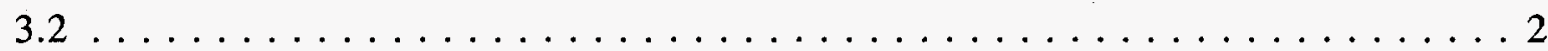

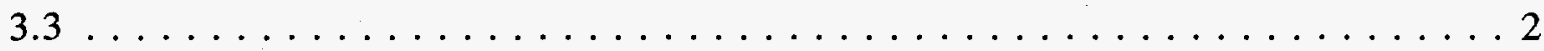

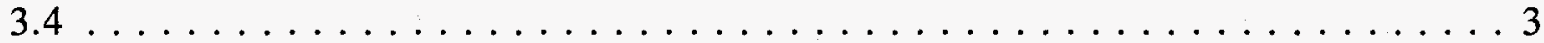

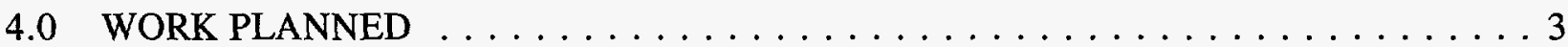

\section{LIST OF FIGURES}

1 Potential applications of the SpinTek process for tank waste remediation $\ldots \ldots \ldots \ldots 3$

\section{LIST OF TABLES}

1 Conditions for Matrix Testing of the ST-IIL Centrifugal Membrane Filtration Unit . . . . . 4 


\section{CENTRIFUGAL MEMBRANE FILTRATION}

\subsection{BACKGROUND}

Work under this task is designed to establish the utility of a novel centrifugal membrane filtration technology for the remediation of liquid mixed waste streams at U.S. Department of Energy (DOE) facilities in support of the DOE Environmental Management (EM) program. The Energy \& Environmental Research Center (EERC) has teamed with SpinTek Membrane Systems, Inc., a small business and owner of the centrifugal membrane filtration technology, to establish the applicability of the technology to DOE site remediation and the commercial viability of the technology for liquid mixed waste stream remediation.

The technology is a uniquely configured process that utilizes ultrafiltration and centrifugal force to separate suspended and dissolved solids from liquid waste streams, producing a filtered water stream and a low-volume contaminated concentrate stream. This technology has the potential for effective and efficient waste volume minimization, the treatment of liquid tank wastes, the remediation of contaminated groundwater plumes, and the treatment of secondary liquid waste streams from other remediation processes, as well as the liquid waste stream generated during decontamination and decommissioning activities.

\subsection{OBJECTIVES}

The overall project consists of several integrated research phases related to the applicability, continued development, demonstration, and commercialization of the SpinTek centrifugal membrane filtration process. Specific objectives of Phase I research activities include the following:

- A problem and opportunity assessment to identify applicable waste streams, including mixed wastes, associated with DOE sites

- Development of detailed process data that will provide information with regard to the application of the technology at DOE sites

- Testing and evaluation of a laboratory centrifugal membrane filtration unit using surrogate waste streams under a variety of operating conditions

- Development of process data that will allow optimization of the technology for appropriate DOE waste stream remediation

\subsection{ACCOMPLISHMENTS}

Activities during this reporting period include the completion and submission of the interim project report concerning problem identification and opportunity assessment for the centrifugal membrane filtration process, equipment procurement and training, baseline performance data 
collection, and waste stream identification followed by preliminary membrane screening and selection.

\subsection{Problem Identification and Opportunity Assessment}

Under this task, available information was reviewed to identify liquid waste streams at DOE facilities that would be amenable to treatment using the SpinTek centrifugal membrane filtration process. An interim project report was prepared and submitted to DOE. This report provided information on the nature of individual contaminants and contaminant mixtures, their frequency of occurrence at DOE facilities, and the potential application of the centrifugal membrane filtration process, alone or as part of an overall treatment or remediation process. The SpinTek centrifugal membrane filtration process is considered a crosscutting technology, i.e., one that overlaps the boundaries of the five focus areas established by DOE to address its most pressing problems. More specifically, the SpinTek process falls under the Efficient Separations and Processing Crosscutting Program, where technologies apply to a broad range of radioactive wastes while reducing overall costs, reducing secondary waste volumes, and improving waste form quality.

Based upon the review conducted during the problem identification and opportunity assessment, the nature of the waste streams identified, and the potential application of the centrifugal membrane filtration process, the Tank Waste Remediation Focus Area will be emphasized for Phase I testing and evaluation. The advantages of the SpinTek process for tank waste remediation are that it is an easily transportable, compact unit that is considered a near-tank technology. The readily apparent benefits to cleanup operations are the efficient removal of suspended and colloidal solids from tank waste supernatants and solid-liquid separation during tank sludge washing, both of which will improve the operation and efficiency of downstream unit operations such as adsorption and ion exchange. These applications are illustrated in Figure 1.

\subsection{Equipment Procurement and Training}

The equipment to be used for membrane screening and selection, the SpinTek STC-X4 cross-flow filtration unit, was received at the EERC in November, 1995. SpinTek personnel provided a 3-day training session in operating procedures, as well as troubleshooting for the SpinTek ST-IIL centrifugal membrane filtration unit. The STC-X4 utilizes static membrane cells, where the feed material flows past small sections of membrane (approximately 3 in. by 5 in.) at velocities of up to $15 \mathrm{ft}$ per second. Up to four different membrane types can be tested simultaneously under the same conditions on a given waste stream.

\subsection{Baseline Data Collection}

Baseline data collection activities using the ST-IIL unit were continued during this reporting period. The general data collection procedure involved varying process parameters of temperature, system pressure, feed rate, and rotor speed and monitoring the effects on permeate flux. During initial testing, a malfunctioning heat-exchanger valve resulted in the inability to maintain constant process temperatures. A loose connection in the control panel was repaired, and the computer logic was adjusted, allowing for proper operational control.

Subsequent baseline testing using tap water was conducted to evaluate process limitations and design parameters for matrix testing. Based on these tests, the high, low, and midpoints for testing 

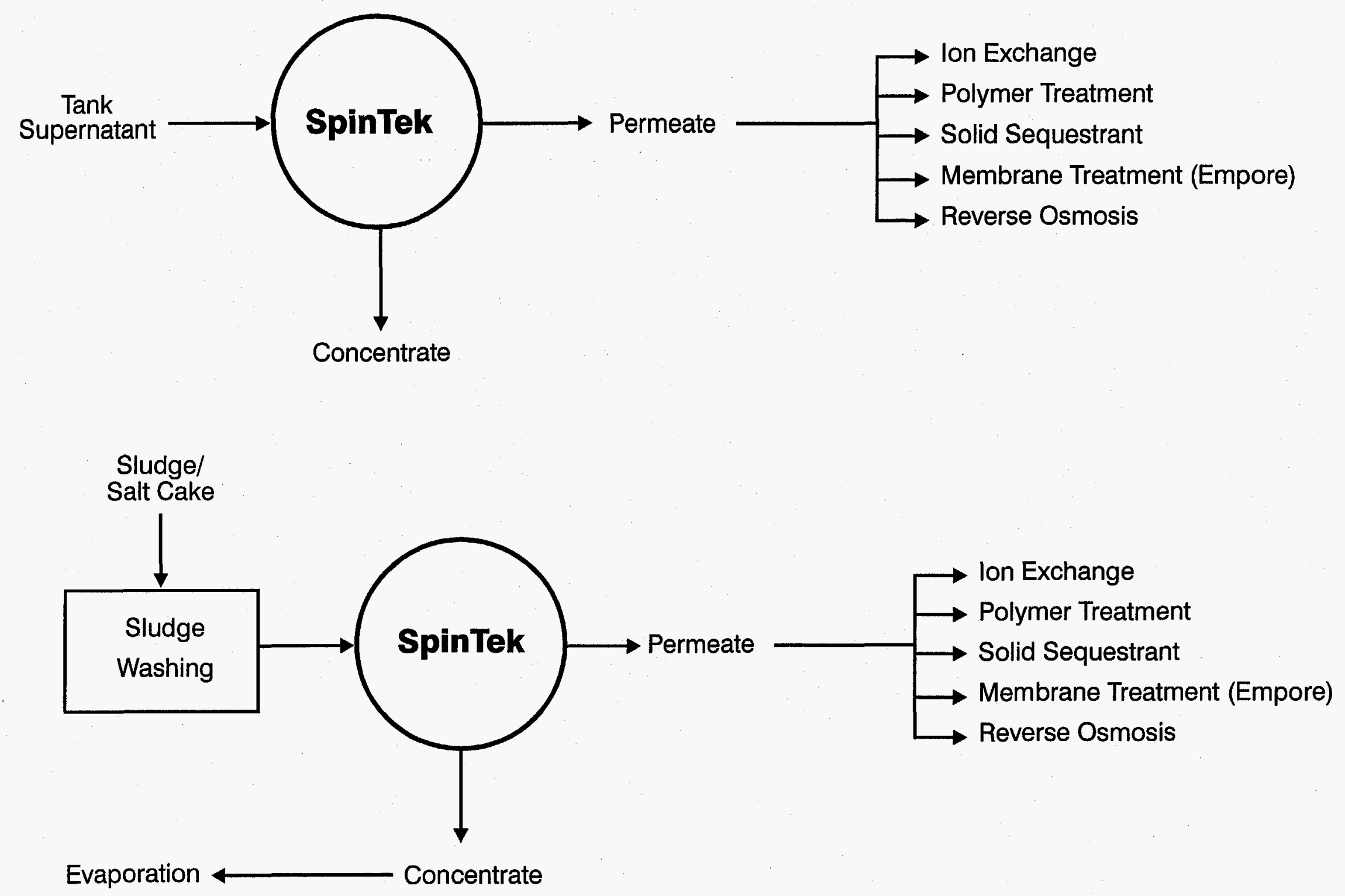

Figure 1. Potential application of the SpinTek process for tank waste remediation. 
were selected and are presented in Table 1. Baseline testing will be completed during the next quarter.

TABLE 1

\begin{tabular}{lrrr}
\multicolumn{4}{c}{ Conditions for Matrix Testing of the ST-IIL Centrifugal Membrane Filtration Unit } \\
\hline Parameter & - & 0 & + \\
Temperature, ${ }^{\circ} \mathrm{F}$ & 60 & 90 & 120 \\
Rotational Speed, rpm & 1000 & 1500 & 2000 \\
Pressure, psig & 40 & 60 & 75 \\
Solids Loading, wt\% & 1 & 15 & 30 \\
\hline
\end{tabular}

\subsection{Membrane Screening and Selection}

Membrane screening and selection activities were initiated during this reporting period. Preliminary membrane selection was based on the character of the waste stream selected for testing and evaluation. As mentioned, Phase I efforts are focusing on radioactive tank waste remediation. There have been 332 underground storage tanks across the DOE complex, which were used to store 100 million gallons of radioactive and chemical mixed wastes. Most tank wastes are alkaline, with components such as nitrates and nitrate salts, hydrated metal oxides, phosphate precipitates, ferrocyanides, and radionuclides, particularly ${ }^{90} \mathrm{Sr}$ and ${ }^{137} \mathrm{Cs}$.

Based on the character of these wastes, ceramic-type membranes appear to be inherently better than polymeric membranes and have been selected for further testing and evaluation. Six different ceramic membranes will be screened using the STC-X4 cross-flow filtration unit, including 1) $\mathrm{SS} 316 \mathrm{~L} / \mathrm{TiO}_{2}(0.14-\mu \mathrm{m}$ pore size $\left.), 2\right) \mathrm{SS} 316 \mathrm{~L} / \mathrm{TiO}_{2}-\mathrm{Al}_{2} \mathrm{O}_{3}(0.25-\mu \mathrm{m}$ pore size $)$ 3) $\mathrm{SS} 316 \mathrm{~L} / \mathrm{TiO}_{2}-\mathrm{Al}_{2} \mathrm{O}_{3}(0.4-\mu \mathrm{m}$ pore size $)$, 4) $\mathrm{SS} 316 \mathrm{~L} / \mathrm{ZrO}_{2}-\mathrm{TiO}_{2}(0.3-\mu \mathrm{m}$ pore size $\left.), 5\right) \mathrm{SS} 316 \mathrm{~L} /$ $\mathrm{TiO}_{2}-\mathrm{SiO}_{2}(0.25-\mu \mathrm{m}$ pore size $)$, and 6$) \mathrm{SS} 316 \mathrm{~L} / \mathrm{ZrO}_{2}(0.6-\mu \mathrm{m}$ pore size $)$. The membrane(s) exhibiting the best overall performance based on permeate flux and permeate quality will be used for further testing and evaluation using the ST-IIL centrifugal membrane filtration unit.

\subsection{WORK PLANNED}

Projected work includes continuation of membrane screening and selection, preparation of the surrogate waste stream, matrix testing and statistical data analysis, and final Phase I project report preparation.

Testing and evaluation of the selected membrane(s) on the ST-IIL unit will be based on a statistical matrix design that considers the interdependence of operating parameters such as temperature, pressure, membrane rotational velocity, and suspended solids loading. All experimental runs will be performed in randomized order to prevent experimental bias. Up to 27 different runs of up to 8-10 hours each will be conducted for statistical analysis of the data. 
The system will then be operated for extended periods of time to determine the effect of filtration rates and process throughput on membrane cleaning frequency. Evaluations of equipment corrosion, scaling, and general fouling potential will also be conducted.

Following completion of testing and data reduction and analysis, a comprehensive report will be prepared detailing process performance of the SpinTek centrifugal membrane filtration process, along with recommendations for DOE facility application and continued demonstration activities. 
FORM APPROVED

OMB NO. 19000127

\begin{tabular}{|l|l|}
\hline $\begin{array}{l}\text { 1. Program/Project Identification No. } \\
\text { DE-FC21-94MC31388 }\end{array}$ & $\begin{array}{l}\text { 2. Program/Project Title } \\
\text { EMTask9 - Centrifugal Membrane Filtration }\end{array}$ \\
\hline
\end{tabular}

4. Name and Address Energy \& Environmental Research Center University of North Dakota

PO Box 9018 , Grand Forks, ND 58202-9018 $\quad$ (701) $777-5000$
3. Reporting Period

1/1/96 through 3/31/96

5. Program/Project Start Date 9/30/94

6. Completion Date 9/29/99

\begin{tabular}{|c|c|c|c|c|c|c|c|}
\hline $\begin{array}{l}\text { 7. } \mathrm{FY} \\
95196\end{array}$ & 8. 1 & nths or & \multicolumn{3}{|c|}{ Quarters } & & \\
\hline \multicolumn{2}{|c|}{$\begin{array}{l}\text { 9. Cost } \\
\text { Status }\end{array}$} & \multicolumn{6}{|c|}{$\begin{array}{l}\text { a. Dollars Expressed In } \\
\text { Thousands }\end{array}$} \\
\hline \multicolumn{8}{|c|}{ 10. Cost Chart } \\
\hline \multirow{2}{*}{\multicolumn{2}{|c|}{$\begin{array}{l}\text { Fund } \\
\text { Source }\end{array}$}} & \multicolumn{4}{|c|}{ Quarter } & \multirow{2}{*}{$\begin{array}{c}\text { Cum. } \\
\text { to } \\
\text { Date }\end{array}$} & \multirow{2}{*}{$\begin{array}{l}\text { Tot. } \\
\text { Plan }\end{array}$} \\
\hline & & 1st & 2nd & 3rd & 4th & & \\
\hline \multirow{2}{*}{ DOE } & $P$ & 0 & 0 & 80 & 94 & 174 & \multirow[t]{2}{*}{293} \\
\hline & A & & & 80 & 8 & 88 & \\
\hline & $\mathbf{P}$ & & & & & & \\
\hline & A & & & & & & \\
\hline & $P$ & & & & & & \\
\hline & A & & & & & & \\
\hline & $\mathbf{P}$ & & & & & & \\
\hline & A & & & & & & \\
\hline Tota & & 0 & 0 & 80 & 94 & 174 & 293 \\
\hline Tota & & & & 80 & 8 & 88 & \\
\hline Varia & cee & & & 0 & 86 & 86 & \\
\hline & & & Planne & $A=$ & ual & & \\
\hline
\end{tabular}

Total Planned Costs for Program/Project

$$
\$ 293
$$
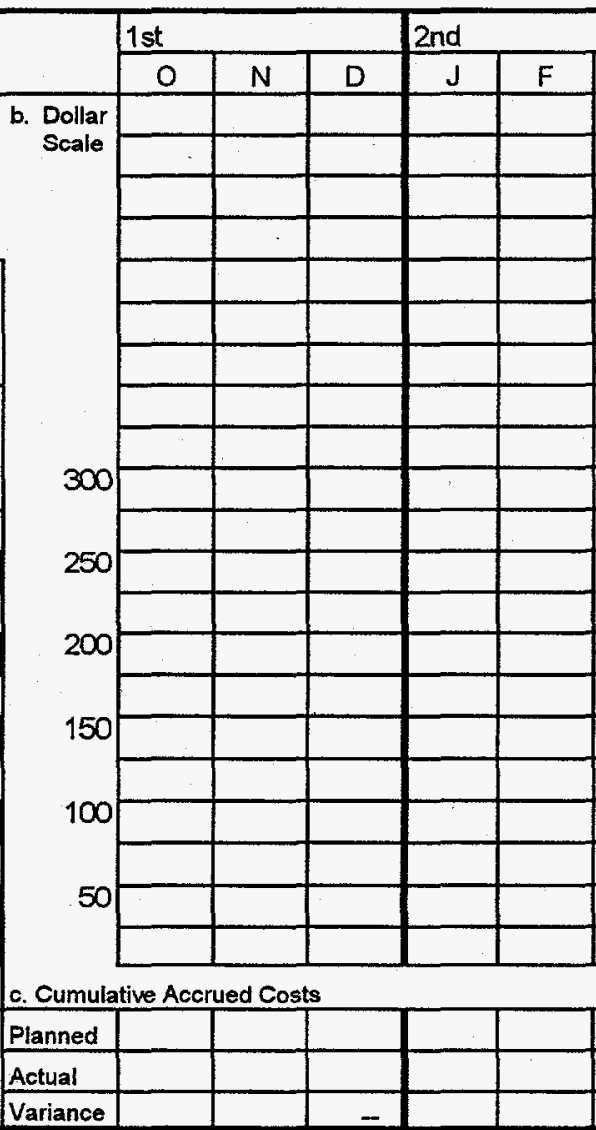

3rd 4 th

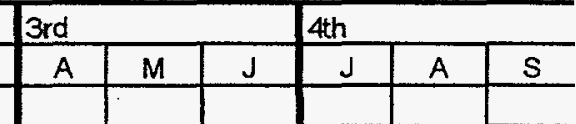

\begin{tabular}{|c|c|}
\hline 11. Major Milestone Status & Units Planned \\
\hline & Units Complete \\
\hline & P \\
\hline & c \\
\hline lo 2 Process Performance Verification & $p$ \\
\hline & $\mathrm{c}$ \\
\hline & P \\
\hline 9.3 Miembrane Screening and Selection & c \\
\hline 9.4 Performance Evaluation & $P$ \\
\hline & $p$ \\
\hline & c \\
\hline & $\mathrm{P}$ \\
\hline & c \\
\hline & $\mathrm{P}$ \\
\hline & $c$ \\
\hline & $P$ \\
\hline & $c$ \\
\hline & \\
\hline
\end{tabular}

12. Remarks 
1. Program/Project Identification No.

2. Program/Project Title

DE-FC21-94MC31388

EM Task 9-Centrifugal Membrane Filtration

Page 2 of 3

4. Name and Address Energy \& Environmental Research Center University of North Dakota

PO Box 9018, Grand Forks, ND 58202-9018

(701) $777-5000$

3. Reporting Period

1/1/96 through 3/31/96

5. Program/Project Start Date 9/30/94

6. Completion Date 9/29/99

\begin{tabular}{|c|c|c|c|c|c|c|c|}
\hline $\begin{array}{l}\text { 7. FY } \\
96 / 97\end{array}$ & 8. & \multicolumn{6}{|c|}{ Quarters } \\
\hline \multicolumn{2}{|c|}{$\begin{array}{l}\text { 9. Cost } \\
\text { Status }\end{array}$} & \multicolumn{6}{|c|}{$\begin{array}{l}\text { a. Dollars Expressed In } \\
\text { Thousands }\end{array}$} \\
\hline \multicolumn{8}{|c|}{ 10. Cost Chart } \\
\hline \multirow[b]{2}{*}{$\begin{array}{l}\text { Fund } \\
\text { Source }\end{array}$} & & \multicolumn{4}{|c|}{ Quarter } & \multirow{2}{*}{$\begin{array}{c}\text { Cum. } \\
\text { to } \\
\text { Date }\end{array}$} & \multirow{2}{*}{$\begin{array}{l}\text { Tot. } \\
\text { Plan }\end{array}$} \\
\hline & & 1 st & 2nd & $3 \mathrm{rd}$ & 4th & & \\
\hline \multirow{2}{*}{ DOE } & $\mathbf{P}$ & 15 & 15 & 54 & 35 & 204 & 293 \\
\hline & A & 43 & 24 & & & 155 & \\
\hline \multicolumn{8}{|c|}{$\mathbf{P}$} \\
\hline \multicolumn{8}{|c|}{ A } \\
\hline \multicolumn{8}{|c|}{$\mathbf{P}$} \\
\hline \multicolumn{8}{|c|}{ A } \\
\hline \multicolumn{8}{|c|}{$\mathbf{P}$} \\
\hline \multicolumn{8}{|c|}{$A$} \\
\hline \multicolumn{2}{|c|}{ Total P } & 15 & 15 & 54 & 35 & 204 & 293 \\
\hline \multicolumn{2}{|c|}{ Total A } & 43 & 24 & & & 155 & \\
\hline \multicolumn{2}{|c|}{ Variance } & 28 & (9) & & & 49 & \\
\hline \multicolumn{8}{|c|}{$P=$ Planned } \\
\hline
\end{tabular}

Total Planned Costs for Program/Project

\section{$\$ 293$}
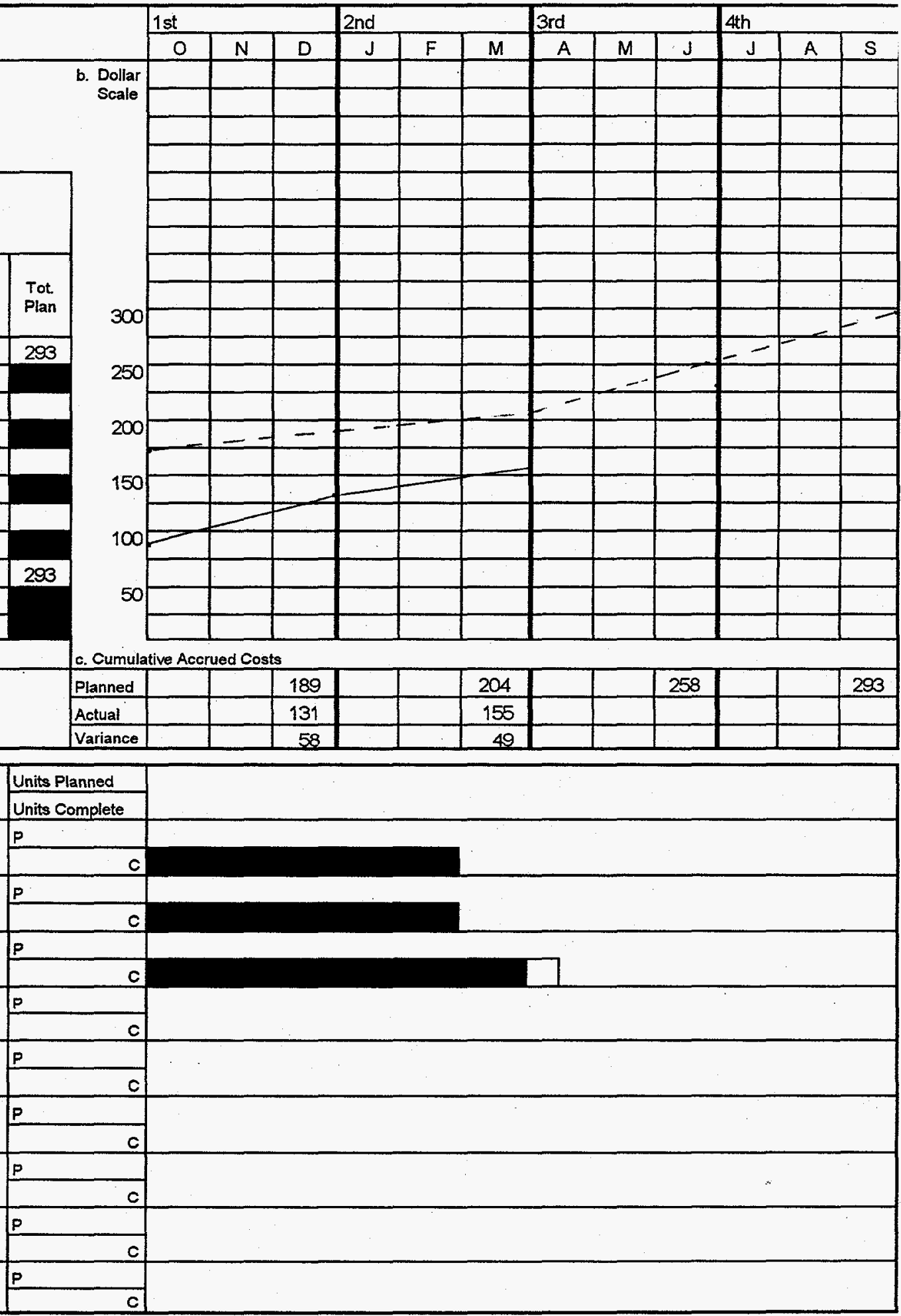

12. Remarks 


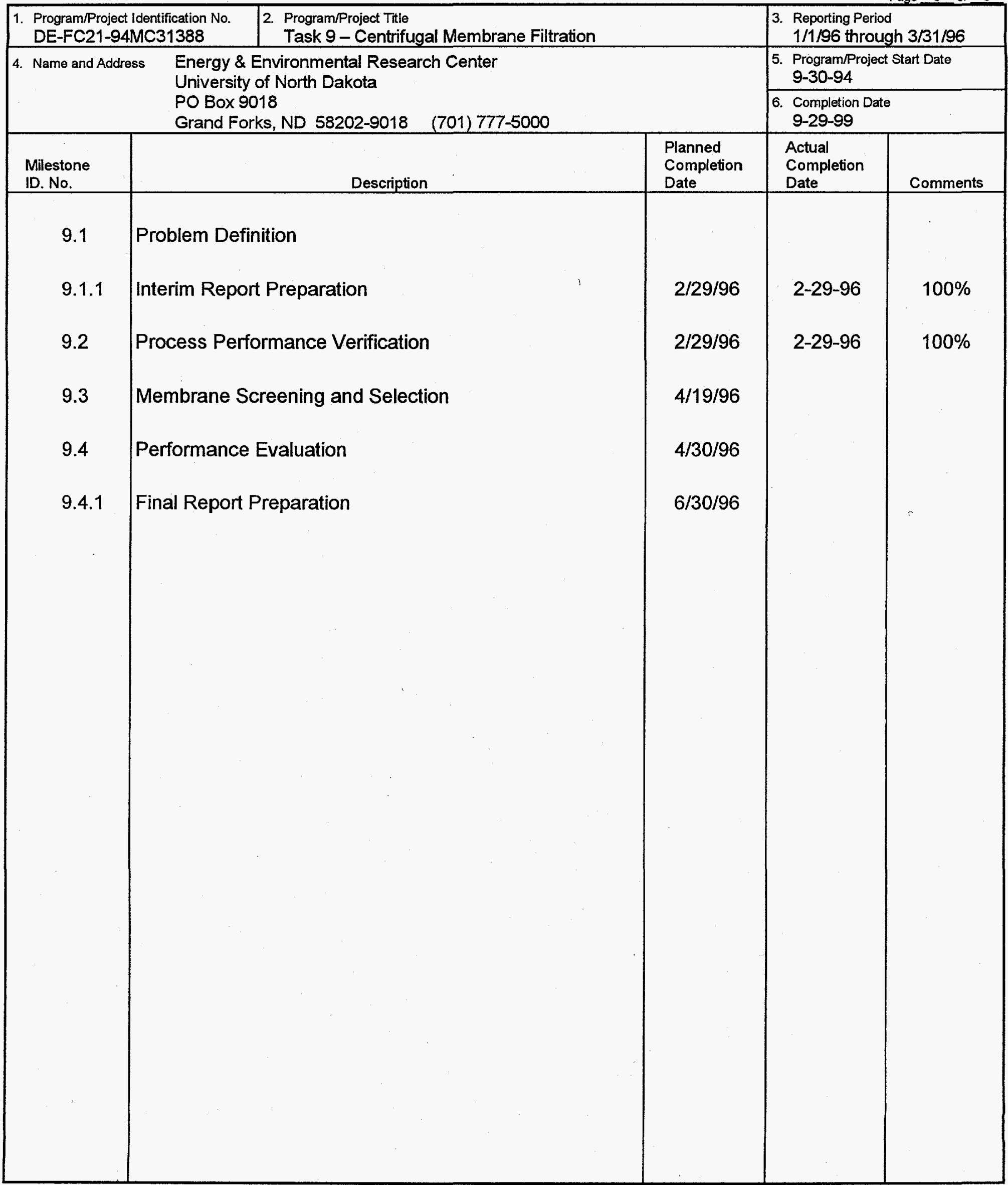




\section{TASK 10 - TECHNOLOGY DEVELOPMENT INTEGRATION}

Semiannual Report

for the period November 1, 1995, through March 31, 1996

Prepared for:

Venkat K. Venkataraman

U.S. Department of Energy

Morgantown Energy Technology Center

3610 Collins Ferry Road

PO Box 880, MS C05

Morgantown, WV 26507-0880

UND EERC-DOE Environmental Management

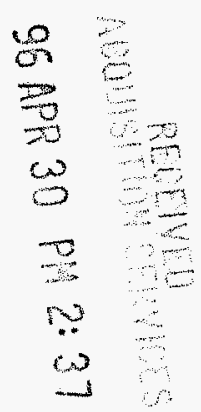

Cooperative Agreement No. DE-FC21-94MC31388

\section{Prepared by:}

John H. Hendrikson Daniel J. Daly

Energy \& Environmental Research Center University of North Dakota PO Box 9018

Grand Forks, ND 58202-9018 


\section{TABLE OF CONTENTS}

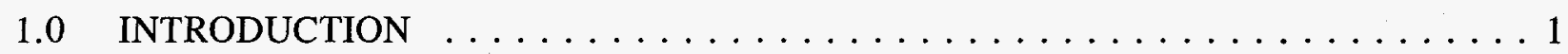

2.0 OBJECTIVES AND ACTIVITIES $\ldots \ldots \ldots \ldots \ldots \ldots \ldots \ldots \ldots$

3.0 ACCOMPLISHMENTS/WORK PERFORMED $\ldots \ldots \ldots \ldots \ldots \ldots \ldots$

4.0 WORK PLANNED FOR NEXT 6 MONTHS $\ldots \ldots \ldots \ldots \ldots \ldots$

Waste Policy Institute Monthly Report to the EERC, November 1995 . . . . . . . . Appendix A

Waste Policy Institute Monthly Report to the EERC, December 1995 . . . . . . . Appendix B

Waste Policy Institute Monthly Report to the EERC, January 1996 . . . . . . . . Appendix C

Waste Policy Institute Monthly Report to the EERC, February 1996 . . . . . . . . Appendix D

Waste Policy Institute Monthly Report to the EERC, March 1996 . . . . . . . . . Appendix E 


\section{TASK 10 - TECHNOLOGY DEVELOPMENT INTEGRATION}

\subsection{INTRODUCTION}

The Energy \& Environmental Research Center (EERC) in conjunction with the Waste Policy Institute (WPI) will identify and integrate new technologies to meet site-specific environmental management (EM) requirements at contaminated sites appropriate to U.S. Department of Energy (DOE) interests. EM technologies offered by developers will be evaluated to determine their complementary contribution to new cleanup systems focused on particular characterization and remediation problems at specific EM sites. The technology clusters identified will provide EM cleanup capabilities that are significantly faster, better, safer, and cheaper than systems that are currently available. Work will be performed under the DOE-EERC EM Cooperative Agreement (CA), which includes provisions "to develop, demonstrate, and commercialize technologies that address environmental management needs of contaminated sites" together with "management activities which accelerate transfer of technologies." The effort began July 1, 1995.

\subsection{OBJECTIVES AND ACTIVITIES}

This task will develop new approaches for evaluating technology focus areas and other research and development technical programs and activities. This includes creating technology development scenarios and formulating streamlined technical approaches that will expedite technology focus area initiatives, other technical programs, and projects. In addition, this task is designed to validate technologies and systems through all phases of research, development, demonstration, testing, and evaluation and ensure public involvement during the development process.

The work is divided into three activities. As part of the Task 10.1, Technology Management, activity, technical reviews of requirements, needs, and assessments related to waste characterization, containment, in situ and ex situ treatment, waste storage, disposal, robotics handling, monitoring, laboratory analysis, and site characterization and remediation will be performed. The activities include but are not limited to the following: development of systems, experimental design, plans; verification of technology performance; establishing regulatory documentation and intermediate products required for testing, demonstration, and validation; and preparation of review documentation. In addition, studies will be performed in various focus areas to facilitate rapid deployment of waste management technologies to the specific DOE sites and transfer to the private sector.

As part of Project Management, Task 10.2, the participants will conduct reviews and analyze and develop strategies for program management systems to integrate and control programs, projects, tasks, and documentation. This includes financial and technical management systems; decision analysis tools and program-planning software; and cost or schedule variance analysis and related software. In addition, the following activities will be carried out: conduct project reviews, public hearings, meetings, and public briefings; develop technical briefings; prepare related materials; plan for the transportation of hazardous waste, including acting as a liaison with the public on routes, safety, and preparedness; provide emergency management plans, training, and 
exercises for facility and transportation preparedness; and develop protocols for collecting, handling, analyzing, and shipping environmental samples.

As part of the Technology Integration (Task 10.3) activities to the private sector, criteria for identifying risks to public health and safety posed by conditions at weapons complex facilities will be established, the extent of these risks will be evaluated, the urgency and priorities for eliminating or minimizing the risks will be determined, and the cost of activities required to meet applicable compliance agreements will be assessed.

\subsection{ACCOMPLISHMENTS/WORK PERFORMED}

Activities over the reporting period have focused on providing logictical and administrative support.

- $\quad$ For the EMCA, activities focused on providing coordination and logistical support for meetings with key EM personnel, particularly in the Mixed Waste Focus Area, and for meetings with commercial partners. These activities were undertaken to explore technology commercialization and deployment options under EMCA and included the following:

- $\quad$ Visit to the EERC by Lockheed Idaho Technologies Company (LITC) in December 1995. LITC agreed to furnish EERC with selected reports and databases dealing with the Mixed Waste Focus Area.

- Visit by EERC staff (Ed Steadman, Everett Sondreal, Greg Weber) to Idaho National Engineering Laboratory offices in Idaho Falls, Idaho, February 29, 1996. The EERC group met with DOE and WPI personnel to discuss Mixed Waste Focus Area issues.

- $\quad$ Stone and Webster (Mr. J. Cardito) visited to the EERC in early March to discuss deployment options for the Thermal Treatment Technology at the Savannah River Site.

- $\quad$ Administrative support was provided for the WPI subcontract. Activities under this subcontract are dealt with in detail for the reporting period in the WPI monthly reports contained in Appendices A through E.

\subsection{WORK PLANNED FOR NEXT 6 MONTHS}

During the coming reporting period, WPI activities will vary by focus area under the three activity areas - Technology Management, Project Management, and Technology Integration. The EERC will continue to perform program integration and coordination activities.

For Technology Management (Task 10.1), WPI will perform technical reviews and assessments as appropriate related to waste and site/facility characterization; containment; in situ 
and ex situ treatment; waste handling, storage, and disposal; laboratory analysis; and monitoring technologies.

For Project Management (Task 10.2), WPI will continue to conduct reviews and analyze and develop strategies and systems for the integration and implementation of focus area programs, projects, and tasks.

For Technology Integration (Task 10.3), WPI will continue to assess regulatory and public health and safety risks posed by conditions at nuclear defense complex facilities that might impede the successful implementation or transfer of focus-area-developed technologies. 
WASTE POLICY INSTITUTE MONTHLY REPORT TO THE EERC, NOVEMBER 1995

APPENDIX A 


\section{UNIVERSITY OF NORTH DAKOTA ENERGY AND ENVIRONMENTAL RESEARCH CENTER}

\section{Monthly Report November, 1995}

\section{TECHNOLOGY DEVELOPMENT INTEGRATION WPI SUBCONTRACT NUMBER 359636}

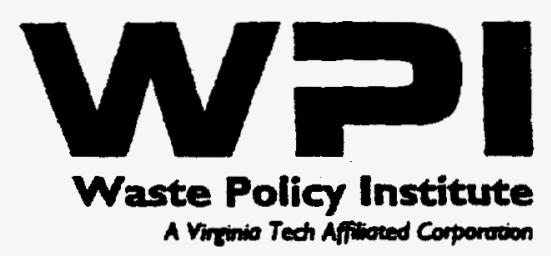


SUBCONTRACT NUMBER: 359636

Report Period: 11/1/95 -11/30/95

CONTRACTOR NAME: Waste Policy Institute

555 Quince Orchard Road

Suite 600

Gaithersburg, MD 20878-1437

CONTRACT PERIOD: $\quad 6 / 28 / 95-12 / 01 / 95$

\section{SUBCONTRACT DELIVERABLES:}

This report is submitted in fulfillment of requirements specified for the University of North Dakota Energy and Environmental Research Center (UNDEERC) Subcontract Number 359636. A list of products developed under this subcontract is provided as Attachment $A$.

\section{SUMMARY OF ACTIVITIES:}

The Subcontract activities continued through November with the WPI team "at risk" awaiting funding from continuing resolutions and final appropriations. Final staffing is being completed at all offices.

\section{TASK A - TECHNOLOGY MANAGEMENT}

A significant technical activity this month was the assistance in conducting a Peer Review for Vitrification Program held on November 13-15 in Dallas, Texas. The review focused on Transuranic (TRU), TRU Mixed, and Mixed Low-Level Waste (MLLW) Treatment technologies. Support was provided from the Aiken, Idaho Falls and Blacksburg Offices.

Several of the focus areas are in the process of analyzing the site-specific regulatory requirements; assistance has been provided to compile the information.

\section{TANKS FOCUS AREA (TFA)}

The team assisted with the coordination of a national needs call for the TFA. The needs call will be used to update the FY95 Needs Assessment performed by the TFA. Responses from the field are requested by December 22. Needs responses will be normalized for consistency and a database and new Needs Breakdown Structure created. Responses to the proposed prioritization criteria will be evaluated and a new procedure developed and implemented.

Provided technical and programmatic review of the TFA's directed call for proposals for cesium removal testing using liter quantities of Hanford supernatant. Provided 
comments to DOE-RL on the call statement of work, i.e., the call contained too much detail, constraining respondents. The comments were incorporated in the final call.

The team has kicked off development of a data package of project-related information. The purpose is to provide a condensed resource book to take to meetings, support short turn-around tasks, or to indoctrinate new employees to Focus Area activities. Pilot "Task Information" sheets with Technical Task Plan, Task Title, Description, Points of Contact, Deliverables, Metrics, and Crosscut Program references are being produced. It is expected that this effort will build the staff's knowledge base while providing a valuable reference tool.

A search concerning Hanford's involvement in immobilization and vitrification activities was performed. This search covered melter selection, melter tests, and documentation. The pilot scale Hanford vitrification plant in 300 Area was visited and contact with the staff was established. This activity resulted in a bibliography of melter technology and tests performed at Hanford for the future use in TFA technical and managerial activities.

Environmental regulation governing Hanford was reviewed. A matrix of regulatory agencies, their contacts, responsibility and concerns was structured.

Participated in preliminary technical and budgetary meetings relating to Laser Ablation/Mass Spectrometry (LA/MS) technology planned for deployment into Westinghouse Hanford Company hot cells. The meeting highlights included potential problems faced with LA/MS integration into the hot cells and solutions were discussed. Sample homogeneity concems and sampling techniques were questioned to both the principle investigator and the technical integration manager. Some solutions were considered for further testing.

Assisted with preparing the Radioactive Tank Waste Remediation section of the EM-50 Annual Report to Congress.

\section{LANDFILL STABILIZATION FOCUS AREA (LFSA)}

Prepared criteria and guidance for reviewing the various thermal treatment technologies during the upcoming technology review that has been requested by the Savannah River Citizens Advisory Board. The results of this review will allow DOE to evaluate future directions the department should take with regard to future funding of technologies to treat TRU, TRU mixed and MLLW problems at various sites.

Developed a prioritization methodology for LSFA projects. Application of this methodology across the focus area will allow more effective management of LSFA activities and will facilitate implementation of budget adjustments.

Provided technical status on LSFA successful technologies to display at the National Engineering /Hazmat Conference. Coordinated and compiled display materials from 
LSFA Principal Investigators (PI), Product Line Managers (PLM) and Headquarters (HQ). The purpose of the conference was to promote and communicate the benefits of developed/developing successful LSFA technologies and highlight program accomplishments.

Provide technical input into a response to Stan Wolf from the LSFA concerning parameters and criteria for the selection of LSFA technologies for cost benefit analysis. The use of standardized criteria for the selection of technologies will allow the LSFA to manage from the same baseline.

Compiled technical input concerning technologies selected for cost benefit analysis. Information was communicated by LSFA management to TPO's at Idaho, Albuquerque, and Savannah River.

Attended the Tech Invest Meeting at Savannah River, November $2-3$ and provided technical support to LSFA personnel concerning the status of LSFA projects and activities and the identification of beneficial opportunities for the application of the software.

Provided programmatic \& technical input into selection of sites to conduct cold and hot bottom-to-top In-Situ vitrification demonstrations. Information on proposal was communicated by DOE to the TPO's, Site Technical Coordination Groups (STCG), Assistant Managers for Environmental Management Systems (AMEMS) and stakeholders and will be utilized as a basis for the review of site proposals.

\section{PLUMES FOCUS AREA (PFA)}

Compiled list of Conference/Symposia/Workshops of interest to the PFA team members. Dissemination of information will assist PFA team members in accessing technical information in a more effective manner.

Revised INEL Site Visit Report to incorporate technical contents and assure factual accuracy. The revised report will provide input into a revision of the PFA needs assessment document.

Researched and analyzed past and current PFA documents to ensure that single technology demonstrations were not claimed to occur in two different fiscal years. Technology demonstrations that appeared similar were investigated further and their scopes were differentiated.

\section{DECONTAMINATION AND DECOMMISSIONING FOCUS AREA (D\&D)}

Provided technical input to the D\&D Monthly Report, a widely distributed document developed to inform interested parties (e.g., DOE, stakeholders, other Federal Agencies) of the progress being made by the Focus Area. 
Provided technical input and coordination for the production of the FY95 end-of-the-year monthly program review briefing. Activities included milestone tracking and analysis of technical results and schedule variances.

Provided a technical review of the task plan for the Three-Dimensional Integrated Characterization and Archiving System (3-D ICAS) project to determine the applicability of this technology to the needs of the Focus Area. This analysis will be used to support a phase decision on the project.

Provided technical review of documentation addressing the issue of "Institutionalizing the Data Quality Objectives Process for EM's Environmental Data Collection Activities," at the METC WPI Morgantown Office. The primary activity was reviewing the "Mixed Waste Integrated Program Quality Assurance Requirement Plan," DOE/MWTP-29, Rev 0 , document for feasibility of modification and incorporation of the Data Quality Objectives (DQO) Process.

Conducted a review of TechExtract process for decontamination of concrete and prepared a report detailing the technology's applicability for use in the DOE complex.

\section{MIXED WASTE FOCUS AREA (MWFA)}

Met with Richard Kimmell of DOE's Mixed Waste Focus Area (MWFA) to initiate a new project. The new task includes a review of the regulatory compliance status for MWFA projects and investigates limitations and special requirements for developing regulatory compliance strategies for siting future projects.

At DOE's request, a meeting was held between a staff member and a Lockheed Martin employee to discuss WPI's MWFA regulatory compliance project and to understand what Lockheed Martin has been doing for the MWFA with respect to regulatory compliance.

Personnel working on the regulatory compliance project started to make contacts with Principal Investigators for MWFA projects and performed background work to understand the regulatory approach for the major MWFA projects in FY96 and 97.

Compiled recommendations from the Technical and User Panels of the Landfills Stabilization sponsored peer review on Transuranic, Mixed Transuranic and Low-Level Waste Thermal Treatment Technologies in Dallas, (November 13-15, 1995). Recommendations were discussed with DOE in a meeting.

The team reviewed the MWFA Home Page for technical content and accuracy and provided comments to DOE.

A staff member participated in the Gamma Camera Technical Review. 
Members of the team participated in the MWFA Technical Baseline review on November $6,1995$.

Tables and draft material for the November 29, 1995 MWFA Technical Baseline presentation to Clyde Frank were provided by the team. Also, one staff member attended this presentation to Dr. Frank to support the MWFA on technical questions.

The team gathered technical information and other data to be used in a presentation by the MWFA to the National Academy of Sciences.

A staff member participated in the planning of a joint MWFA and Landfills Stabilization sponsored peer review on Nondestructive Examination and Nondestructive Assay via conference calls between the two focus areas.

A staff member reviewed the "Minimum Technical Regulatory Requirements for OnSite Low Temperature Thermal Desorption Treatment of Petroleum/Coal Tar/Gas Plant Wastes Contaminated Soil".

Members of the team prepared summary tables of the Mixed Waste Low-Level and Transuranic Waste inventories.

\section{TASK B - PROJECT MANAGEMENT}

Significant efforts were provided in each of the focus areas to provide assistance in response to budget changes and redistributions resulting from continuing resolutions and final appropriations. Changes to PEGs, TTPs and financial plans were provided throughout the month. Technical analyses of the implications of the budget changes were provided.

\section{TANKS FOCUS AREA (TFA)}

Assisted the Program Manager with assessing the status of Tank Focus Area FY95 Technical Task Plan project milestones. This status of FY95 milestones is crucial in the planning of the FY96 program.

Assisted the Program Manager with documenting the strengths and successes of the Tank Focus Area in fiscal year 1995, in preparation of defending a request for increased funding for the program in FY96

Provided DOE-RL with several talking papers on tank closure EM-50 initiative. Identified retrieval candidates with alternative tank selection criteria and a strawman program management and execution schedule. Prepared supporting documentation and strawman review of TWRS-RL proposal for tank closure. Continued review of proposal drafts providing third-party overview for Technology Development Division. 
Participated in the TFA Kick-Off Meeting held in Las Vegas, NV, October 31 November 3,1995 . The purpose of the meeting was to bring together representatives from all of the TFA subgroups to discuss the FY96 program. Objectives of the meeting included: discussion of FY96 program plans and metrics; definition of programmatic and working level interfaces between the TFA, User Steering Groups, Field Offices and Crosscut Programs; and development of a calendar of activities for the TFA and other contributors. Several action items resulted from the meeting including formation of five teams to address immediate issues. These included: Waste Forms; Corporate Performance Measurement; Documented Input from User to TFA and Robotics Crosscut; Communication to Mid-Level Management at HQ and in the Field (Feds and Contractors); and Incentives for Working on a National Level.

Finalized FY95 performance metric table for the TFA. Coordinated with the Field Office Operations Office and the technical team to complete the product. The information presented includes technology demonstrations completed in FY95 for both TFA and crosscut funded projects and which technologies are available for transfer to users at the close of FY95. The total number of demonstrations (bench, pilot, and full scale) totaled 28 , of which 13 were crosscut funded projects. Only 4 of the 28 demonstrated technologies are available for transfer; all 4 were crosscut funded programs.

\section{LANDFILL STABILIZATION FOCUS AREA (LFSA)}

Prepared a technical outline of the final internal DOE report covering the Vitrification Technical Program Review held November 13-15, 1995 in Dallas, TX. This report will cover TRU, TRU Mixed, and Mixed Low-Level Waste Treatment Technologies and will allow DOE to proceed with development of these technologies.

Prepared a presentation outline/schedule for the "Landfill Stabilization and Mixed Waste Focus Areas, and Characterization, Monitoring and Sensor Technology Crosscutting Program Non-Destructive Assay/Non-Destructive Evaluation (NDANDE) Technical Peer Review" to be concluded in January, 1996. The results of this review will be used by DOE to determine funding levels for future NDANDE activities.

Researched and developed LSFA technology cards. The cards are utilized by DOE as a tool to communicate the capabilities and parameters of the technologies developed/under development by the LSFA.

Provided technical input, editing support, cost comparisons, and recommended cost effective options for developing LSFA Monthly reports for October and November. Completion of the monthly report is an LSFA reporting requirement.

Responded to a request from stakeholder/community leaders for network information concerning the LSFA strategies/activities planned for FY96 and prepared a calendar of activities and demonstrations proposed to increase stakeholder involvement and input. 
Provided programmatic and technical input into FY 97 prioritization methodology. The methodology will be used by DOE to score and rank FY97 technology development proposals.

Developed technical information utilized for the presentation to the GAO on FY96 project selection and FY97 draft prioritization methodology. The review was held by DOE in response to a GAO request.

Provided technical input into the revision of low level/other humid product line. Information used for TTP revision by DOE.

\section{PLUMES FOCUS (PFA)}

Provided technical and programmatic input and coordinated the production of the FY95 end-of-the-year monthly program review briefing. Activities included clarification of: overdue milestones, project schedule variance, and Focus Area performance measures. Additional actions included determining successful completion of monthly performance measures (e.g., technology demonstrations, technology transfers).

Prepared technical input into the PFA Weekly Management Report (November 2-8, 1995) and the PFA Monthly Report in order for DOE to meet existing reporting requirements.

Prepared the FY96 PEG worksheet for project planning in the PFA. The worksheet will be utilized by the PFA product line managers to prepare future PEG input in a consistent manner.

Developed technical information for the November 28, GAO review of the PFA activities, management structure, and project status. Information on technologies provided DOE with baseline and status information for presentation to GAO.

Reviewed milestones reports from DOE-RL in order to determine if projects met FY95 TTP technical milestones. Status Information used by DOE to determine project status in relation to schedules and assisted in management of the LSFA.

Provided input to the Technology Development Program Review for Field Office Managers. Activities included updating documents that were necessary to complete this presentation and might have been affected by possible budget changes.

Initiated a list of individuals affected by the actions of the PFA for inclusion in the Focus Area monthly report. Individuals on this list to include DOE employees and contractors, stakeholders, other Federal Agency employees, and others. 


\section{DECONTAMINATION AND DECOMMISSIONING FOCUS AREA (D\&D)}

Provided a technical review of the D\&D "Implementation Plan." The review provided technical guidance in forming the technology development strategy of the Focus Area for FY96.

Provided a quality assurance review of all D\&D Technical Task Plans (TTPs) to ensure accuracy of forecasted technology development milestones and consistency with DOE guidance. Inconsistencies were resolved by contacting the project's principal investigator.

Initiated a historical review of EM-50 funded D\&D projects. This review will assess project funding and current status of approximately 100 completed or ongoing D\&Drelated projects within the D\&D Focus Area as well as Crosscutting Programs.

\section{MIXED WASTE FOCUS AREA (MWFA)}

A milestone and performance measure calendar for the MWFA was assembled.

Assisted DOE MWFA management to prepare input for Monthly Program Review.

A one-page Summary Profile of a MWFA Technical Task Plan was prepared for the DOE MWFA team to review and decide if Summary Profiles would be useful for all the Technical Task Plans.

\section{TASK C - TECHNOLOGY INTEGRATION}

\section{MIXED WASTE FOCUS AREA (MWFA)}

Met with Advanced Sciences, Inc., personnel to integrate their DOE project on risk management methodology with the MWFA projects.

Attended the Focus Area Integration Meeting on November 7-8 in Gaithersburg.

Attended the Stakeholder Participation in Decision Process Workshop on November 29, 1995.

\section{LIAISON AND COMMUNICATION}

Drafted a technical issue paper for the METC WPI Morgantown Office. The theme was, "How can METC best assist participating organizations in implementing quality controls selected for each element of work, consistent with the risk, complexity, duration, importance, and health and safety considerations of the work they perform?" 
Contacted numerous government and governmental associations to identify information sources relevant to State environmental regulatory activity.

Provided meeting planning support for the Technical Peer Review Meeting in Dallas Texas, November 13-17, 1995. 


\section{ATTACHMENT A}

\section{PRODUCTS DELIVERED: TASK A - TECHNOLOGY MANAGEMENT}

\section{TANKS FOCUS AREA (TFA)}

- Prepared comments on TFA Cesium removal call for proposals

- Technical inputs for use in EM-50 Annual Report to Congress

\section{LANDFILL STABILIZATION FOCUS AREA (LFSA)}

- NDA/NDE Conference: Independent Review Panel Qualifications

- Rough Outline for the Final Internal DOE Report Covering Vitrification Review held November 13-15, 1995 in Dallas, TX

- Outline and Guidance for Reviewing Technologies and Drafting Report

- Landfill Stabilization and Mixed Waste Focus Areas and Characterization, Monitoring, and Sensor Technology Crosscutting Program NDANDE Technical Peer Review

\section{PLUMES FOCUS AREA (PFA)}

- FY95 end-of-the-year monthly program review briefing

- Conferences/Symposia/Workshops of Interest to Plumes Focus Area

- Technical Inputs for use in GAO November 28, 1995 Plumes Focus Area Presentation

- August 1995 Monthly Review Support

MIXED WASTE FOCUS AREA (MWFA)

- Comments on MWFA Home Page

DECONTAMINATION AND DECOMMISSIONING FOCUS AREA (D\&D)

- D\&D Monthly Report 
- FY95 end-of-the-year monthly program review briefing

- Technical Review --Task plan for the 3-D ICAS Plan

- Review--documentation addressing the issue of "Institutionalizing the Data Quality Objectives Process for EM's Environmental Data Collection Activities," Primary document: "Mixed Waste Integrated Program Quality Assurance Requirement Plan," DOE/MWTP-29, Rev 0

- Assembled a D\&D Focus Area Fact Sheet for and STCG meeting held December 4 at the Savannah River Site

\section{PRODUCTS DELIVERED: TASK B - PROJECT MANAGEMENT}

\section{TANKS FOCUS AREA (TFA)}

- Draft TFA project plan/charter developed from outline provided by DOE-RL

- Team review of draft TFA documents -- Strategic Plan, Management Plan, and Roles and Responsibilities

- Table of Budget cuts to Dave Geiser

- Financial Plan Status Report for Spreadsheet

- Draft AFP changes to TFA for December, 1995

- Crosswalk of TWRS Technical Development Tasks to TFA/EM-50 FY96 Tasks

- Talking papers on tank closure initiative to DOE-RKL

- Draft input for memos to Technical Program Officers regarding assistance and addressing funding issues

- Draft input for available FY 1995 carryover pull backs for the TFA

- Draft input for Headquarters' requested budget cuts

- Technical inputs for use in one-page abstract of TFA strengths to increase FY96 funding

- Table of budget cuts from TFA to EM-50 for DOE-RL 
- Draft AFP changes for TFA for December 1995

\section{PLUMES FOCUS AREA (PFA)}

- Inputs for use in Technology Development Program Review for Field Office Managers.

- WETO/MSSE Support Analyses

- Comparison of PFA FY95 and FY96 Funding by Field Office

- Milestones converted into electronic (spreadsheet) format

- Review of Draft Strategic Plan

- PEG/TTP Resolution Support

- Predecisional draft concerning the release of several TTPs for funding

MIXED WASTE FOCUS AREA (MWFA)

- MWFA Milestone Calendar

- TTP Funding Log Sheet

DECONTAMINATION AND DECOMMISSIONING FOCUS AREA (D\&D)

- Review -- D\&D “Implementation Plan

PRODUCTS DELIVERED: TASK C - TECHNOLOGY INTEGRATION

\section{LIAISON AND COMMUNICATION}

- Draft technical issue paper for the METC WPI Morgantown Office on "How can METC best assist participating organizations in implementing quality controls selected for each element of work consistent with the risk, complexity, duration, importance, and health and safety considerations of the work they perform?" 


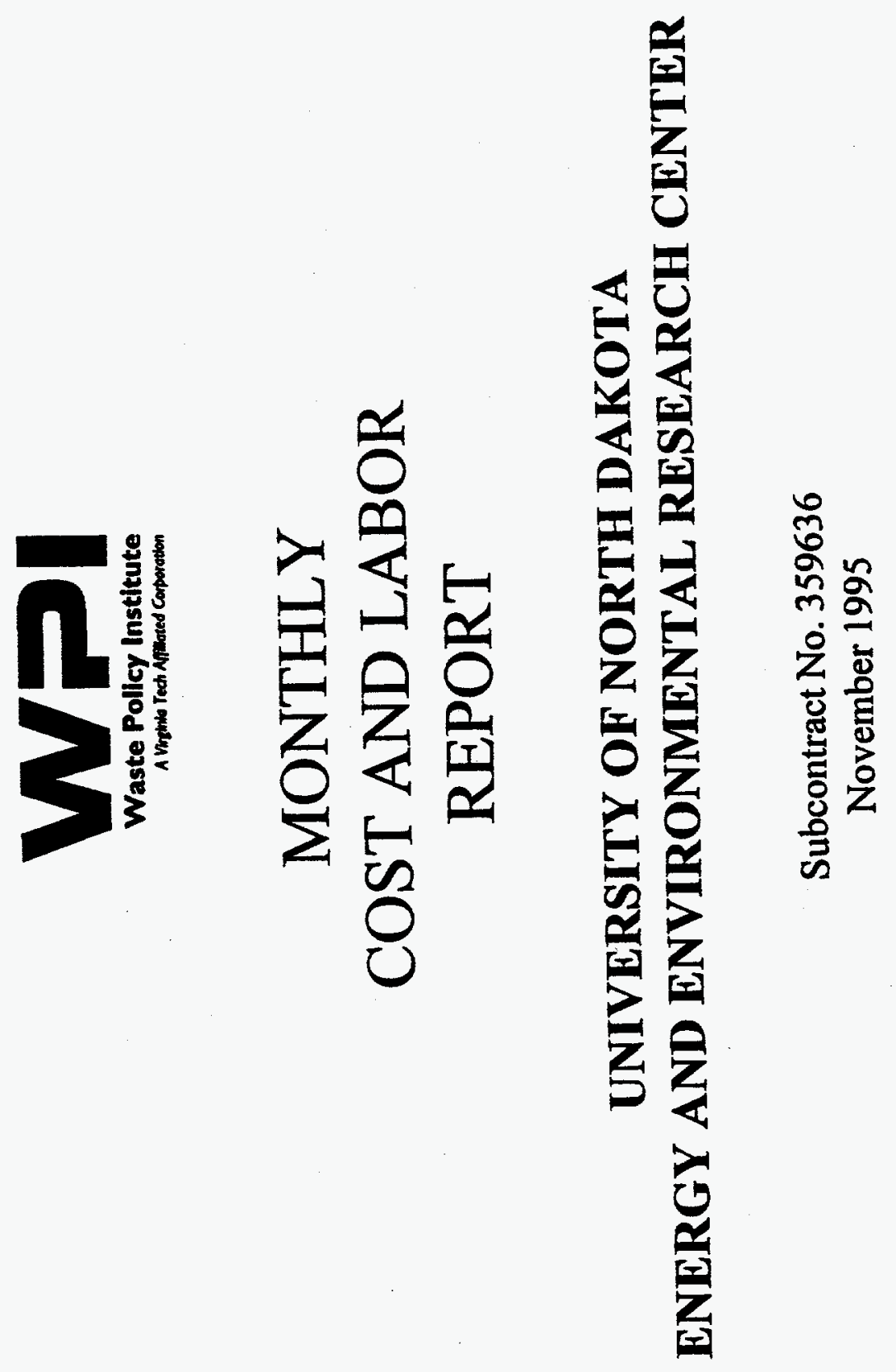




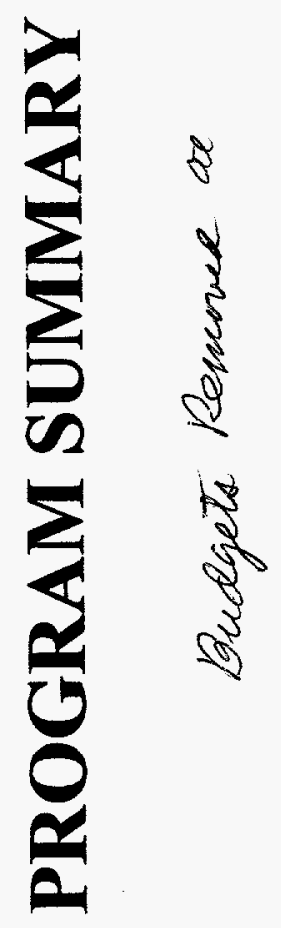




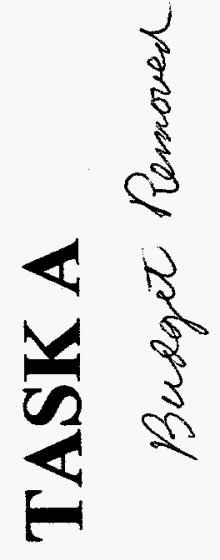




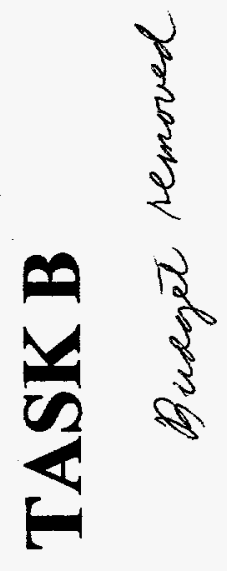




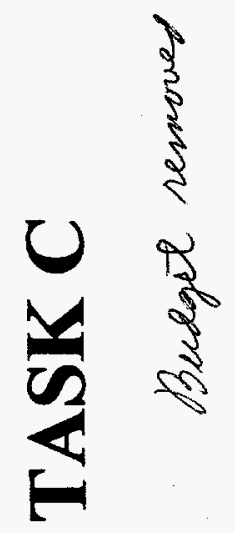


WASTE POLICY INSTITUTE MONTHLY REPORT
TO THE EERC, DECEMBER 1995

APPENDIX B 


\section{UNIVERSITY OF NORTH DAKOTA ENERGY AND ENVIRONMENTAL RESEARCH CENTER}

Monthly Report December, 1995

\section{TECHNOLOGY DEVELOPMENT INTEGRATION WPI SUBCONTRACT NUMBER 359636}

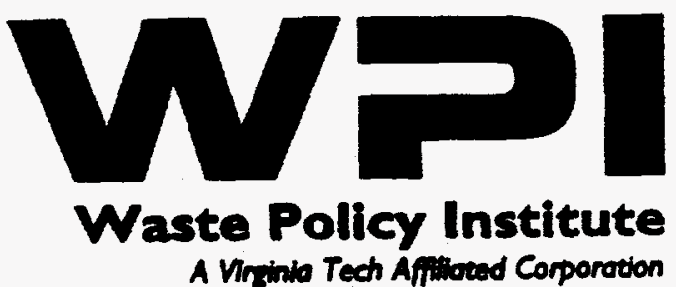


CONTRACTOR NAME: Waste Policy Institute 555 Quince Orchard Road

Suite 600

Gaithersburg, MD 20878-1437

CONTRACT PERIOD: $\quad 6 / 28 / 95-12 / 01 / 96$

\section{SUBCONTRACT DELIVERABLES:}

This report is submitted in fulfillment of requirements specified for the University of North Dakota Energy and Environmental Research Center (UNDEERC) Subcontract Number 359636. A list of products developed under this subcontract is provided as Attachment A.

\section{SUMMARY OF ACTIVITIES:}

During the recent budget process, technical inputs were researched and provided across all focus areas in the subcontract. The ability of the focus areas to meet identified strategic goals within budget constraints was analyzed so that Technical Task Plan (TTP) activities could be realigned. Program Execution Guidelines (PEGs) were also reviewed and reworked based on new program funding.

The Idaho Falls office has moved into permanent office space during December. We expect the Richland Office to be permanently located in mid-January bringing our field support to its permanent configuration.

\section{TASKA - TECHNOLOGY MANAGEMENT}

\section{TANKS FOCUS AREA (TFA)}

A meeting was held to discuss a TFA initiative to develop an interagency/interstate agreement between the regulating agencies in South Carolina, Tennessee, Idaho, and Washington; states with DOE's high-level radioactive waste storage tanks. The agreement is a first step in a process to facilitate discussions on requirements for such issues as definition of "tank closure" and determination of required low-level waste form. Currently, the four states have very different standards and requirements and the Tank Focus Area would like to facilitate dialogue to streamline the regulations and requirements. Such dialogue and cooperation would also benefit the other focus areas, and the TFA is attempting to set up a model other focus areas could repeat and build on. 
DOE-RL TFA was provided with several draft documents regarding the Hanford Tank Closure initiative from EM-50. The documentation included a list of tanks that would be primary candidates for retrieval and suggested technologies that could be demonstrated during the closure process; an outline of tank selection activities with discussion points; a program management and execution schedule; management roles and responsibilities; and a proposed schedule framework to further enhance the planning process.

The team reviewed the white paper, Conceptual Proposal for a Hanford Waste Tank Technology Demonstration Project, which was submitted by EM-30 Tank Waste Retrieval System (TWRS) as their Hanford tank closure demo proposal. A prime comment regarding the proposal was that the tank selection may be premature and that the mission and objectives would best be determined first. This project would be a coordinated effort between EM-30 and EM-50 to demonstrate technologies (e.g. characterization, retrieval, leak detection, etc.) and regulatory approaches (closure plan, risk assessment) that will accomplish waste removal and tank closure.

A review of the FY96 TTPs was conducted to confirm that the program described in the formal documentation matches the intentions of the planning process, and also to maintain the contractor's technical knowledge and understanding of the program.

In conjunction with the DOE Technology Development Information Office, the team documented Tank Focus Area presentations and photographs. This database is updated periodically and maintained in a state of readiness so that Office Managers have immediate access to current and correct information for presentations.

Members of the team attended a meeting, and participated in a telephone conference to plan for conducting the review of the Long Reach Manipulator program. This program has received two unfavorable Preliminary Design Reviews, is overspent and behind schedule, and the Tank Focus Area has been assigned the task of conducting a final review and determination of the disposition of the program.

\section{LANDFILL STABILIZATION FOCUS AREA (LFSA)}

Fact Sheets for the Landfill Stabilization Focus Area Technology were researched and developed. This information will be used by DOE-SR for a presentation at DOE-HQ.

LSFA developing technology was researched and technology cards developed which highlight benefits and contacts. These cards will be used by DOE-SR to promote utilization of developed technologies.

Prioritization methodologies were developed for the evaluation of proposed host sites for the InSitu Vitrification Technology. In-situ demonstration proposals were reviewed, evaluated, and recommendations made to DOE-SR on a technically optimal site. 
$R \& D$ permitting requirements for In-Situ vitrification demonstrations were researched. This information will be used by DOE-SR to proactively manage and plan for In-Situ demonstrations at selected host sites.

The team investigated and completed a report on the Plutonium (PU) Stabilization and Immobilization workshop describing PU technologies and strategies. The report will be used by DOE-SR to align relevant LSFA activities with future of PU stabilization and immobilization.

Technical inputs were completed on the LSFA strategic plan and the team provided strategic and planning input into short and longer range goals.

The team coordinated with the product manager and the Systems Engineering Analysis team from Idaho National Engineering Laboratory (INEL) to define a scope of work to provide a usable product to the LSFA Program Manager for use in the development of the FY98 Budget request and in the development of the FY97 Program Execution Guideline (PEG). A one day meeting was held with INEL personnel to properly define the scope and desired products.

The path forward was defined to complete the near term analyses to support PEG and Internal Review Budget exercises. A plan is being developed to provide the long term goal: a computeraided system/database for the evaluation of technology investments.

\section{PLUMES FOCUS AREA (PFA)}

PFA technical information and research on available technologies were incorporated into an abstract for the Spectrum ' 96 Conference. This abstract presents the goals and FY96 activities of the PFA. This conference is an important gathering of commercial, government, and international experts in nuclear and hazardous waste management, and represents an opportunity for PFA management to educate attendees on PFA activities.

Technical input was provided into the Plumes Focus Area Weekly Management Report for November and December 1995.

The team compiled a list of candidate sites for the demonstration of a heavy metal and radionuclide bioremoval technology for PFA response to the SRS ERD. The focus of this task was to find an appropriate DOE site for the demonstration of this innovative technology.

The scope of the Tulane/Xavier project was researched so that it could be included on a list of candidate projects to be considered for funding through the new EM Basic Science Initiative.

A detailed study of PFA FY96 product lines and milestones on a task specific basis was prepared. The completed document will be utilized by PFA management to proactively manage milestone completion. 


\section{DECONTAMINATION AND DECOMMISSIONING FOCUS AREA (D\&D)}

The team attended a meeting with the Strategic Alliance Technology Assessment Group for the CP-5 Large Scale Demonstration. Technical input for the review and selection of D\&D technologies for inclusion in the large scale demonstration were provided.

The TechXtract process, the Babcox and Wilcox chelating solvent extraction decontamination process, and the Isotron electrokinetic treatment process for decontamination of concrete, other porous media, and metal surfaces were researched and analyzed. Their relative effectiveness and applicability to D\&D activities in the DOE complex was evaluated.

The team prepared a report detailing the individual technology development activities' relationship to the three large-scale demonstration projects.

Technical inputs were provided for the D\&D Focus Area Monthly Report for November, 1995.

Members of the team attended the D\&D Decisionmakers' Forum organized by Weapons Complex Monitor from December 13-15, at Leesburg, Virginia. While there, they collected information on technology challenges faced by D\&D Decisionmakers and future technology trends in D\&D.

The team conducted a technical review of documentation addressing the Grumbly issue "Institutionalizing the Data Quality Objectives Process for EM's Environmental Data Collection Activities". The primary activity was the review of "Mixed Waste Integrated Program Quality Assurance Requirement Plan", DOE/MWTP-29, Rev 0, document for feasibility of modification and incorporation of the Data Quality Objectives Process. Following a review of the data quality objectives document for the MWFA , the team prepared a plan to develop data quality objectives for the D\&D Focus Area.

\section{MIXED WASTE FOCUS AREA (MWFA)}

The team provided technical reviews of the Draft Final Mixed Waste Focus Area Technical Baseline Report and prepared technical summary sheets for the FY96 funded technical task plans for the MWFA.

Russian Proposals for the MWFA were reviewed and prioritized.

A literature search of selected technology deficiencies identified by the MWFA was initiated. This search documented current technology throughputs and capacities, regulatory limits pertaining to a contaminant of concern, additional regulatory issues and developments, and brief descriptions of available technologies. 
Members of the team continued to make contacts with Principle Investigators for MWFA projects and assembly of background information to understand the regulatory approach for the major MWFA projects in FY96/97. Inputs have been received from Rocky Flats, Oak Ridge, and Savannah River. Team members met with the MWFA Regulatory Team to mesh regulatory requirements for characterization needs with treatment train flow sheets outlined in the Technical Baseline Document. Currently working to assemble information for a meeting in Salt Lake City on January $17-18,1996$. This information will ultimately be presented in a characterization reference document.

The team initiated contacts with site information sources to acquire existing site-wide National Environmental Policy Act (NEPA) documents and current Federal Facility Compliance Agreements (FFCA) Site Treatment for each major DOE site.

\section{TASKB-PROJECT MANAGEMENT}

\section{TANKS FOCUS AREA (TFA)}

The team assisted with the resolution of comments from review of the draft Strategic Plan for the TFA and incorporated these suggestions into a final revision for review and approval by DOE$R L$ and DOE-HQ. The document is the result of a national team composed of DOE, national laboratory, and contractor personnel to assure that the long term objectives of the Department are met by the TFA.

A needs/activities database was defined, and development initiated. The needs were assembled through a national survey of DOE sites to define all remediation problems related to High-Level Waste (HLW) tank remediation. Activities in the database incorporate all known technology development projects and off-the-shelf technologies from federal, industry and academia programs related to the TFA. The database is envisioned as a historical archive of information that can be accessed for prioritization of FY97 activities and development of future program plans for the TFA.

Performance metrics for FY96 were verified and submitted to DOE for incorporation into the HQ program tracking system. This data is an aid for TFA management in tracking technical progress, and is used by HQ to evaluate the performance of the program throughout the fiscal year.

Site baseline data for Appendix A of the TFA Multi-Year Program Plan (MYPP) was collected. Important sources of information include the latest versions of the waste management plans for each of the four TFA sites. The emphasis this year will be on updating the current information on site baselines in the MYPP and adding technology schedule segments that show how the technology developed by the TFA fits into site baseline schedules and milestones. Site baseline data for Savannah River contained in the Savannah River Waste Management Environmental Impact Statement (EIS) issued in July 1995 was reviewed. 


\section{LANDFILL STABILIZATION FOCUS AREA (LSFA)}

The team developed LSFA Program requirement PEG scope based on breakout of TTP activities into Site specific TTPs. This information will be used by DOE-SR to increase effectiveness of LSFA project management activities.

Technical inputs were prepared for the October and November LSFA monthly reports. The completion of the monthly report is an LSFA requirement to DOE-HQ.

The team researched and developed a display of LSFA materials for the Assistant Managers for Environmental Management, Citizens Advisory Board, Site Technical Coordination Group (AMEM/CAB/STCG) meeting. The purpose of the meeting was to educate attendees on LSFA activities, actions, and accomplishments.

\section{PLUMES FOCUS AREA (PFA)}

A Plumes Focus Area roles and responsibilities document was developed and was utilized by DOE-SR for a DOE-HQ presentation.

Inputs to the Plumes Focus Area Program Plan was completed. The plan was submitted by PFA management to DOE-HQ for review and approval and represents completion of a requirement.

\section{DECONTAMINATION AND DECOMMISSIONING AREA (D\&D)}

The team provided input into the METC Project Management System for FY96 D\&D projects.

Briefing materials for the meeting of DOE Operations Office Managers for the review of FY96 EM-50 Program were prepared by the team.

\section{MIXED WASTE FOCUS AREA (MWFA)}

Review comments were provided on the MWFA October 1995 Monthly Progress Report. The team recommended a format revision to the Monthly Progress Report to provide an evaluation of progress against major milestones, budgets, and schedules.

Technical comments were provided on the scope of a limited number of MWFA work packages.

Ten one-page Summary Profiles of MWFA Technical Task Plans were prepared.

Final slides from the MWFA Review Meeting with the Options Analysis Team on November 27 and December 5, 1995 were completed. 


\section{TASK C-TECHNOLOGY INTEGRATION}

\section{TANKS FOCUS AREA (TFA)}

The team assisted the Focus Area Lead in preparing a response to DOE-HQ on the basis for selecting TFA projects for Cost Analyses (CA) and the involvement of EM-30/40 in the selection process. Both projects selected by TFA (Cesium Removal and Enhanced Sludge Washing) are high priority projects for Hanford. The TFA is soliciting comments from the users on the CA products.

\section{LANDFILL STABILIZATION FOCUS AREA (LSFA)}

The team has assisted in coordination between LSFA and MWFA activities. Weekly conference calls between the MWFA and the LSFA are one mechanism for the coordination. Technical exchanges are also being facilitated. Provided input to the LSFA and MWFA-funded Continuous Emission Monitors projects.

\section{PLUMES FOCUS AREA (PFA)}

A briefing was presented to DOE LSFA and PFA management on a concept for development of a TTP Schedule Tracking System (STS). The concept was endorsed by DOE. System development is now underway. Implementation of the system will increase the ability of the focus areas to proactively manage activities.

\section{MIXED WASTE FOCUS AREA (MWFA).}

A draft was developed of the document entitled: Strategy For Responding to Headquarters Directives and Working with Crosscuts and Other Focus Areas. This document facilitates the interaction among the DOE MWFA Organizations and the Contractor-support Teams, and provides a framework for proactive MWFA management and effective program coordination and implementation. 


\section{PRODUCTS DELIVERED:TASKA - TECHNOLOGY MANAGEMENT}

\section{TANKS FOCUS AREA (TFA)}

- Draft Robotics Technology Development Activities memo to EM-50

- Comments on the Spectrum '96 abstracts

- Comments to the Draft Environmental Management 1996 Annual Report to Congress

- Comments to the TFA section of the Draft FY 1995 Office of Technology Development Report to Congress

\section{LANDFILL STABILIZATION FOCUS AREA (LSFA)}

- LSFA Presentation Fact Sheets for presentation at DOE-HQ

- LSFA information cards

- Trip Report on PU Stabilization and Immobilization Workshop

- Briefing prepared for LSFA DOE meeting

- LSFA display materials prepared for AMEM/CAB/STCG meeting

- Prioritization Methodology prepared for proposed host site for the In-Situ Vitrification Technology

- Briefing prepared for review of LSFA Program

- Information compiled for Product Line Meeting, Jan 9-12, 1996

- TTP project listing prepared with past history funding levels, amount of cuts per TTP per recission spreadsheet

- Break-out Program Management TTPs into site specific TTPs and composed PEG scope

- LSFA information provided to DOE at BNL

\section{PLUMES FOCUS AREA (PFA)}

- FY 1996 PEG for Plumes Focus Area for the January FIN Plan and PFA Program Impacts on PFA Performance Measures, re-issuing TTPs, and TTP Closeouts 
- PFA Roles and Responsibilities Draft Document for presentation at DOE-HQ

- Plumes Focus Area information cards preliminary use with interim logo produced

- Revision 0 of the Program Plan for the contaminant Plumes Containment and Remediation Focus Area

- Funding Cuts for Organic Product Line

- Graph of Impact of FY96 Budget Reduction by Product

- Abstract presenting goals and FY96 activities of the PFA for the Spectrum '96 Conference

- Vugraphs detailing PFA FY96 product lines and important milestones for each task

- Revised TTPs during recent Budget recission process. The TTPs were sent electronically to DOE-HQ for use in the budgeting process.

- Plumes Focus Area Weekly Management Reports

DECONTAMINATION AND DECOMMISSIONING FOCUS AREA (D\&D)

- Large-Scale Demonstration Slide Presentation for Lansdowne D\&D Meeting

- Trip Report and Action Item List Argonne CP-5 Facility Trip

- D\&D Focus Area Monthly Report

PRODUCTS DELIVERED: TASK B - PROJECT MANAGEMENT

\section{TANKS FOCUS AREA (TFA)}

- White Paper on Tanks Focus Area Request for Increase in FY96 Funding

- Action Tracking Database for tracking commitments assigned by DOE

- Spreadsheet reflecting FY95 carryover, FY96 funding, and all budget reductions

- Draft changes to TFA Financial Plans and revised Program Execution Guidance

- Draft Memorandum of Commitment to Support and promote Interagency Regulatory Radioactive Waste Tanks addressed to Site Managers at the Field Offices in Richland, 
- Memo to DOE-RL reporting status of initial communication with responsible DOE Field Offices requesting closure verification and delivery to DOE-HQ of FY95 Deliverables

- TFA Kickoff Meeting Minutes and Addendum for distribution

- Draft Program Execution Guidance and Financial Plan changes transferring the Long Reach Arm Robotics work to TFA

- Schedule of FY96 Milestones with a completion date of $12 / 30 / 95$ to status impact of Continuing Resolution and to recommend corrective action, if necessary

- Draft Strategic Plan for the TFA

\section{MIXED WASTE FOCUS AREA (MWFA)}

- Comments on the MWFA October 1995 Monthly Progress Report

- Submittal of Minutes of Meeting Subcommittee on Continuous Emission Monitors, The American Society of Mechanical Engineers

- Summary of the Las Vegas Project Tracking System Workshop

- MWFA Work Package Comments

DECONTAMINATION AND DECOMMISSIONING FOCUS AREA (D\&D)

- Back-up Materials for January Change Control Process

- Draft Management Agreement for Implementation of the Chicago CP-5 Reactor Demonstration

- Draft Technology Comparison Matrix - B\&W, TechXtract, ISOTRON

PRODUCTS DELIVERED: TASK C - TECHNOLOGYINTEGRATION

TANKS FOCUS AREA (TFA)

- Comments on TFA cost-benefit analyses of Cesium removal projects and enhanced sludge washing 



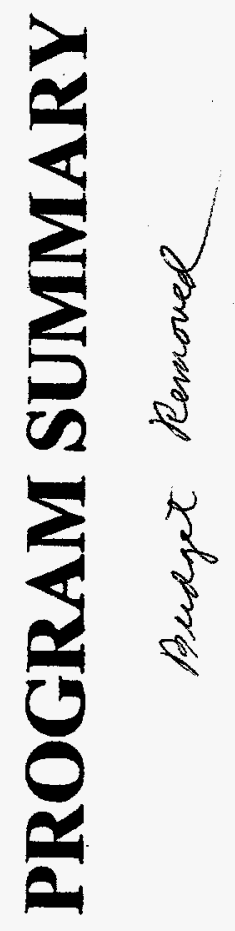




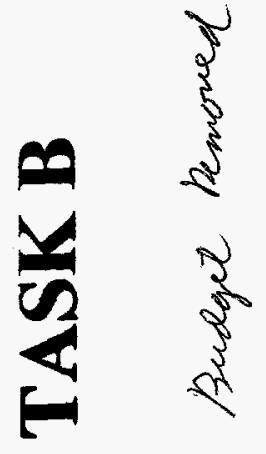




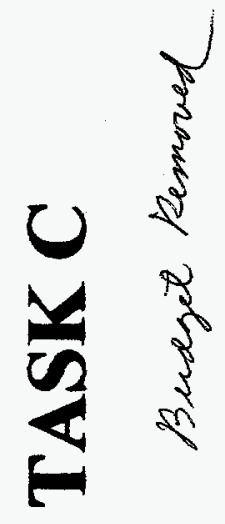




\section{WASTE POLICY INSTITUTE MONTHLY REPORT TO THE EERC, JANUARY 1996}




\section{UNIVERSITY OF NORTH DAKOTA ENERGY AND ENVIRONMENTAL RESEARCH CENTER}

Monthly Report January, 1996

\section{TECHNOLOGY DEVELOPMENT INTEGRATION WPI SUBCONTRACT NUMBER 359636}

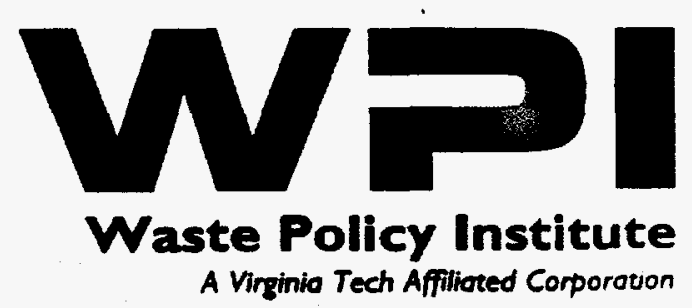


February 15, 1996

Mr. John G. Hendrikson

Assistant to the Director

Energy and Environmental Research Center

University of North Dakota

15 North 23rd Street

Grand Forks, ND 58203

Subject: UNDEERC Fund No. 4624-0936, Technology Development Integration WPI Subcontract No. 359636

Dear Mr. Hendrikson:

The Waste Policy Institute (WPI) is pleased to submit the enclosed report of activities conducted during the period of January 1, 1996 through January 31, 1996, in compliance with Articie VI and Appendix A of Subcontract Number 359636. A list of products developed during this period is provided as Attachment A to the activities report.

Through January 31, 1996, WPI has expended \$7,016,094. Our monthly cost and labor report provides the details of our costs to date. Although the current contract period extends through December 1, 1996, it should be noted that we anticipate the subcontract ceiling will be reached on or about September 30, 1996. This expenditure rate is consistent with our proposal for the new budget period. Our current ceiling has not been fully funded. Our current obligated amount (\$8,996,285 of the $\$ 13,994,893$ ceiling) will be expended on or about March 31, 1996.

Please do not hesitate to call me if you have any questions or require additional information.

Sincerely,

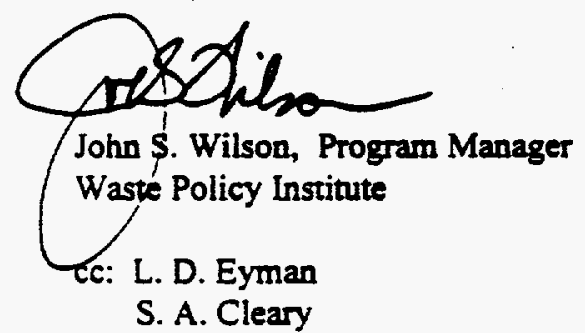

S. A. Cleary 
SUBCONTRACT NUMBER: 359636

Report Period: $1 / 1 / 96-1 / 31 / 96$

CONTRACTOR NAME: Waste Policy Institute

555 Quince Orchard Road

Suite 600

Gaithersburg, MD 20878-1437

CONTRACT PERIOD: $\quad 6 / 28 / 95-12 / 01 / 96$

\section{SUBCONTRACT DELIVERABLES:}

This report is submitted in fulfillment of requirements specified for the University of North Dakota Energy and Environmental Research Center (UNDEERC)

Subcontract Number 359636. A list of products developed under this subcontract is provided as Attachment A.

\section{SUMMARY OF ACTIVITIES:}

Significant technical support was provided across the sites this month to the review of Russian proposals for technology development. Program management support was focused on two major meetings, the budget meeting in Gaithersburg on January 12 and 13 and the "Big-5" review in Augusta on January 30 and 31.

\section{TASKA-TECHNOLOGYMANAGEMENT}

\section{TANKS FOCUS AREA (TFA)}

In order to prepare the DOE baseline needs data, the WPI technical team solicited SRS, ORNL, INEL, and Hanford's site needs and incorporated them for a review meeting held at PNNL the week of January 29. The data collected included description of the need, the priority of the need, and the functional area (characterization/safety, immobilization, etc). The needs were reviewed by the Technical Integration Team and will be available for discussion with DOE site representatives during the week of February 12.

The WPI technical team completed the EM activities database. The database included information on current EM-funded projects that are related to the Tanks Focus Area. The information was distributed to all four sites for review and comments. The information will be used to identify technologies that could be used to meet the site needs for high level waste.

An issue paper was developed for DOE-RL on technology areas being funding by the TFA and the tank waste remediation technology needs identified by TFA for FY97 that are relevant to Waste Form Crosscutting Program planner. The strategy for developing 
formal TFA recommendations to the Waste Form Crosscutting Program and some preliminary recommendations for projects of interest to TFA are then discussed in the issue paper.

The staff reviewed the white paper, Conceptual Proposal for a Hanford Waste Tank Technology Demonstration Project, which was submitted by EM-30 Hanford Tank Waste Remediation System (TWRS) as their Hanford tank closure demo proposal. A prime comment regarding the proposal was that the tank selection may be premature and that the mission and objectives would best be determined first. This project would be a coordinated effort between EM-30 and EM-50 to demonstrate technologies (e.g. characterization, retrieval, leak detection, etc.) and regulatory approaches (closure plan, risk assessment) that will accomplish waste removal and tank closure.

Members of the staff attended the Efficient Separations and Processing (ESP) Technical Exchange meeting in Gaithersburg. This included presentations by the Focus Areas, as well as the complete ESP program for FY96. Certain radionuclide absorber development projects are maturing and will soon be ready for implementation. Coordination and integration between the Focus Areas, crosscuts, and ER programs is improving. Greater effort is needed to integrate between EM organizations.

The FY97 technology needs statements for the TWRS were reviewed as they were incorporated into the TFA consolidated database of needs. The Hanford needs statements and priorities from the Hanford Site Technology Coordination Group (STCG) tanks subgroup were incorporated into the TFA database. The new needs superseded the FY96 needs statements. There are thus a few TWRS development activities in FY96 that do not match with needs listed in the database.

A team member attended the Tank Retrieval Technologies Workshop held in Augusta, Georgia, (January 22-26). The workshop involved a discussion of the problems of remediation of high level waste tanks with the representative from Russia. The report of this interaction will be compiled for review. Topics, issues, and experiences appropriate for use in remediation of DOE tanks will be identified for further consideration.

Five draft "issue papers" for the Program Manager to present to Clyde Frank were prepared. Dr. Frank uses this system to stay on top of issues in the Technology Development program. The topics were: 1) the status of the Long Reach Manipulator review, 2) the status of the "Hanford Tankfarm Initiative" (a project to create a "new way of doing business" at Hanford, by working closely with regulators and stakeholders to completely empty one tank and certify it closed), 3) the Interagency Technology and Regulatory Cooperation agreement between the states of Georgia, Washington, Tennessee, and Idaho, by which each state agrees to streamline approval of new technologies by accepting data from testing in the other states, 4) management issues in the Tank Focus Area, and 5) the effect that the Tank Waste Remediation System Environmental Impact Statement may have on tank technology development, if the EIS recommends an in-situ disposal approach. 
Staff members participated in a meeting to work on Office of Science and Technology Cost Savings Analyses. Cost savings analyses are used by the focus areas in the field to "sell" their technologies, and used at headquarters in the Baseline Environmental Management Report, and various reports and information sent to Congress. The team is working on a report entitled: "Technology Development Impact Analysis (TDIA) Report with Initial Emphasis on Potential Cost Savings".

\section{LANDFILL STABILIZATION FOCUS AREA (LSFA)}

Members of the team provided technical information concerning the Landfill Stabilization Focus Area FY96/97 Program Plan to meet requirements and requests for the "Program Review and Integration Meeting" in Augusta, Georgia, March 5 - 8, 1996.

Technical reviews of proposals for "In-Situ Plutonium Fixation for Nevada Test Site Soils Hazardous Waste Plant (HZWP)" and "In-Situ Immobilization of Strontium by Electrokinetic Injection" were performed. Based on these technical reviews, funding was not recommended.

\section{PLUMES FOCUS AREA (PFA)}

A technical and programmatic analysis for inclusion in PFA briefing to the Environmental Management Advisory Board (EMAB) was provided. This briefing showcased near-term (FY96) technical successes of the Focus Area. The EMAB is an extemal review organization providing merit review with peer evaluation of the EM research program.

Inputs were provided to the November/December Plumes Focus Area Monthly Report with recent technical and programmatic accomplishments. This report is distributed to DOE employees and contractors, stakeholders, other Federal Agency employees, and others involved with the Focus Area. Beginning with this edition, plumes-related technologies managed by Industrial Programs will be included. The team is currently in the process of managing the report's production, review, and distribution.

Technical information concerning the Plumes Focus Area FY96/97 Program Plan was provided to meet requirements and requests for the "Program Review and Integration Meeting" in Augusta, Georgia, March 5 - 8, 1996.

Team members provided a technical review of the Plumes Focus Area activities for the month of January by product line and team breakdown and technical input and analyses for the FY97 Internal Review Budget (IRB) presentation that was made by PFA Lead Organization Management to DOE-HQ.

The PFA's Draft Project Review Process was reviewed. This process evaluates the merits of a technology to go on to the next stage of development. It's purpose is to insure that PFA projects are on the right track for development and commercialization. 


\section{DECONTAMINATION AND DECOMMISSIONING FOCUS AREA (D\&D)}

The WPI team prepared a report summarizing advantages and disadvantages of lasers for decontamination and decommissioning (D\&D) activities; and research and development (R\&D) and demonstration, testing, and evaluation (DT\&E) activities of DOE and other government agencies relating to lasers for $D \& D$. This information is useful for determining the need for laser R\&D in the D\&D Focus Area.

WPI team staff developed a list of D\&D basic research needs, and provided a discussion of the potential applications of the information that might be developed by the research and be of benefit to the D\&D efforts in DOE.

The WPI team provided technical input to develop revised D\&D Focus Area performance measures corresponding with the current budget. This information will provide DOE a basis for comparing expectations between technology development efforts and generate a baseline for expected outcomes.

Proposals for D\&D research from several Russian research institutes were reviewed by the WPI team. The team prepared a written summary of technical comments, assessments of applicability to the D\&D Focus Area goals, and needs for further information when the information provided in the proposal was inadequate to assess applicability.

The WPI team technical support staff provided input to develop detailed technology data sheets for D\&D technologies nearing implementation status. These documents were developed in response to a request by the Environmental Management Advisory Board.

The technical support staff reviewed the D\&D contribution to the EM-50 Annual Report to Congress (ARC). The ARC is a congressionally-mandated document designed to present EM-50 highlights and R\&D accomplishments for the previous fiscal year (i.e., FY95). Revisions and improvements were made to the text to reflect the final FY95 status of notable D\&D technical activities.

Technical input was provided to help DOE (METC/EWM) personnel develop a series of fact sheets on EM-50 technologies with potential application, benefit, or impact to the U.S. Steel Industry. This effort was in support of the Office of Energy Efficiency and Renewable Energy's "Industry of the Future" program.

A member of the WPI team attended a meeting at Argonne National Lab with the Strategic Alliance Technology Assessment Team. This group is responsible for reviewing and recommending EM-50 and commercially-developed technologies for demonstration in the Large-Scale Demonstration project at the Chicago Pile-5 test reactor. A draft D\&D baseline was presented at the meeting and technologies were selected for 2 of 6 planned demonstration "sets". In addition, initial requirements for 
D\&D Test Plans and programmatic documentation were defined. Technical staff provided input on technology readiness and test parameters.

A D\&D Focus Area Opportunities Assessment was developed. This task presented a topical review of DOE's D\&D program including departmental roles, prominent risks, current programmatic activity, and likely future activities. Potential D\&D Focus Area opportunities were provided in light of this information.

Technical inputs were provided for the D\&D Focus Area Monthly report for December, 1995.

The team started development of the D\&D Focus Area Internet homepage. This homepage will be a showcase of all the activities of the D\&D focus area and other related activities.

\section{MIXED WASTE FOCUS AREA (MWFA)}

The draft "Selected Technology Deficiencies Resource Manual" was completed and submitted to the Mixed Waste Focus Area (MWFA) at the Idaho National Engineering Laboratory (INEL). The manual summarizes the capabilities of technologies that are available or in the developmental stage that relate to selected deficiencies identified by the MWFA.

A completeness check was performed on a summary report on needs identified in Site Visit Reports at nine DOE sites. Site visits were performed by the Landfills Stabilization Focus Area (LSFA) to prioritize site needs for funding in FY97 and FY98.

Staff members prepared a synopsis of the Hanford Tank Waste Remediation System Approach to Waste Treatment, Disposal and Final Waste Form Performance Criteria for DOE-ID to identify other sites and focus areas' current thinking on waste form issues.

The review and prioritization of the Russian Proposals for the MWFA was continued. This resulted in the preparation of a presentation folder including all the proposals, summary tables of the proposals, prioritization tables of the proposals and summary overhead slides.

The WPI team assisted DOE-ID in organizing and planning the Russian Workshop, as well as interfacing with the Russians throughout their visit with the MWFA.

In a continuing attempt to understand the regulatory approach for the major MWFA projects in FY96 and 97, staff pursued contacts with Principal Investigators for the MWFA and contact with DOE Site Points of Contact to gather documentation and information on regulatory compliance strategies and the current status of regulatory compliance activities at their respective sites. This information has included existing site- 
wide National Environmental Policy Act (NEPA) documents and current Site Treatment Plans for each major DOE site.

Team members attended a kick-off meeting in Salt Lake City on January 17-18, 1996 with the MWFA Regulatory Team to discuss approaches to analyzing characterization and regulatory requirements for the treatment trains outlined in the MWFA Technology Baseline Document. The goal is to identify approaches to reduce characterization requirements through new technologies, more robust treatment systems, or better emissions on monitoring, for example. This information will ultimately be presented in a Characterization Reference Document.

The staff continued working with the MWFA Regulatory Team to flesh out baseline requirements for the treatment trains agreed to at the Salt Lake City meeting and continue development of alternatives identified by the group.

\section{TASK B - PROJECT MANAGEMENT}

\section{TANKS FOCUS AREA (TFA)}

Representatives of the Richland WPI Team participated in the EM-50 sponsored budget planning meeting for the focus areas. The meeting consisted of an overview of FY97/98 budget, goals, and strategy; Internal Review Budget (IRB) and Office of Management and Budget (OMB)/Congressional changes; and issues associated with budget development, prioritization, distribution by site, and performance.

The team prepared draft briefing materials for presentation by the TFA at this meeting. Materials laying out the top level structure of the TFA in FY97 were drafted based on previous FY97 Internal Review Budget submissions. A draft package defining work packages, funding distributions, issues, and reaction to budget reductions was prepared.

WPI team technical support staff participated in the TFA site identified "Needs Prioritization" meeting involving the PNNL Technical Team and focus area Technical Integration Managers. We maintained the master needs directory, compiled questions for sites to answer to clarify needs, and maintained a list of action items. Needs Prioritization is a first step in next fiscal year technical program development.

The format and content for site-specific briefing books was developed for the TFA Lead (DOE-RL) and DOE-Headquarters Program Manager to use in briefing Site Managers at the Big-5 Meeting in February on TFA activities and how they dovetail into site programs. Four individual books are being prepared describing Hanford, Idaho, Savannah River, and Oak Ridge site objectives and the corresponding TFA activities.

A number of activities to support the retrieval and program areas were conducted, including: providing information on NEPA activities in support of the Light Duty Utility Arm (LDUA) to WPI Idaho, developing summary sheets for EMAB for the LDUA and 
for the Cone Penetrometer Raman Probe, and producing a list of EM activities in the area of robotics for use during TFA budget meetings at $\mathrm{HQ}$.

Members of the team coordinated with the National Academy of Sciences Board on Radioactive Waste Management to develop an agenda for a joint briefing on the TWRS and TFA technology development programs. The briefing dates are set for March 6-7, 1996 at Hanford and will include tours of some of the development facilities.

The WPI team toured the LDUA Cold Test Facility. A report on the tour was provided to DOE-RI which discussed issues such as technical aspects, applicability of the technology, progress reports, future milestones, and contract issues.

In response to a HQ-directed budget reduction, the team assisted the TFA Program Manager (PM) in organizing and facilitating a meeting of the technical team to discuss options for addressing the reductions. Made recommendations to TFA Management, and prepared draft allocated financial plan transfers and program execution guidance for review by DOE.

Final drafts of the TFA Strategic and Management Plans were provided to DOE for approval. Both documents were approved, given a document control number, and sent to the printer for publication. Distribution of the plans to all concerned parties was also carried out at the request of DOE-HQ.

Updates to the TFA Technology Summary Book were kicked-off at the request of the TFA PM. A draft schedule was prepared in coordination with the technical team to allow appropriate time for writing a review. A straw man of the document was laid out along with specific items that needed to be included in each technology write-up and provided to the TFA PM for review and distribution. Discussions were held with $\mathrm{HQ}$ regarding the content and schedule of the document, and working agreements made. The TFA has continued to review and consult with $\mathrm{HQ}$ regarding the Rainbow Book projects.

The staff prepared a draft briefing to the Assistant Manager of Technology Development for Hanford to be presented by the TFA Program Manager. In addition to reviewing cost and schedule status of all TFA Richland TTPs and identifying all variances, the briefing included issues and concerns of the TFA as they relate to Richland, corrective actions to be taken, accomplishments, and an up-to-date status of all milestones.

\section{LANDFILL STABILIZATION FOCUS AREA (LSFA)}

A milestone guidance package was developed for Product Line Managers and Principle Investigators to allow LSFA management to more effectively manage LSFA activities.

Staff reviewed the LSFA "Cost/Performance Variance Analyses Report for LSFA for November 1995". Incorrect or misleading statements and/or conclusions were identified and statements were prepared to explain the inaccuracies. The methodology to identify 
and correct inconsistencies that exist in the Project Tracking System (PTS) was defined. The final FY96 Technical Task Plans (TTPs) were reviewed as they were received to identify inconsistencies with the final approved FY96 Program Execution Guideline (PEG).

\section{PLUMES FOCUS AREA (PFA)}

Members of the team completed criteria summary sheets for the procurement supporting the FY96 Western Environmental Technology Office (WETO) sponsored tasks, Engineering Support for Six New Tasks for the Plumes Focus Area, In-Situ Mining, and Biomass Remediation System.

\section{DECONTAMINATION AND DECOMMISSIONING AREA (D\&D)}

An EERC support team developed a D\&D Focus Area prioritized activity spreadsheet for planned activities in the FY97 budget. The spreadsheet provides the DOE D\&D Focus Area Lead input for comparison analysis and budget forecasting.

WPI Team members input additional FY96 D\&D Technical Task Plan data (descriptive text) into the Morgantown Energy Technology Center (METC) Project Management System (MPMS), and provided a hard copy for review of the current D\&D TTP content of the MPMS database. The MPMS is used by METC for tracking and managing technical tasks, and for preparing information for public dissemination about METC projects, including D\&D projects.

Technical input was provided for the development of a draft of an Implementation Plan for the D\&D Focus Area. This document outlines three primary work packages designed to define and assign work to best accomplish the program goals and objectives, and to measure progress toward these goals. In addition, the organizational structure and specific responsibilities are defined, as well as a schedule for completion of key implementation actions.

The D\&D technical staff provided input to develop background and presentation materials for the EM-50 FY97/98 budget meeting held January 17 and 18. Presentation materials included programmatic goals and objectives for FY97/98, programmatic thrusts and budget impact summaries. A series of budget impact scenarios were developed in support of this activity.

The D\&D technical support staff provided input in developing background materials related to the D\&D program for a January 24 meeting with the Government Accounting Office (GAO). The GAO met with D\&D representatives from DOE/METC to discuss issues such as the focus area's organizational structure, interrelationships with headquarters personnel, end users, and the cross-cutting areas. Also included in the discussions were: the process used to select FY96 TTPs, and rationale for programmatic changes since the baseline PEG was released (August 28, 1995). 
Members of the staff continued developing the D\&D Focus Area FY95 Report of Activities, including completing text, incorporating comments from editorial review, providing a draft report to the DOE client for review, and establishing graphic layout.

A draft briefing was prepared for presentation by D\&D Focus Area Lead, Paul Hart, to stakeholders at Fernald Environmental Management Project concerning the Large-Scale Demonstration Project to be conducted there.

A team member participated in a two-day kickoff meeting for the Fernald Environmental Management Project Large-Scale Demonstration. Issues related to this demonstration project were discussed and resolved in various meetings to get the project on a fast-track schedule.

A technical review of three Cost/Benefit Analyses prepared by Hazardous Waste Remedial Action Program (HAZWRAP) and Principal Investigators was performed in support of 1996 Baseline Environmental Management Report (BEMR) Update.

A WPI team member attended the FY $97 / 98$ budget planning meeting in Gaithersburg, $\mathrm{MD}$ on January $17-18$. This meeting provided crucial insight to the budget planning processes for the out-years.

The team prepared a briefing for presentation at the January 17-18 budget planning meeting to discuss issues relative to FY97/98 budgets.

The WPI team provided technical input for the D\&D focus area's FY97 priorities. Members of the WPI team reviewed the Quality Assurance Requirements Plan (QARP) previously prepared for the Mixed Waste Integrated Program (MWIP) for adaptation for use by the D\&D Focus Area, determining gaps relative to the METC Quality Assurance/Quality Control (QA/QC) Manual, and the EM Data Quality Objectives process requirements. The Team prepared a written analysis of gaps in the MWIP QARP, in preparation for preparing a D\&D Focus Area Quality Implementation Plan.

\section{MIXED WASTE FOCUS AREA (MWFA)}

The team submitted final copies of the seventy-seven, one-page Summary Profiles of Mixed Waste Focus Area Technical Task Plans to DOE-ID along with suggested improvements to the content and quality of the Technical Task Plans.

The draft Gantt and PERT charts for the MWFA Request for Interest to address the thirty deficiencies identified during the development of the MWFA Technical Baseline Document was prepared.

A letter report was submitted to the INEL MWFA which provides suggestions on improving the guidance for the development of TTPs to be requested in the FY97 call by 
the MWFA at INEL, and contains ITP summary profiles which provide a one-page outline of project scope, funding plan, milestones, project organization and performance metrics of each funded TTP.

Members of the team reviewed a Draft Implementation plan for the Thermal Treatment Technologies. This plan is being developed jointly by the MWFA and the LSFA. A revised outline of the Implementation Plan was provided, and strategies for coordination among MWFA, LSFA, and Crosscuts in funding thermal treatment technologies was proposed.

\section{TASK C - TECHNOLOGY INTEGRATION}

A staff member began development of an integrated schedule, which will show EM-50 technology development activities, and the EM-30 and EM-40 milestones these activities will help meet.

The collection of needs documents for evaluation and subsequent distribution to field offices commenced.

A meeting was held with field office managers to establish formal integration procedures and discuss headquarters issues of interest to the field offices.

A regular conference call schedule was established to coordinate across focus areas and cross-cuts, and to discuss headquarters and regulatory issues.

A team member provided information to field offices regarding regulatory developments and proposals for improved management and oversight of DOE cleanup operations, as well as weekly legislative updates.

Staff assisted WPI managers with planning of 1996 activities on the EERC contract, primarily in Gaithersburg, and in the role Gaithersburg can play in facilitating communication between sites, between focus areas, and between crosscutting programs.

An EERC support planning meeting was held in Gaithersburg to discuss value-added tasks for DOE. The participants, EERC Gaithersburg support staff, focused on responsibilities and products which could be developed from an integrated operations office. The brainstorming session resulted in a number of ideas that will be presented to all EERC focus area support teams at a meeting in February. This activity will provide DOE with a systematic approach to providing the best and most useful products.

A member of the D\&D Focus Area EERC support staff participated in a meeting with a Landfill's EERC program support staff person regarding TTP activities scheduling. This coordination meeting will provide for a consistent approach to scheduling DOE focus area activities. 


\section{ATTACHMENT A}

\section{PRODUCTS DELIVERED; TASK A - TECHNOLOGYMANAGEMENT}

\section{TANKS FOCUS AREA (TFA)}

- Draft memo from DOE-RL to TPO and site representatives for needs/activities confirmation

- Draft Memo from DOE-RL to National Academy of Science (NAS) with agenda and alternative agenda for NAS presentations on TFATTWR programs.

- Draft White Paper - TFA Recommendations to the Waste Form Crosscutting Program

- Draft issue papers used by TFA HQ Program Manager to brief Clyde Frank, DOE$\mathrm{HQ}$, and Office of Technology Development management

- Technical inputs to Environmental Management 1996 Report to Congress

- Technical inputs to FY 1996 Office of Technology Development Report to Congress

- Draft informational memo to Site Technology Coordination Group on TFA Program for DOE-RL

- Fact sheets on TFA technologies for EMAB meeting on January 30, 1996

- Draft memo to EM-50 outlining Needs Prioritization Meeting to be held at Hanford January 29-31, 1996 for DOE-RL

- Technical input for use in a response to Inquiry on Eastlund Enterprises technology

- Trip Report on Effluent Separations and Processing Technical Exchange Meeting

\section{LANDFILL STABILIZATION FOCUS AREA (LSFA)}

- Technical Information (slides, transparencies, \& hard copies) of the Office of Science and Technology, Landfill Stabilization Focus Area, FY 96/97 Program Plan

- Technical review of funding through LSFA of "In-Situ Plutonium Fixation for Nevada Test Site Soils (HZWP)" and "In-Situ Immobilization of Strontium by Electrokinetic Injection" 
- Landfill Stabilization Focus Area Contact Cards

\section{PLUMES FOCÚS AREA (PFA)}

- Technical Information (slides, transparencies, \& hard copies) of the Office of Science and Technology, Plumes Focus Area, FY 96/97 Program Plan

- Technical input and analyses for FY97 IRB presentation

- Review of PFA's Technical Team's Draft Project Review Process

- Specifications for the Construction, Installation and Operation of a Membrane Barrier with Pass Through for Application of InSitu Groundwater Treatment

MIXED WASTE FOCUS AREA (MWFA)

- WPI Review and Recommendation of the Russian Proposals

- Review of Interface Control Document for Immobilized Low-Level Waste (ILLW) (WHC-50-WM-ICD-027, REV. 0)

- Selected Technologies Deficiencies Reference Manual (Draft)

- Needs Assessment Completeness Check for LSFA

DECONTAMINATION AND DECOMMISSIONING FOCUS AREA (D\&D)

- Technical analysis of laser Applications in D\&D

- Technical inputs to D\&D Basic Research Needs

- Review of Russian Institutes' Proposals Relating to D\&D

- D\&D Focus Area Opportunities Assessment

- Technical Input and Review of D\&D Technology Factsheets for EMAB

- Summary Factsheets of D\&D Technology with Potential Impact on the U.S. Steel Industry 


\section{BRODUCTS DELIVERED : TASK B - PROJECT MANAGEMENT}

\section{TANKS FOCUS AREA (TFA)}

- Memo to DOE-RL discussing LA/MS project update

- Final Draft of the Strategic Plan

- Final Draft of the Management Plan

- Draft memo, outline, and schedule for the TFA Rainbow Book

- Package for Field Office site review before needs prioritization meeting at Hanford which included needs, activities, and memo

- Meeting report of LDUA Cost Test Facility site visit

- Table of EM-50 planned performance demonstrations at DOE-RL for FY 1996

- Draft presentation for DOE-RL to present to site management on status of TFA Program

- Table of distribution of funding for TFA

- Table highlighting FY96 activities related to TFA

\section{LANDFILL STABILIZATION FOCUS AREA (LSFA)}

- Cost/Performance Variance Analyses Report for LSFA November 1995 Review

- Milestone package including guidance for Product Line Managers and Principle Investigators, copies of current Financial, Cost and Schedule, and Milestone Guidance from US-DOE, and copy of final FY96 TTP task ranking.

PLUMES FOCUS AREA (PFA)

- Summary sheets for the procurement supporting FY96 WETO sponsored tasks

DECONTAMINATION AND DECOMMISSIONING AREA (D\&D)

- Written Analysis of Gaps in the MWIP Quality Implementation Plan

- Current D\&D TTP Content of the MPMS Database. 
- Draft briefing: Budget Planning Meeting (Jan. 17-18, 1996)

- Draft FY97 prioritization matrix

- Draft briefing: D\&D Focus Area FY96/97 Program Plan

- Draft Implementation Plan for D\&D Focus Area

- Draft briefing for Fernald Environmental Management Project 


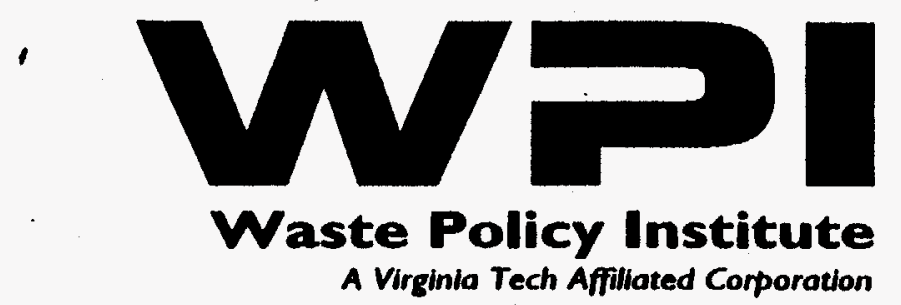

\section{MONTHLY \\ COST AND LABOR REPORT}

\section{UNIVERSITY OF NORTH DAKOTA ENERGY AND ENVIRONMENTAL RESEARCH CENTER}

Subcontract No. 359636

January, 1996 


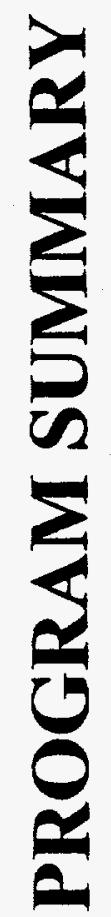


WPI Subcontract--EERC Coop. Agreement $(\$ \times 1000)$

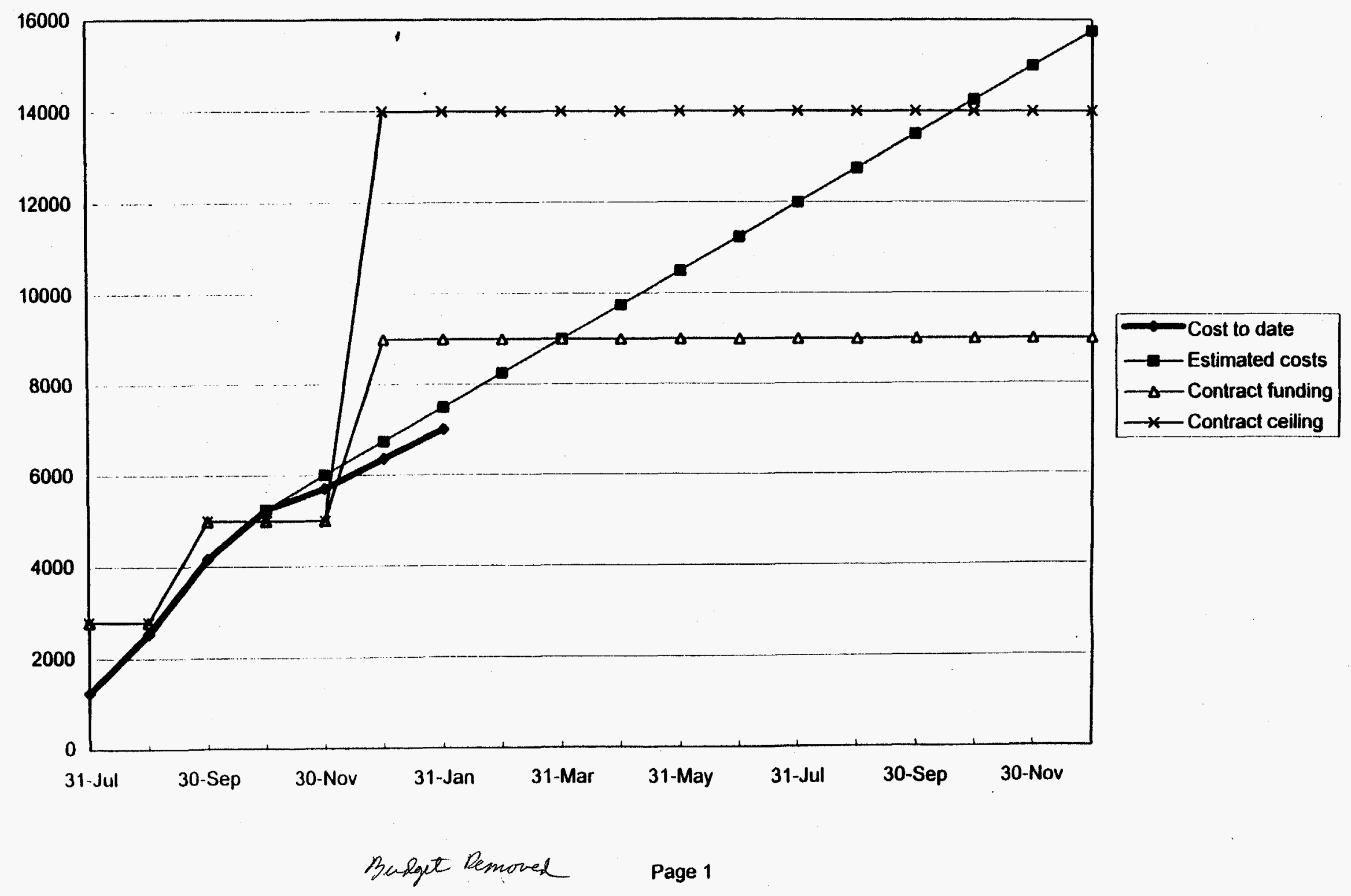




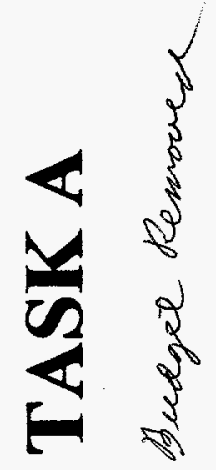




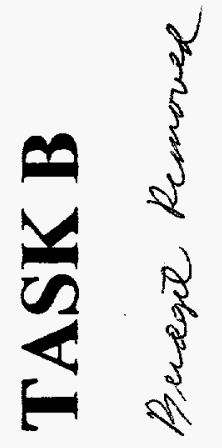




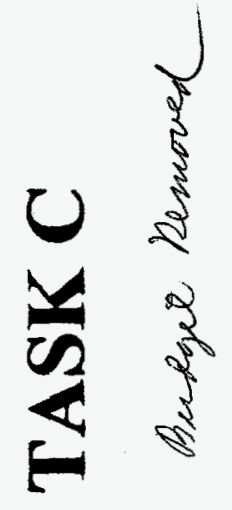


WASTE POLICY INSTITUTE MONTHLY REPORT TO THE EERC, FEBRUARY 1996

APPENDIX D 


\section{UNIVERSITY OF NORTH DAKOTA ENERGY AND ENVIRONMENTAL RESEARCH CENTER}

Monthly Report

February, 1996

\section{TECHNOLOGY DEVELOPMENT INTEGRATION WPI SUBCONTRACT NUMBER 359636}

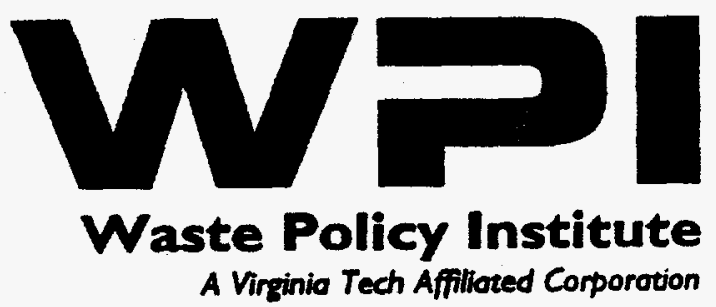


CONTRACTOR NAME: Waste Policy Institute

555 Quince Orchard Road

Suite 600

Gaithersburg, MD 20878-1437

CONTRACT PERIOD: $\quad 6 / 28 / 95-12 / 01 / 96$

\section{SUBCONTRACT DELIVERABLES:}

This report is submitted in fulfillment of requirements specified for the University of North Dakota Energy and Environmental Research Center (UNDEERC) Subcontract Number 359636. A list of products developed under this subcontract is provided as Attachment $A$.

\section{SUMMARY OF ACTIVITIES:}

During the month activities were completed to support all focus areas in preparing for "Big-5" meeting in Augusta, Georgia. Technical inputs were also being provided in all areas to support the preparation of "Rainbow" Books.

\section{TASKA-TECHNOLOGYMANAGEMENT}

\section{TANKS FOCUS AREA (TFA)}

Staff provided input to draft minutes from the Tank Retrieval Technologies Workshop (January 22-26). The workshop was held to exchange technical information between DOE and the Russians. The final comprehensive report, currently being prepared by WHC and WPI, will reflect and evaluate the Russian participants' experiences, technologies, and approaches in the remediation of the waste tanks for future use in DOE complex and will be completed next month.

Staff prepared talking points addressing obstacles to deployment of new technologies for the TFA Lead to use in briefing the DOE-RL Assistant Manager for Technology.

Obstacles to deployment are becoming an issue as the focus areas begin to deliver new technologies to the users. Briefing points included developer-user interface, site-to-site interface, and staff/budget impact that results from implementing new technologies.

A list of major TFA activities planned for FY97, what sites benefit from those activities, and funding distribution by site were prepared by the staff and submitted to the TFA Program Manager for use in briefing the Office of Science and Technology Manager. 
CONTRACTOR NAME: Waste Policy Institute 555 Quince Orchard Road Suite 600 Gaithersburg, MD 20878-1437

CONTRACT PERIOD: $\quad 6 / 28 / 95-12 / 01 / 96$

\section{SUBCONTRACT DELIVERABLES:}

This report is submitted in fulfillment of requirements specified for the University of North Dakota Energy and Environmental Research Center (UNDEERC) Subcontract Number 359636. A list of products developed under this subcontract is provided as Attachment A.

\section{SUMMARY OF ACTIVITIES:}

During the month activities were completed to support all focus areas in preparing for "Big-5" meeting in Augusta, Georgia. Technical inputs were also being provided in all areas to support the preparation of "Rainbow" Books.

\section{TASK A-TECHNOLOGYMANAGEMENT}

\section{TANKS FOCUS AREA (TFA)}

Staff provided input to draft minutes from the Tank Retrieval Technologies Workshop (January 22-26). The workshop was held to exchange technical information between DOE and the Russians. The final comprehensive report, currently being prepared by WHC and WPI, will reflect and evaluate the Russian participants' experiences, technologies, and approaches in the remediation of the waste tanks for future use in DOE complex and will be completed next month.

Staff prepared talking points addressing obstacles to deployment of new technologies for the TFA Lead to use in briefing the DOE-RL Assistant Manager for Technology. Obstacles to deployment are becoming an issue as the focus areas begin to deliver new technologies to the users. Briefing points included developer-user interface, site-to-site interface, and staff/budget impact that results from implementing new technologies.

A list of major TFA activities planned for FY97, what sites benefit from those activities, and funding distribution by site were prepared by the staff and submitted to the TFA Program Manager for use in briefing the Office of Science and Technology Manager. 


\section{LANDFILL STABILIZATION FOCUS AREA (LSFA)}

WPI team members developed the Landfill Stabilization Focus Area Weekly Management Report. The report identifies LSFA progress, pertinent facts, and activities within the focus area.

\section{PLUMES FOCUS AREA (PFA)}

Members of the team surveyed baseline cost data for groundwater and soil remediation technologies for input to the Baseline Environmental Management Report (BEMR). The $B E M R$ has several functions, including establishing an estimated cost of remediating the DOE Complex and determining the potential for cost savings through technology development.

A review was performed comparing the ORO PFA performance measures, and the originally planned PFA performance measures identified in the PEG. The discrepancies were identified and utilized by PFA management to proactively address completion of the identified milestones.

The WPI team developed the Plumes Focus Area Weekly Management Report. The report identifies PFA progress, pertinent facts, and activities with the focus area.

\section{DECONTAMINATION AND DECOMMISSIONING FOCUS AREA (D\&D)}

WPI Team members performed a technical review of the D\&D Focus Area component of the Office of Science and Technology input to the 1996 Baseline Environmental Management Report (BEMR) Update. Review included four cost/benefit analyses and the D\&D Focus Area narrative and briefing DOE-METC on the conclusions reached. The objective of the project is to determine the impact of selected technologies on the baseline environmental management cost reported to Congress in 1995. Input was reviewed by METC and forwarded to DOE-HQ for roll-up.

The WPI Team updated a technology assessment report, previously prepared by the WPI Team, on laser technologies for D\&D applications (especially metal cutting and surface cleaning), based on new papers and information recently obtained. The report will be used by the Field D\&D Focus Area Team Lead in discussions with the EM-50 Deputy Assistant Secretary to plan the future laser technology development strategy for the Focus Area.

A document entitled "Development of a High Sensitivity Monitor for Radionuclides Characterization, Base Phase Draft Final Report" was reviewed and comments were provided to DOE. WPI Team technical expertise was used to examine the technical issues addressed in the report. 


\section{LANDFILL STABILIZATION FOCUS AREA (LSFA)}

WPI team members developed the Landfill Stabilization Focus Area Weekly

Management Report. The report identifies LSFA progress, pertinent facts, and activities within the focus area.

\section{PLUMES FOCUS AREA (PFA)}

Members of the team surveyed baseline cost data for groundwater and soil remediation technologies for input to the Baseline Environmental Management Report (BEMR). The BEMR has several functions, including establishing an estimated cost of remediating the DOE Complex and determining the potential for cost savings through technology development.

A review was performed comparing the ORO PFA performance measures, and the originally planned PFA performance measures identified in the PEG. The discrepancies were identified and utilized by PFA management to proactively address completion of the identified milestones.

The WPI team developed the Plumes Focus Area Weekly Management Report. The report identifies PFA progress, pertinent facts, and activities with the focus area.

\section{DECONTAMINATION AND DECOMMISSIONING FOCUS AREA (D\&D)}

WPI Team members performed a technical review of the D\&D Focus Area component of the Office of Science and Technology input to the 1996 Baseline Environmental Management Report (BEMR) Update. Review included four cost/benefit analyses and the D\&D Focus Area narrative and briefing DOE-METC on the conclusions reached. The objective of the project is to determine the impact of selected technologies on the baseline environmental management cost reported to Congress in 1995. Input was reviewed by METC and forwarded to DOE-HQ for roll-up.

The WPI Team updated a technology assessment report, previously prepared by the WPI Team, on laser technologies for D\&D applications (especially metal cutting and surface cleaning), based on new papers and information recently obtained. The report will be used by the Field D\&D Focus Area Team Lead in discussions with the EM-50 Deputy Assistant Secretary to plan the future laser technology development strategy for the Focus Area.

A document entitled "Development of a High Sensitivity Monitor for Radionuclides Characterization, Base Phase Draft Final Report" was reviewed and comments were provided to DOE. WPI Team technical expertise was used to examine the technical issues addressed in the report. 
WPI team members initiated the development of "The Mixed Waste Characterization, Treatment and Disposal Focus Area Technology Summary Book" by contacting each Waste Type Manager and principal investigator for their input on the technology summary section.

Information was provided by the staff to a Hanford call for a request for information pertaining to projects funded under the MWFA that support tank waste treatment technologies.

The WPI team obtained information pertaining to the Engineering Design Reports to assist in making a decision as to whether this is an activity that needs to be initiated by the MWFA.

A revised draft of the "Implementation Plan for Thermal Treatment Systems" was prepared. This draft provides responses to the recommendations from both the Technical and Use Panels which were convened during the Thermal Treatment Systems Workshop in November, 1995.

Members of the WPI team participated in the development of a MWFA approach to the Waste Forms initiative. The Waste Forms Initiative will be initiated by the MWFA and will be applied to the other focus areas. It will also coordinate other EM-related Waste Form activities.

\section{TASK B - PROJECT MANAGEMENT}

\section{TANKS FOCUS AREA (TFA)}

Staff provided highlights and recommendations from the Hanford Tank Waste Remediation System (TWRS) Tank Farm Demonstration Initiative planning session. One important result from the meeting was that the state Department of Ecology representative came away with a very positive view of the proposal. The TWRS organization broadened their focus to allow consideration of several tanks to demonstrate aspects of retrieval of waste from a single shell tank and actions needed to prepare the tanks for closure. The WPI team recommended that detailed planning for the demonstration go forward with scope and preliminary cost estimate to be developed by June, 1996.

The WPI team prepared site-specific briefing books for each Site Manager from Hanford, Idaho, Savannah River, and Oak Ridge. These were used by the TFA Lead (DOE-RL) at the Big-5 Meeting in Savannah River, February 6-7, 1996, to brief the respective Site Managers. The books describe TFA activities and how they help meet site-specific objectives. Following the Big-5 Meeting, the TFA Program Manager (DOE-HQ/EM-50) requested copies to brief the EM-30 counterparts at DOE-HQ. 
WPI team members initiated the development of "The Mixed Waste Characterization, Treatment and Disposal Focus Area Technology Summary Book" by contacting each Waste Type Manager and principal investigator for their input on the technology summary section.

Information was provided by the staff to a Hanford call for a request for information pertaining to projects funded under the MWFA that support tank waste treatment technologies.

The WPI team obtained information pertaining to the Engineering Design Reports to assist in making a decision as to whether this is an activity that needs to be initiated by the MWFA.

A revised draft of the "Implementation Plan for Thermal Treatment Systems" was prepared. This draft provides responses to the recommendations from both the Technical and Use Panels which were convened during the Thermal Treatment Systems Workshop in November, 1995.

Members of the WPI team participated in the development of a MWFA approach to the Waste Forms initiative. The Waste Forms Initiative will be initiated by the MWFA and will be applied to the other focus areas. It will also coordinate other EM-related Waste Form activities.

\section{TASK B - PROJECT MANAGEMENT}

\section{TANKS FOCUS AREA (TFA)}

Staff provided highlights and recommendations from the Hanford Tank Waste Remediation System (TWRS) Tank Farm Demonstration Initiative planning session. One important result from the meeting was that the state Department of Ecology representative came away with a very positive view of the proposal. The TWRS organization broadened their focus to allow consideration of several tanks to demonstrate aspects of retrieval of waste from a single shell tank and actions needed to prepare the tanks for closure. The WPI team recommended that detailed planning for the demonstration go forward with scope and preliminary cost estimate to be developed by June, 1996.

The WPI team prepared site-specific briefing books for each Site Manager from Hanford, Idaho, Savannah River, and Oak Ridge. These were used by the TFA Lead (DOE-RL) at the Big-5 Meeting in Savannah River, February 6-7, 1996, to brief the respective Site Managers. The books describe TFA activities and how they help meet site-specific objectives. Following the Big-5 Meeting, the TFA Program Manager (DOE-HQ/EM-50) requested copies to brief the EM-30 counterparts at DOE-HQ. 
Applicability Matrix being prepared at DOE-HQ. The matrix has modifiers or filters that account for various uncertainties regarding the cost savings data.

\section{LANDFILL STABILIZATION FOCUS AREA (LSFA)}

The team provided meeting planning support for a Landfill Program Review at the Harvey Hotel in Atlanta, Georgia, March 26 - 29, 1996.

WPI staff completed a review of all unfunded LSFA TTPs and proposals for possible submission for funding under the Basic Science Program. A number of tasks were recommended to be funded based on their technical and scientific merit.

Members of the team developed a prototype Program Management ITP Scheduling Tool for LSFA Management. The tool identifies TTP milestones of importance to LSFA management that should be completed within a given monthly reporting period. The tool is used by LSFA management to manage focus area activities to meet strategic goals.

A review was performed of the December 95 CostPerformance Variance Analysis Report to identify discrepancies with the current LSFA budget baseline.

\section{PLUMES FOCUS AREA (PFA)}

A member of the team reviewed the Program Manager's report from the Project Tracking System (PTS), evaluating all TTPs for cost and schedule variances. This was discussed with the Program Manager, and assistance in planning and decision-making for the remainder of the fiscal year was provided.

The production of the PFA monthly report was complete. This report is distributed to DOE employees and contractors, stakeholders, other Federal Agency employees, and others involved with the Focus Area. Beginning with this edition, plumes-related technologies managed by Industrial Programs will be included.

Staff provided technical and programmatic input and coordinated the production of the December monthly program review briefing. Activities included clarification of: overdue milestones, project schedule variance, and Focus Area performance measures. Additional actions included determining successful completion of monthly performance measures (e.g., technology demonstrations, technology transfers).

The team gathered data for inclusion in the Techinvest database software. This TechInvest software should ease management of Plume Technology development by assisting in linking technologies with sites and discovering new areas for investment.

Staff developed a list of the Plumes Focus Area FY 1996 Performance Measures. The list reflects the FY96 budget changes and includes the relevant projects from cross-cutting 
Applicability Matrix being prepared at DOE-HQ. The matrix has modifiers or filters that account for various uncertainties regarding the cost savings data.

\section{LANDFILL STABILIZATION FOCUS AREA (LSFA)}

The team provided meeting planning support for a Landfill Program Review at the Harvey Hotel in Atlanta, Georgia, March 26 - 29, 1996.

WPI staff completed a review of all unfunded LSFA TTPs and proposals for possible submission for funding under the Basic Science Program. A number of tasks were recommended to be funded based on their technical and scientific merit.

Members of the team developed a prototype Program Management TTP Scheduling Tool for LSFA Management. The tool identifies TTP milestones of importance to LSFA management that should be completed within a given monthly reporting period. The tool is used by LSFA management to manage focus area activities to meet strategic goals.

A review was performed of the December 95 Cost/Performance Variance Analysis Report to identify discrepancies with the current LSFA budget baseline.

\section{PLUMES FOCUS AREA (PFA)}

A member of the team reviewed the Program Manager's report from the Project Tracking System (PTS), evaluating all TTPs for cost and schedule variances. This was discussed with the Program Manager, and assistance in planning and decision-making for the remainder of the fiscal year was provided.

The production of the PFA monthly report was complete. This report is distributed to DOE employees and contractors, stakeholders, other Federal Agency employees, and others involved with the Focus Area. Beginning with this edition, plumes-related technologies managed by Industrial Programs will be included.

Staff provided technical and programmatic input and coordinated the production of the December monthly program review briefing. Activities included clarification of: overdue milestones, project schedule variance, and Focus Area performance measures. Additional actions included determining successful completion of monthly performance measures (e.g., technology demonstrations, technology transfers).

The team gathered data for inclusion in the Techinvest database software. This TechInvest software should ease management of Plume Technology development by assisting in linking technologies with sites and discovering new areas for investment.

Staff developed a list of the Plumes Focus Area FY 1996 Performance Measures. The list reflects the FY96 budget changes and includes the relevant projects from cross-cutting 
The WPI Team provided technical input to the D\&D Focus Area Monthly Report of the work accomplished in January. This report informs interested parties of the progress being made by the Focus Area.

WPI Team members continued input of FY96 D\&D Technical Task Plan data (descriptive text) into the Morgantown Energy Technology Center (METC) Project Management System (MPMS). MPMS is used by METC for tracking and managing technical tasks, including the D\&D Focus Area Technical Tasks.

A WPI Team staff member attended a Risk Data Sheet meeting in Gaithersburg, MD on February 23. This meeting provided guidance for incorporating technology risk considerations into the Internal Review Budget planning processes for FY98 for the D\&D Focus Area.

The WPI Team provided technical input to briefings being prepared for Site Technology Coordination Group (STCG) meetings at various DOE sites.

The D\&DFA FY 95 Report of Activities is currently being developed. Client comments were incorporated and the graphic layout finalized. The annual report, when complete, will provide a comprehensive overview of D\&DFA activities for FY95.

The D\&DFA Homepage is currently being developed. The basic format of the Homepage was designed and November and December Monthly Progress Report information was loaded.

The METC Project Selection Policy for the International Union of Operating Engineers Cooperative Agreement was reviewed and comments provided in a deliverable to DOE.

Hanford's Technology Needs Assessment was reviewed and comments provided to DOE.

WPI staff provided technical input to HQ for information on major FY97 D\&D activities by site.

Members of the team provided technical analysis of D\&D FY95 carryover in response to a $\mathrm{HQ}$ request.

Staff provided technical input to the field for the request for final FY96 work scope and budget information.

Technical support and overall lead coordination for the development of the D\&D Focus Area FY96 Technology Summary Report were provided by the WPI team. 
The WPI Team provided technical input to the D\&D Focus Area Monthly Report of the work accomplished in January. This report informs interested parties of the progress being made by the Focus Area.

WPI Team members continued input of FY96 D\&D Technical Task Plan data (descriptive text) into the Morgantown Energy Technology Center (METC) Project Management System (MPMS). MPMS is used by METC for tracking and managing technical tasks, including the D\&D Focus Area Technical Tasks.

A WPI Team staff member attended a Risk Data Sheet meeting in Gaithersburg, MD on February 23. This meeting provided guidance for incorporating technology risk considerations into the Internal Review Budget planning processes for FY98 for the D\&D Focus Area.

The WPI Team provided technical input to briefings being prepared for Site Technology Coordination Group (STCG) meetings at various DOE sites.

The D\&DFA FY 95 Report of Activities is currently being developed. Client comments were incorporated and the graphic layout finalized. The annual report, when complete, will provide a comprehensive overview of D\&DFA activities for FY95.

The D\&DFA Homepage is currently being developed. The basic format of the Homepage was designed and November and December Monthly Progress Report information was loaded.

The METC Project Selection Policy for the International Union of Operating Engineers Cooperative Agreement was reviewed and comments provided in a deliverable to DOE.

Hanford's Technology Needs Assessment was reviewed and comments provided to DOE.

WPI staff provided technical input to HQ for information on major FY97 D\&D activities by site.

Members of the team provided technical analysis of D\&D FY95 carryover in response to a HQ request.

Staff provided technical input to the field for the request for final FY96 work scope and budget information.

Technical support and overall lead coordination for the development of the D\&D Focus Area FY96 Technology Summary Report were provided by the WPI team. 
The team began examining technical issues critical to technology implementation, and examining EM-50 implementation "success" stories to assist in writing a handbook on requirements (technical, regulatory, institutional) which a Focus Area must meet to ensure its technologies are implemented.

Federal and state legislation of interest to the field offices was tracked and the first edition of "State Environmental Watch" was produced and distributed.

Staff reported on the DOE proposal to revise National Environmental Policy Act (NEPA) rules for nuclear waste facilities, and provided the details of the proposed rulemaking to the field offices..

The WPI team provided analysis of "treatability study exemptions" and the "research, development, and demonstration permits requirements" in the environmental regulations of Colorado, Idaho, Ohio, South Carolina, and Tennessee. Also performed related research concerning other state environmental regulations.

WPI team members developed technical input into a memorandum to the PFA TPO's \& PLM's to elicit comments on the data quality problems which are documented in the November 95 Cost/Performance Variance Analysis Reports compiled from PTS records.

A review was completed of the EM-50 Field Cost Estimating Guide to determine the content and relevance of the document as it pertains to the cost estimating of tasks completed in the Landfill Stabilization Focus Area (LSFA) Technical Plans (TTPs).

An updated schedule of conferences/symposia/workshops/etc. in the waste management/environmental restoration area was developed. Regular updates will be provided. 
The team began examining technical issues critical to technology implementation, and examining EM-50 implementation "success" stories to assist in writing a handbook on requirements (technical, regulatory, institutional) which a Focus Area must meet to ensure its technologies are implemented.

Federal and state legislation of interest to the field offices was tracked and the first edition of "State Environmental Watch" was produced and distributed.

Staff reported on the DOE proposal to revise National Environmental Policy Act (NEPA) rules for nuclear waste facilities, and provided the details of the proposed rulemaking to the field offices..

The WPI team provided analysis of "treatability study exemptions" and the "research, development, and demonstration permits requirements" in the environmental regulations of Colorado, Idaho, Ohio, South Carolina, and Tennessee. Also performed related research concerning other state environmental regulations.

WPI team members developed technical input into a memorandum to the PFA TPO's \& PLM's to elicit comments on the data quality problems which are documented in the November 95 Cost/Performance Variance Analysis Reports compiled from PTS records.

A review was completed of the EM-50 Field Cost Estimating Guide to determine the content and relevance of the document as it pertains to the cost estimating of tasks completed in the Landfill Stabilization Focus Area (LSFA) Technical Plans (TTPs).

An updated schedule of conferences/symposia/workshops/etc. in the waste management/environmental restoration area was developed. Regular updates will be provided. 
- Review Comments on Pipe Exporer Cost/Benefit Analysis

- Review comments from the document entitled, "Development of a High Sensitivity Monitor for Radionuclides Characterization," Base Phase Draft Final Report

- Review comments on D\&D Focus Area input to 1996 Baseline Environmental Management Report Update

- Review comments on PipeExplorer cost/benefit analysis

- Cost/benefit analysis prioritization matrix

- Technical Assessment of Electrohydraulic Scabbling

- List of technologies to be considered for Large-Scale Demonstration at Fernald Environmental Management Project

- Meeting records for Fernald Large-Scale Demonstration meetings on February 15 and 20

- Draft Scope-of-Work for Florida International University participation in the Fernald Large-Scale Demonstration

- Draft plan for the assessment of depleted uranium hexafluoride

\section{PRODUCTS DELIVERED: TASK B - PROJECT MANAGEMENT}

TANKS FOCUS AREA (TFA)

- EM-30 Crosswalk - table linking EM-30 activities to TFA

- TFA Briefing Books for Idaho, Hanford, Oak Ridge and Savannah River

- Needs roll up summarizing the needs and subordinate needs for the TFA from all the sites

- Draft attachment to DOE-RL Needs Prioritization letter to Site Representatives on Duplications, Scope/Description, and Priorities of Needs

- FY 1995 Metrics describing technology development and status

- Big Five Briefing for DOE-RL (TFA) for February 6, 1996 meeting at Headquarters

- Business Review Briefing as of December 31, 1995 for the TFA for EM-50 
- Review Comments on Pipe Exporer Cost/Benefit Analysis

- Review comments from the document entitled, "Development of a High Sensitivity Monitor for Radionuclides Characterization," Base Phase Draft Final Report

- Review comments on D\&D Focus Area input to 1996 Baseline Environmental Management Report Update

- Review comments on PipeExplorer cost/benefit analysis

- Cost/benefit analysis prioritization matrix

- Technical Assessment of Electrohydraulic Scabbling

- List of technologies to be considered for Large-Scale Demonstration at Fernald Environmental Management Project

- Meeting records for Fernald Large-Scale Demonstration meetings on February 15 and 20

- Draft Scope-of-Work for Florida International University participation in the Fernald Large-Scale Demonstration

- Draft plan for the assessment of depleted uranium hexafluoride

\section{PRODUCTS DELIVERED: TASK B - PROJECT MANAGEMENT}

TANKS FOCUS AREA (TFA)

- EM-30 Crosswalk - table linking EM-30 activities to TFA

- TFA Briefing Books for Idaho, Hanford, Oak Ridge and Savannah River

- Needs roll up summarizing the needs and subordinate needs for the TFA from all the sites

- Draft attachment to DOE-RL Needs Prioritization letter to Site Representatives on Duplications, Scope/Description, and Priorities of Needs

- FY 1995 Metrics describing technology development and status

- Big Five Briefing for DOE-RL (TFA) for February 6, 1996 meeting at Headquarters

- Business Review Briefing as of December 31, 1995 for the TFA for EM-50 
- Three Decision Criteria Summary Sheets

- Technical materials included in briefing to Congress for EM-50 FY97 Budget by DOE

- Technical Review of cost projections for Chemically Enhanced Barrier Project (RL36PL41, task 1)

- Comparison Review of ORO PFA Performance Measures and the originally planned PFA identified in the PEG (ITP)

\section{DECONTAMINATION AND DECOMMISSIONING AREA (D\&D)}

- Revised FY96 Performance Measure Matrix

- D\&D Focus Area Monthly Report

- Big Five Briefing for the D\&D Focus Area

- December D\&DFA Monthly Progress Report

- Review comments from "METC Project Selection Policy for the International Union of Operating Engineers Cooperative Agreement"

- Review comments from Hanford's Technology Needs Assessment.

- Summary information on major FY97 D\&D activities by site.

- Technical input to the field for the request for final FY96 work scope and budget information.

- Technical input for an analysis of FY95 milestone report deliverables.

MIXED WASTE FOCUS AREA (MWFA)

- Technical Task Plan Summary Profiles

- Draft Schedule for MWFA Request for Information to address 30 Deficiencies

- Transmittal of Monthly Report

- Review of Program Management Plan for the DOE-EM Mixed Waste Focus Area 
- Three Decision Criteria Summary Sheets

- Technical materials included in briefing to Congress for EM-50 FY97 Budget by DOE

- Technical Review of cost projections for Chemically Enhanced Barrier Project (RL36PL41, task 1)

- Comparison Review of ORO PFA Performance Measures and the originally planned PFA identified in the PEG (ITP)

\section{DECONTAMINATION AND DECOMMISSIONING AREA (D\&D)}

- Revised FY96 Performance Measure Matrix

- D\&D Focus Area Monthly Report

- Big Five Briefing for the D\&D Focus Area

- December D\&DFA Monthly Progress Report

- Review comments from "METC Project Selection Policy for the International Union of Operating Engineers Cooperative Agreement"

- Review comments from Hanford's Technology Needs Assessment.

- Summary information on major FY97 D\&D activities by site.

- Technical input to the field for the request for final FY96 work scope and budget information.

- Technical input for an analysis of FY95 milestone report deliverables.

\section{MUXED WASTE FOCUS AREA (MWFA)}

- Technical Task Plan Summary Profiles

- Draft Schedule for MWFA Request for Information to address 30 Deficiencies

- Transmittal of Monthly Report

- Review of Program Management Plan for the DOE-EM Mixed Waste Focus Area 


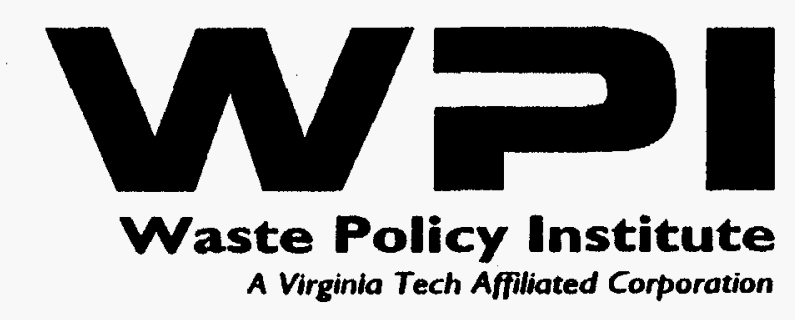

\section{MONTHLY \\ COST AND LABOR REPORT}

\section{UNIVERSITY OF NORTH DAKOTA ENERGY AND ENVIRONMENTAL RESEARCH CENTER}

Subcontract No. 359636

February, 1996 


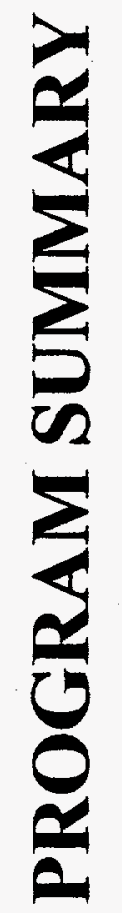




\section{WPI Subcontract--EERC Coop. Agreement \\ $(\$ \times 1000)$}

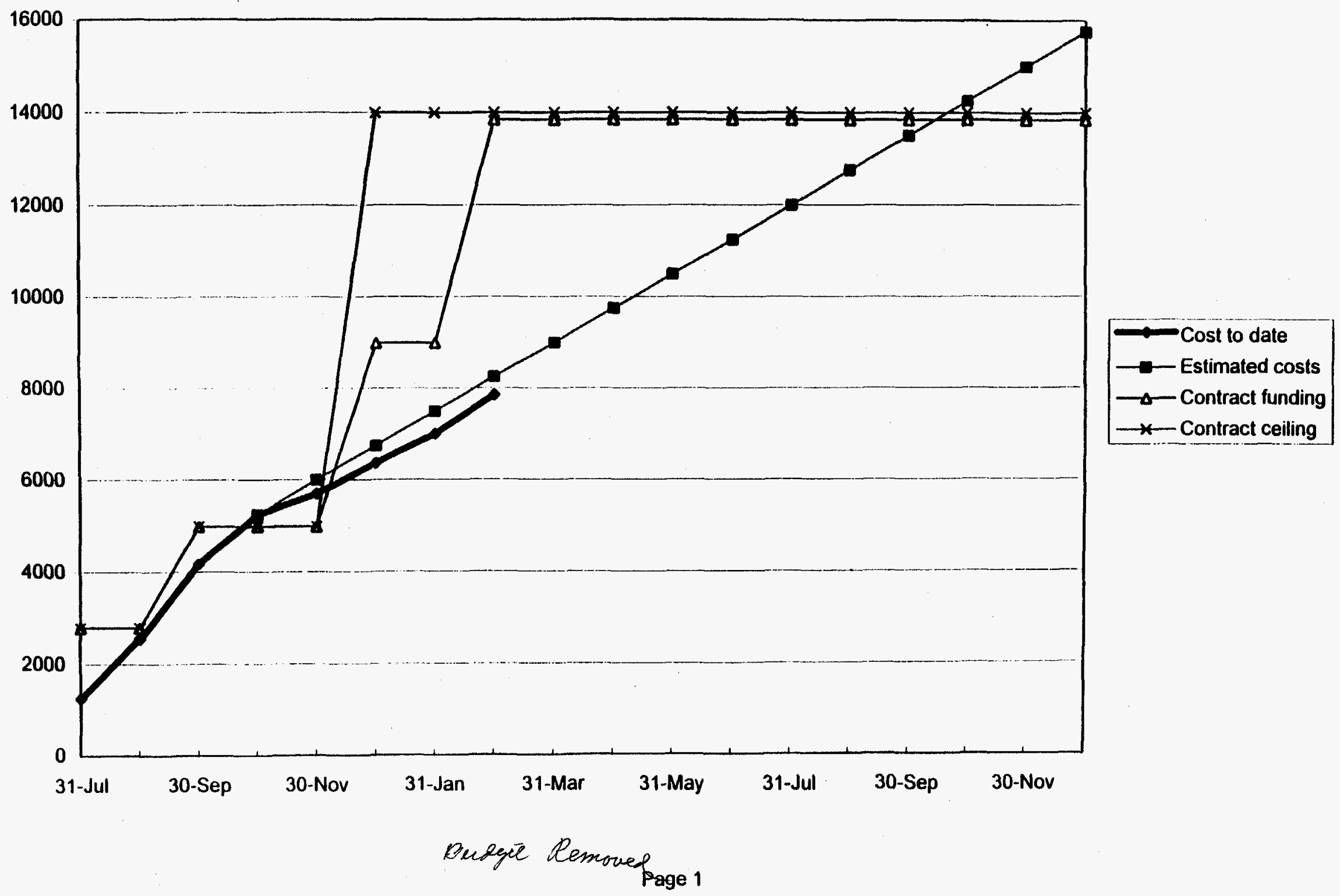




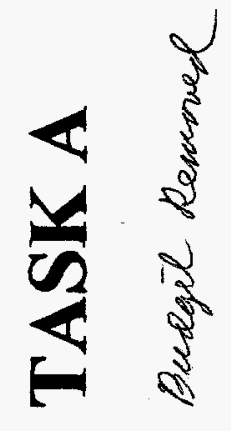




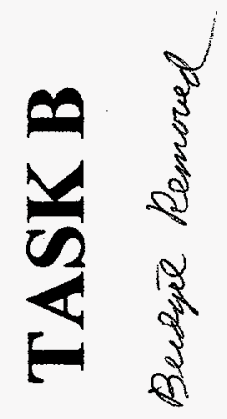




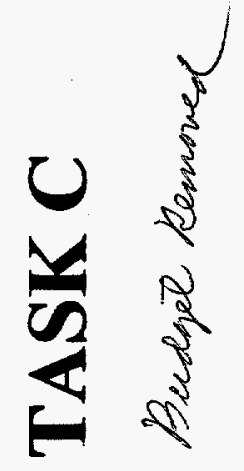


WASTE POLICY INSTITUTE MONTHLY REPORT TO THE EERC, MARCH 1996 


\section{UNIVERSITY OF NORTH DAKOTA ENERGY AND ENVIRONMENTAL RESEARCH CENTER}

Monthly Report March, 1996

\section{TECHNOLOGY DEVELOPMENT INTEGRATION WPI SUBCONTRACT NUMBER 359636}

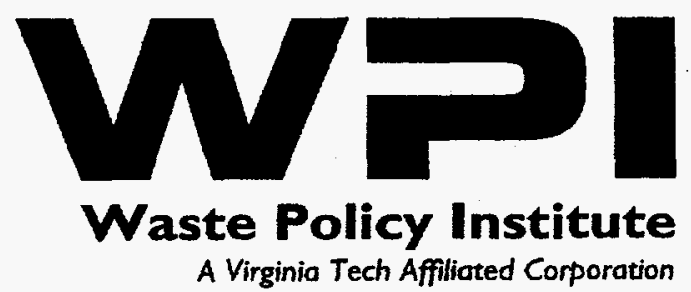




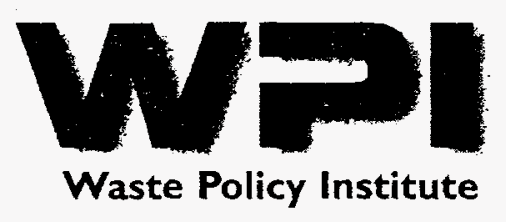

1262 Pineview Drive - Morgantown, WV 26505

Telephone (304) 598-9383 - Telefax (304) 598-9392

April 15, 1996

Mr. John G. Hendrikson

Assistant to the Director

Energy and Environmental Research Center

University of North Dakota

15 North 23rd Street

Grand Forks, ND 58203

Subject: UNDEERC Fund No. 4624-0936, Technology Development Integration

WPI Subcontract No. 359636

Dear Mr. Hendrikson:

The Waste Policy Institute (WPI) is pleased to submit the enclosed report of activities conducted during the period of March 1, 1996 through March 3 I, 1996, in compliance with Article VI and Appendix A of Subcontract Number 359636. A list of products developed during this period is provided as Attachment A to the activities report.

Through March 31, WPI has expended $\$ 8,590,455$. Our monthly cost and labor report provides the details of our costs to date. Although the current contract period extends through December 1, 1996, it should be noted that we anticipate the subcontract ceiling will be reached on or about September 30, 1996. This expenditure rate is consistent with our proposal for the new budget period.

Please do not hesitate to call me if you have any questions or require additional information.

Sincerely,

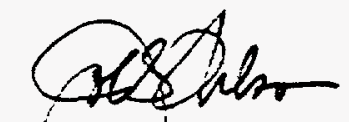

John S. Wilson, Program Manager

Waste Policy Institute

con

cc. L. D. Eyman

S. A. Cleary 
SUBCONTRACT NUMBER: 359636

Report Period: 3/1/96-3/31/96

CONTRACTOR NAME: Waste Policy Institute 555 Quince Orchard Road

Suite 600

Gaithersburg, MD 20878-1437

CONTRACT PERIOD: $\quad$ 6/28/95 -12/01/96

\section{SUBCONTRACT DELIVERABLES:}

This report is submitted in fulfillment of requirements specified for the University of North Dakota Energy and Environmental Research Center (UNDEERC) Subcontract Number 359636. A list of products developed under this subcontract is provided as Attachment A.

\section{SUMMARY OF ACTIVITIES:}

The WPI Team across all sites has been involved in the finalization of the Technology Summary Books ("Rainbow Books"). Assembly of information, editing and review activities are being completed to meet the publication schedule. The final books are scheduled for release at the Spectrum ' 96 meeting this summer.

The team has participated and provided support to the consolidation of Plumes and Landfills Focus Areas into the Subsurface Contaminant Focus Area. This consolidation has essentially been completed and the team is directing it's support to the new Focus Area.

\section{TASK A-TECHNOLOGY ASSESSMENT}

\section{TANKS FOCUS AREA (TFA)}

Staff participated in a meeting chaired by the Characterization, Monitoring, and Sensor Technology (CMST) crosscutting program. The purpose was to identify field deployable chemical sensors available for implementation. The meeting brought together users and developers to identify the DOE needs and prospective commercial technologies that could meet the needs.

Staff started collecting information and drafting an outline for "site primers". Last year the Tanks Focus Area developed a book that provides an overview of Hanford tanks their construction history, the history of the processes that fed waste to the tanks, the physical and chemical constituents currently in the tanks. It is the goal to produce similar 
volumes describing the tanks at each of the other tank sites: Oak Ridge, Idaho, and Savannah River.

Members of the WPI Team attended the Tanks Focus Area Midyear Review in Richland, Washington, 19-21 March. The Midyear Review provides an opportunity to evaluate all aspects of the program at once, particularly their interaction and cooperation, and their interactions with other focus areas and crosscutting programs.

\section{LANDFILL STABILIZATION FOCUS AREA (LSFA)}

Members of the team prepared a technical analysis of the LSFA Peer Review Process for Spectrum "96 entitled "Thermal Treatment Technology Technical Peer Review". The paper analyzes the benefits and economics of the Peer Review Process.

Staff reviewed the Landfill Stabilization and Contaminant Plumes Containment and Remediation Focus Areas funded projects and prepared a list of technologies which DOE may elect to transfer to the Mixed Waste Focus Area and Characterization, Monitoring, and/or the Sensor Technology Crosscutting Program technology development activities.

Landfill Stabilization Weekly Reports were prepared. These reports reflect any actions, program changes, communication/meanings pertaining to the Landfill Stabilization Focus Area activities during the month of March.

\section{PLUMES FOCUS AREA (PFA)}

WPI Team members supported the development of the FY98 Risk Data Sheets (RDS). The construction of RDS is a new action for EM-50, for which the focus area must show how their individual technology systems will reduce risk during the remediation of identified DOE sites, and reduce the cost of this action.

The WPI Technical Team provided updates on Peer Review processes for the RDS including copies of the hand-outs given the Tier 2 peer reviewers who will be meeting in mid-April to review the EM-30, EM-40, and EM-60 RDS.

An estimate of remediation/assessment cost savings attributable to PFA technologies was submitted, as well as supporting material (assumptions, scenarios, relevant EM-40 sites). This material is in support of the DOE Environmental Management's Baseline Environmental Management Report.

Staff members produced a bullet point description of the FY98 PFA Program based upon technical review of the FY97 Program. This workscope may be used as preliminary work packages for future planning of the FY98 Internal Review Budget (IRB) and Risk Data Sheets (RDS). 
Plumes Focus Area Weekly Reports were prepared. These reports reflect any actions, program changes, communication/meanings pertaining to the Plumes Focus Area activities during the month of March.

Members of the WPI team submitted comments and suggestions on the Plumes Focus Area draft Review Procedure dated January 11, 1996. A draft procedure for the PFA project review process was prepared by the Technical Team and circulated for comments. The review comments were utilized by DOE-SR to structure the Focus Area technical review process.

\section{DECONTAMINATION AND DECOMMISSIONING (D\&D) FOCUS AREA}

The WPI Team continued support of the Fernald Plant 1 Large-Scale Technology Demonstration for the D\&D Focus Area. Meetings were held on March 7 and 25 to review detailed technology demonstration proposals prepared by the Technology Screening Team and conduct other business of the Integrating Contractor Team. Written meeting records were prepared for each meeting

The WPI Team initiated development of a technical report on state-of-the-art for recycling radioactively contaminated scrap metal for presentation to the Big 5 Group in May 1996. Purpose of the report is to present the existing capability for recycling of radioactively contaminated scrap metal from DOE operations and assess the need for EM-50 to support additional technology development in this area.

The WPI Team prepared draft technical input to the D\&D Focus Area component of the Office of Science and Technology input to the 1996 Baseline Environmental Management Report (BEMR) Update. The input included supporting data and assumptions for cost/benefit analyses to determine the impact of D\&D technologies on the BEMR Update. Input was reviewed by METC and forwarded to DOE-HQ.

The WPI Team provided technical input to an assessment of processes and cleanup scenarios for remediation of a tritium facility at the Mound Site in Ohio. The site may be proposed as a site for a D\&D Focus Area Large Scale Demonstration in FY97 or FY98.

The WPI Team provided a comparative analysis to support the Phase II decision process for the Multisensor Inspection and Characterization Robot for Small Pipes (Microspi). In this comparative analysis, the team gathered and evaluated data from other piping characterization systems and also contacted numerous DOE sites to determine Microspi need.

The WPI Team initiated development of an issue paper regarding the free-release of residually contaminated metals for recycling. 


\section{MIXED WASTE FOCUS AREA (MWFA)}

The team provided guidance to the MWFA lead as to suggestions on development of performance specifications relating to new and mortgaged activities.

Staff members incorporated MWFA DOE-ID comments on the Draft Implementation Plan for Thermal Treatment Systems. This draft provides responses to the recommendations from both the Technical and User Panels which were convened during the Thermal Treatment Systems Workshop in November, 1995.

Performance data on refractories which have been utilized on MWFA funded thermal treatment projects was collected.

Team members participated in a Technical Resource Team meeting on the development of generic Demonstration Test Plans for thermal and non-thermal treatment systems in Salt Lake City, Utah on March 26 and 27.

The WPI team began gathering data and preparing draft language for selected MWFA Technology Development Requirements Document (TDRD).

A draft format and example of the Regulatory Summary Matrix was submitted to the Site Technical Coordinator Groups throughout DOE complex for review and comments. This matrix assists understanding the regulatory status and complexities of seven major DOE sites before siting of technology demonstrations.

Members of the WPI team assisted DOE-ID in organizing and producing the Russian Workshop Proceedings from March 1 through March 22, 1996.

Staff assisted DOE-ID with Waste Forms Initiative. Tasks included literature review of various topics related to Waste Forms, development of a Waste Forms bibliography, attendance at a Waste Forms Initiative Teleconference, preparation of meeting minutes and drafting the Waste Forms Performance Specifications.

The staff reviewed the Continuous Emissions Monitors Test Plan for a demonstration of four CEMs at the Research Triangle Park.

\section{TASK B- PROJECT ASSESSMENT}

\section{TANKS FOCUS AREA (TFA)}

The WPI staff provided comments to DOE-RL and PNNL on the FY96 TFA Needs Assessment. Most comments addressed how to increase the clarity of the information presented. Recommendations for next year's needs solicitation and prioritization were also included. 
Staff reviewed all TFA Technical Task Plans (TTP) submitted to date in the retrieval and closure, characterization, immobilization, and pretreatment functional areas. They were reviewed for consistency of scope, schedule, and budget; agreement with December/January Program Execution guidance; and for incorporation of carryover from the March Fin Plan. Provided comments and recommendations to DOE-RL.

A waste form white paper was prepared by the WPI staff for DOE-RL and the TFA regarding coordination of the MWFA. The white paper summarizes recommendations for collaboration between the TFA and the MWFA in waste forms development. The purpose of the paper was to respond to comments from the Field Office Principals Meeting at Savannah River Site on February 6-7, 1996 regarding the need for more coordination between the Focus Areas.

The WPI Team developed a list of TFA contacts including DOE, DOE Contractor, and Support Contractor employees in addition to User Steering Group members, Site Representatives, Site Technical Coordination Groups (STCG) Tanks Subgroup members, and the TFA Technical Review Group and provided this matrix to WPI-DC to distribute as necessary in support of the various Focus Areas.

Staff prepared a briefing on FY96 and FY97 Technology Implementation for the Tanks Focus Area. Topics covered included the technology baselines, integration and coordination, addressing user technology acceptance, and program definition and management.

Staff provided recommendations for use in responding to a request made by EM-50 to reduce the number of TFA FY96 Milestones. WPI staff reviewed the 200 TFA Milestones and made recommendations to reduce them to less than 150 .

Staff completed first draft of site baselines for Appendix A of the TFA Multi-Year Program Plan (MYPP) and provided the draft to DOE-RL and PNNL. Efforts for this month included incorporating comments from DOE West Valley into the draft.

\section{LANDFILL STABILIZATION FOCUS AREA (LSFA)}

The team developed Desktop Instructions for the Coding Structure used in the TTP Program Management Tracking Tool. The instructions have been developed as a tool for DOE-SR to utilize the coding structure used in the TTP Program Management Tool.

The Landfill Stabilization Focus Area December 31, 1995 OST Business Review briefing information was reviewed and technical input and status information was prepared. Attached tables replace inaccurate information portrayed in the DOE-HQ briefing information. The review also included revision of the Focus Area Mission, Identification of Areas of Needs/Product Lines, and revision of the Work Breakdown Structure. 
Team members reviewed the Landfill Stabilization Focus Area Program Plan briefing information and prepared technical input and status information for use at the Big 5 Program Planning Meeting in Augusta, GA. The technical information was utilized by DOE-SR to prepare a Focus Area presentation at the Big 5 meeting.

\section{PLUMES FOCUS AREA (PFA)}

Spreadsheets that detail FY96 TTP in the Plumes Focus Area were developed. The spreadsheets define the status of TTP within the Plumes Focus Area and one per site that details actions required by individual TPOs.

Staff provided general support as well as meeting planning support to Plumes Focus Area members during the retreat of the Plumes and Landfills Focus Areas March 25-29 in Atlanta, Georgia. The subject of this meeting is the consolidation of the two focus areas into one focus area, the Subsurface Contaminants Focus Area. The objective of the consolidation is to: 1) clarify relevant problem sets and missions, 2) realign organization based on lessons learned from operational experience, 3) minimize program management costs, and 4) mitigate unfounded perceptions of parochialism and duplication of effort.

\section{DECONTAMINATION AND DECOMMISSIONING (D\&D) FOCUS AREA}

Members of the WPI team completed the gap analysis of the METC QA/QC Manual and the Grumbly issue "Institutionalizing the Data Quality Objectives Process for EM's Environmental Data Collection Activities." They are compiling revision comments on the QA/QC Manual as a secondary activity to the gap analysis, as directed by METC QA group.

The WPI Team completed the First Pass input of FY96 D\&D Technical Task Plan data (descriptive text) into the Morgantown Energy Technology Center (METC) Project Management System (MPMS). MPMS is used by METC for tracking and managing technical tasks, including the D\&D Focus Area Technical Tasks.

The WPI Team drafted a short paper on environmental requirements/regulations with which the D\&D Focus Area must comply. The paper describes specifics on regulatory framework, but does not provide for implementing a compliance plan.

The team reviewed the Progress Tracking System's (PTS) January data and updated the METC managed TTP and identified other reporting disparities for the rest of D\&D's TTP.

The team finalized a matrix of site $D \& D$ problems/needs vs. $D \& D$ technology development activities. Site fact sheets were drafted to provide background information. The details for the fact sheets were mainly gathered from the 1995 BEMR report. This product will be used in future accountability presentations for the D\&D program (e.g., IRB). 
The team delivered the contents of the D\&DFA Annual Report to METC for printing by the Government Printing Office. The annual report, when complete, will provide a comprehensive overview of D\&DFA activities for FY 95.

The team continued development of the D\&DFA Homepage. Included January D\&DFA Monthly data into the homepage. The D\&DFA Homepage was made available to public on the World Wide Web in March.

The WPI Team prepared the D\&DFA February Monthly Progress Report. Evaluated input data from multiple sources, technically reviewed the data, and provided appropriate input to develop the report.

The WPI Team provided technical and programmatic support for the initiation of the CReactor LSD at Hanford. Attended meetings between all three LSD representatives and METC and helped resolve funding and technology selection and demonstration issues.

The WPI Team provided technical input to the field for the request for the initiation of FY96 carryover analysis.

Staff prepared a poster for presentation at a D\&D conference to be hosted by the American Nuclear Society beginning April 15.

The WPI Team provided technical support for the development of the D\&DFA FY98 Budget briefing and associated materials.

\section{MIXED WASTE FOCUS AREA (MWFA)}

Staff members provided a quick review of the MWFA Project Management Plan (PMP) for DOE-ID (March 4 and March 5) and compiled a list of the major comments. A redlined copy of the PMP was provided to DOE-ID, documenting other, less significant comments.

The MWFA Home Page was reviewed for accurate and current technical information. Comments were provided verbally to DOE-ID.

\section{TASK C-TECHNOLOGY INTEGRATION}

The WPI Team Morgantown office provided the Focus Area support teams at all the other field locations software to run the Progress Tracking System (PTS). The Morgantown office also provided assistance in administering and analyzing the software.

Staff helped facilitate the briefing to the National Academy of Sciences on the Tanks Focus Area and remediation of the High Level Waste (HLW) tanks at Hanford. Assisted in preparing presentation materials for the Focus Area Lead. Provided follow-up to 
subcommittee requests for technical information and provided a recap of the overall presentation for transmittal to the DOE-HQ Program Manager.

Members of the team completed drafts of two papers evaluating ways of improving the electronic communication methods between EERC sites. Staff also delivered the Data Communication Reference Paper Electronic Data Interchange (Draft) White Paper for review by each of the WPI team offices. EDI software is being evaluated to see how it can assist activities under the EERC contract.

Staff began preparing for the upcoming production of the Internal Review Budget. Activities included learning and distributing software for the Activity Data Sheets (ADS) software, the Risk Data Sheets (RDS) software, and beginning work on these deliverables.

Staff researched and tracked state environmental and legislative issues of interest to the field for upcoming March-April "State Environmental Watch."

The team continued developing background information and analysis of the technical issues critical to technology implementation, and examining EM-50 implementation "success" stories to assist in writing a handbook on requirements (technical, regulatory, institutional) a Focus Area must meet to ensure its technologies are implemented.

The team completed a rough draft white paper on needs assessments conducted within the focus areas. The purpose of the paper is to communicate processes utilized by each of the focus areas and share ideas on integration and standardization activities that may add value to the focus areas' processes. Additional information was collected and contacts made for further clarifications. This information is being incorporated into the paper, and it will be distributed to WPI focus area leads for review when finalized.

Members of the WPI team completed the gap analysis of the METC QA/QC Manual and the Grumbly issue "Institutionalizing the Data Quality Objectives Process for EM's Environmental Data Collection Activities." They are compiling revision comments on the QA/QC Manual as a secondary activity to the gap analysis, as directed by METC QA group.

Team members worked with the EM-50 contract managers and crosscutting program technical support staff to develop activities that can be performed on the EERC contract to facilitate communication between the focus areas managed at field sites and the crosscutting programs managed at headquarters. Crosscutting support staff are frequently in a position of having to provide information to five or more focus area contract support staff, as both focus area staff in the field and at headquarters need them to provide information during budget and other quick response activities. It is our goal that the Gaithersburg EERC office assist the crosscutting programs in these exercises. 


\section{ATTACHMENT A}

\section{PRODUCTS DELIVERED: TASK A - TECHNOLOGY ASSESSMENT}

\section{TANKS FOCUS AREA (TFA)}

- Staff provided input to memo sent by Clyde Frank and Steve Cowan to DOE Richland, authorizing starting work on the Hanford Tank Initiative.

- Response to question asked of the TFA at the March "Big 5" meeting. "Why is characterization so important to the TFA?"

- Map of 1995 TFA dollars to the Industrial Partners was developed and used by Clyde Frank in briefing to the House of Representatives.

- White Paper "Recommendations for Collaboration between the Tank Focus Area and the Mixed Waste Focus Area

- Questions, Answers, Comments and Notes from the National Academy of Sciences Meeting at Richland WA, March 6-7, 1966

- Meeting Minutes Report: Needs Prioritization Teleconference with Site Representatives

- Comments on FY 1996 Needs Assessment

\section{LANDFILL STABILIZATION FOCUS AREA (LSFA)}

- Review of Landfill Stabilization and Contaminant Plumes Containment and Remediation Focus Area funded projects \& list of technologies to be evaluated for transfer to Mixed Waste Focus Area and CMST Crosscutting Program technology development activities.

- Review of Landfill Stabilization Focus Area December OST Business Review.

- Review of Landfill Stabilization Focus Area Program Plan

- LSFA Weekly Reports

\section{PLUMES FOCUS AREA (PFA)}

- Estimate of Remediation/Assessment Cost Savings Attributable to PFA Technologies

- Bullet Point Description of FY98 PFA Program 
- Spreadsheets detailing FY96 TTPs in the PFA

- Plumes Focus Area Weekly Reports

- Suggestions/Comments on the PFA Draft Review Procedure

DECONTAMINATION AND DECOMMISSIONING (D\&D) FOCUS AREA

- 1996 BEMR Update- D\&D Focus Area Reply

- Fernald Large-Scale Demonstration Meeting Record March 7, 1996

- Fernald Large-Scale Demonstration Meeting Record March 25, 1996

- Microspi Comparative Analysis to support Phase II decision process

MIXED WASTE FOCUS AREA (MWFA)

- Waste Forms Information

- Draft Site Regulatory Summaries

\section{PRODUCTS DELIVERED: TASK B: PROJECT ASSESSMENT}

TANKS FOCUS AREA (TFA)

- White Paper "Why Characterization is Important to the TFA"

- White Paper "How Does the Tanks Focus Area Coordinate with Other Focus Areas"

- FY96 and FY97 Technology Implementation Briefing

- Site Baselines for Appendix A of the Multi-Year Program Plan

- Technology Integration Activities for "Omega" Meeting, March 14, 1996

- Notes from CMST/TFA Technical Team Meeting on March 20, 1996

- Revision of FY96 TFA Milestones

- Trip Report from CMST Workshop on Chemical Sensors and Field Deployable Instruments 
- Report on Demonstration and Presentation on Particle Size Probe and Density Probe

- Review of Draft Report on Confined Sluicing End Effector (CSEE)

- Briefing to DOE-RL on "Omega" meeting and IFD program

- Memo and Planned FY96 TFA Demonstrations for DOE-HQ

- Review of Retrieval and Closure, TFA Management, Pretreatment, Immobilization and Characterization TFA TTPs for DOE-RL

- Final Draft of FY96 revision of the Radioactive Tank Waste Focus Area Technology Summary - Rainbow Book

\section{LANDFILL STABILIZATION FOCUS AREA (LSFA)}

- Spectrum "96 Paper - "Thermal Treatment Technology Technical Peer Review"

- Desktop Instructions for the Coding Structure Used in the TTP Program Management Tracking Tool

\section{DECONTAMINATION AND DECOMMISSIONING (D\&D) FOCLS AREA}

- D\&D Environmental Compliance One-Pager

- 1995 Milestone Reconciliation

- Forecasting Site Problems (BEMR Data)

- January D\&DFA Monthly Progress Report

- An Operating D\&DFA Internet Homage

- D\&D Focus Area poster presentation for ANS conference

MIXED WASTE FOCUS AREA (MWFA)

- Program Management Plan for the DOE-EM Mixed Waste Focus Area Review

- Confidentiality and Non-Disclosure Certification Forms and Conflict of Interest Avoidance Plan

- MWFA Monthly Report 


\section{PRODUCTS DELIVERED: TASK C - TECHNOLOGY INTEGRATION}

- Summary of Treatability Study Exemptions and R\&D Permit Requirments

- Cost Variance Analysis for LSFA and PFA Milestone Chart for LSFA \& Plumes Monthly Business Review

- Presentation of SRS Achievements, Core Competencies, and Technology

- Spreadsheets for LSFA and PFA which compare FY96 PEG and PTS Budgets with FIN Plans for January, February, and March

- Trip Report - "Clemson University Hydrogeology Symposium".

- Schedule and list of Conferences, Meetings, etc. pertaining to environmental issues. 


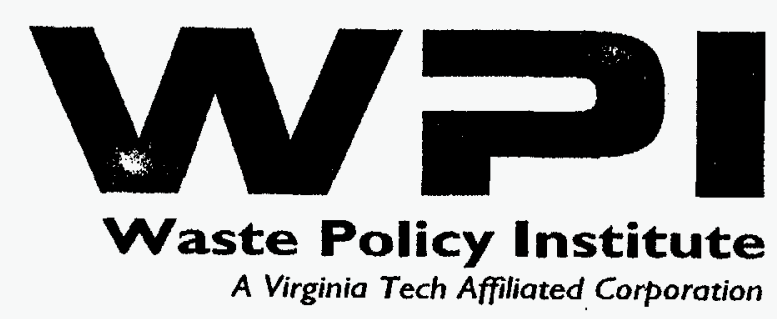

\section{MONTHLY \\ COST AND LABOR REPORT}

\section{UNIVERSITY OF NORTH DAKOTA ENERGY AND ENVIRONMENTAL RESEARCH CENTER}

Subcontract No. 359636

March, 1996 


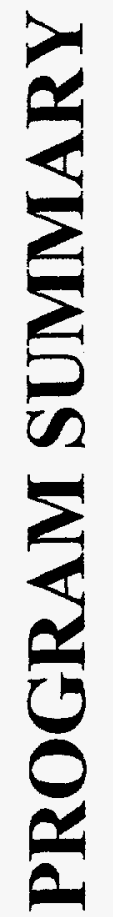


WPI Subcontract--EERC Coop. Agreement

$(\$ \times 1000)$

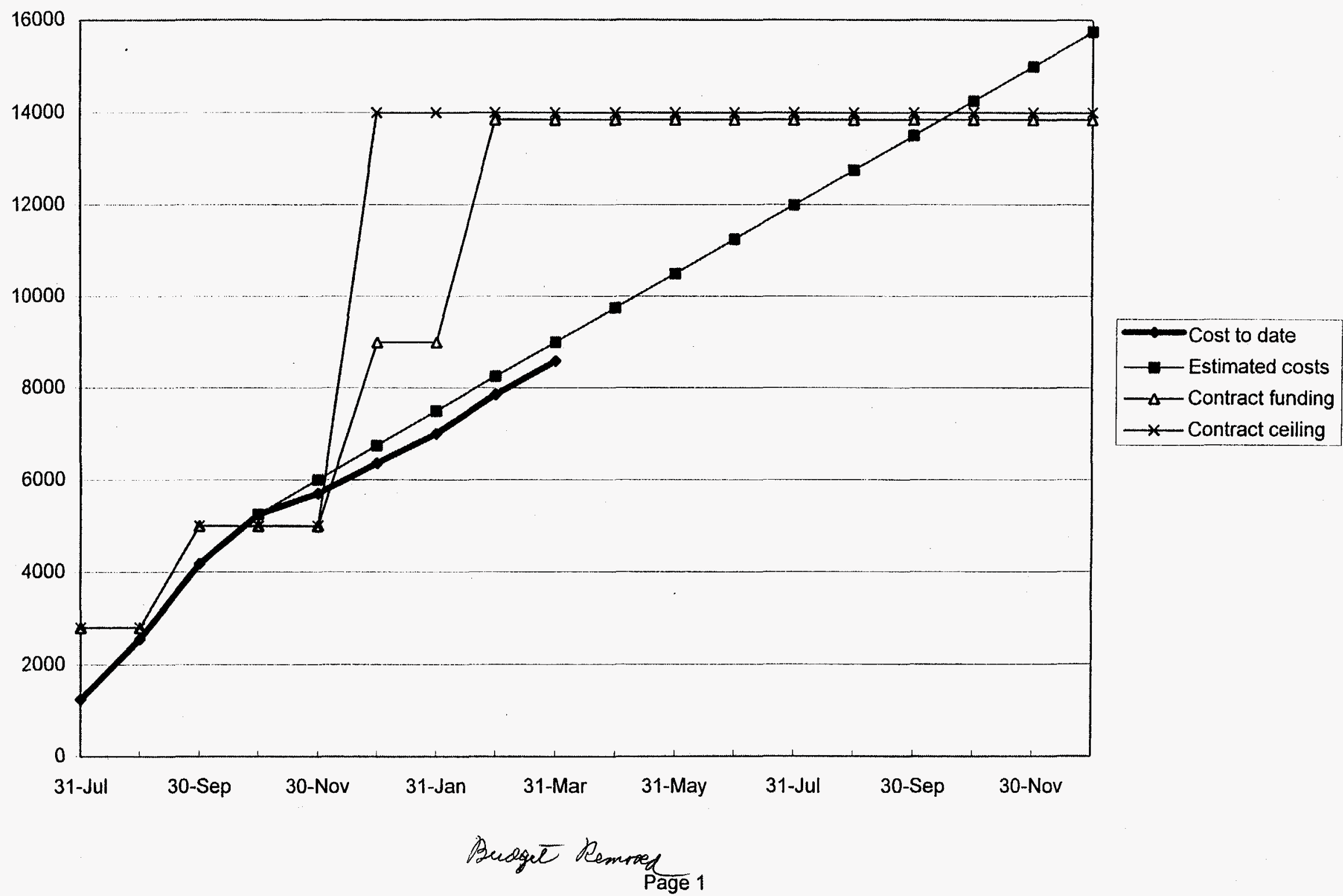




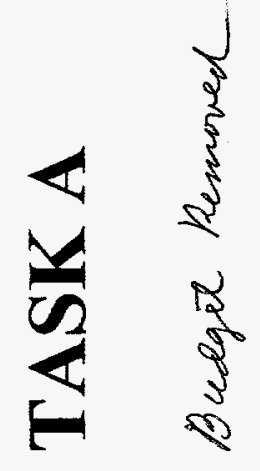




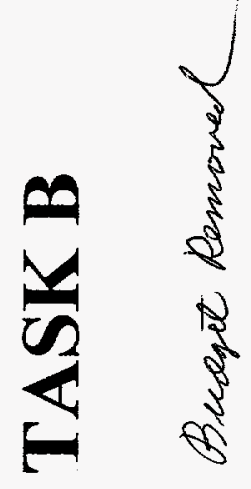


2. Program/Project Title EM Task 10-Technology Development Integraton DE-FC21-94MC31388

4. Name and Address

Energy \& Environmental Research Center University of North Dakota

PO Box 9018

Grand Forks, ND 58202-9018 (701) $777-5000$

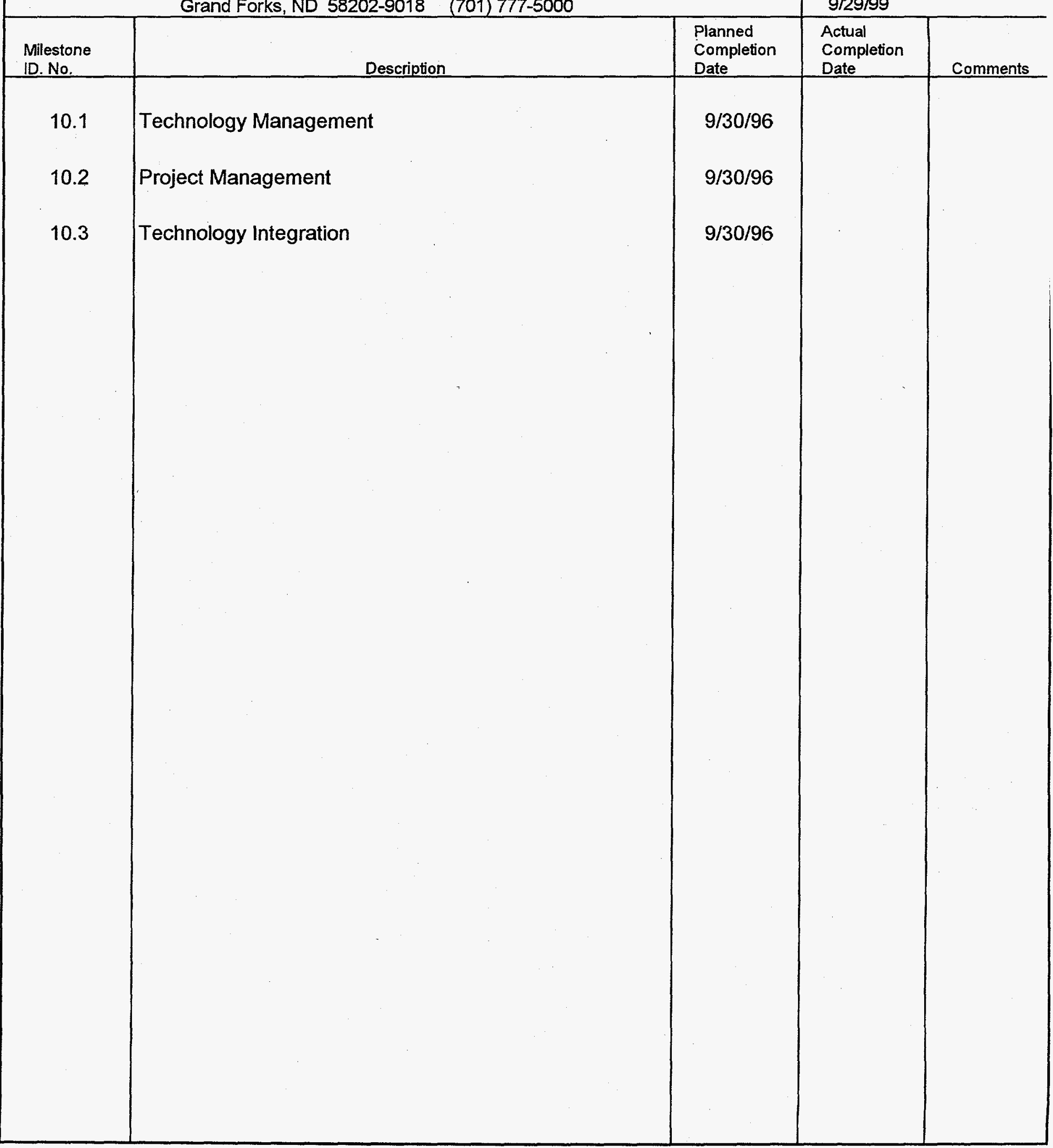

3. Reporting Period $1 / 1 / 96$ through 3/31/96

5. Program/Project Start Date 9/30/94

6. Completion Date 9/29/99 


\title{
TASK 12 - LASER CLEANING OF CONTAMINATED PAINTED SURFACES
}

\author{
Semiannual Report
}

for the period November 1, 1995, through March 31, 1996

Prepared for:

Venkat K. Venkataraman

U.S. Department of Energy

Morgantown Energy Technology Center

3610 Collins Ferry Road

PO Box 880, MS C05

Morgantown, WV 26507-0880

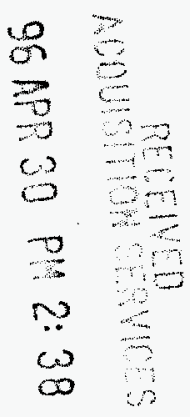

EERC-DOE Environmental Management

Cooperative Agreement No. DE-FC21-94MC31388

Prepared by:

Ames A. Grisanti

David J. Hassett

Energy \& Environmental Research Center

University of North Dakota

PO Box 9018

Grand Forks, ND 58202-9018 


\section{TABLE OF CONTENTS}

TABLE OF CONTENTS $\ldots \ldots \ldots \ldots \ldots \ldots \ldots \ldots \ldots \ldots \ldots \ldots$

1.0 INTRODUCTION $\ldots \ldots \ldots \ldots \ldots \ldots \ldots \ldots \ldots \ldots \ldots \ldots \ldots \ldots$

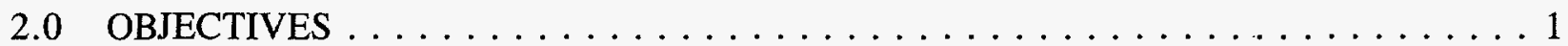

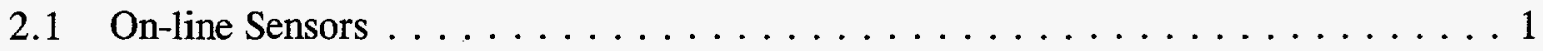

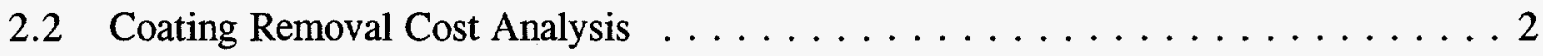

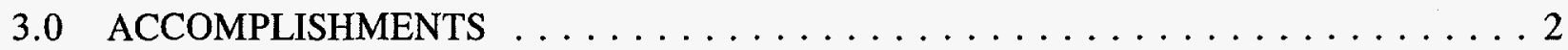

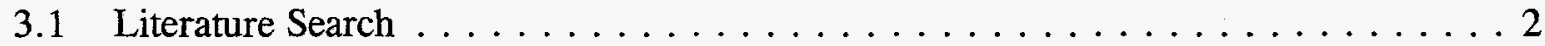

3.2 Development of On-line Sensor Specifications $\ldots \ldots \ldots \ldots \ldots \ldots \ldots \ldots \ldots$

3.2 .1 General Sensor Criteria . . . . . . . . . . . . . . . . 3

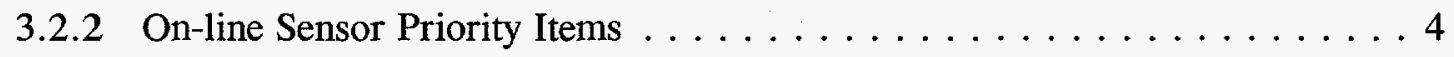

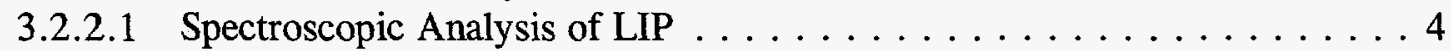

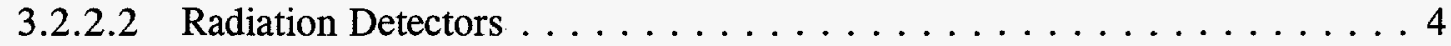

3.2.2.3 Laser-Induced Breakdown Spectroscopy $\ldots \ldots \ldots \ldots \ldots \ldots$

3.2.2.4 Inductively Coupled Plasma-Atomic Emission Spectropscopy . . . . . . . . 7

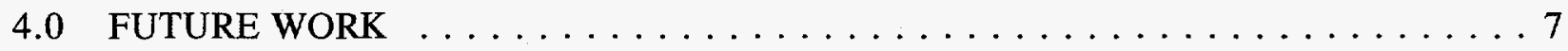

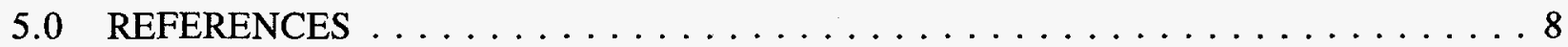

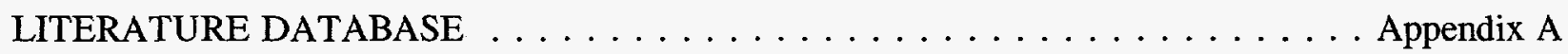




\subsection{INTRODUCTION}

Paint contaminated with radionuclides and other hazardous materials is common in U.S. Department of Energy (DOE) facilities. Facility decommissioning and decontamination (D\&D) require the removal of contaminated paint. Paint removal technologies include laser- and abrasivebased systems. F2 Associates are utilizing a pulsed-repetition $\mathrm{CO}_{2}$ laser that produces a $2.5-\mathrm{cm}-$ diameter beam that can be scanned across a $30-\times 100-\mathrm{cm}$ raster and, when placed on a robot, can be designed to clean any surface that the robot can be programmed to follow. Causing little or no damage to the substrate (concrete, steel, etc.), the laser ablates the material to be removed from a given surface; ablated material is then pulled into a filtration and collection (VAC-PAC) system to prevent the hazardous substances from entering the atmosphere. The VAC-PAC system deposits the ablated material into 23-gallon waste drums, which may be removed from the system without compromising the integrity of the seal, allowing a new drum to be set up for collection without leakage of the ablated material into the atmosphere.

\subsection{OBJECTIVES}

The overall objectives of this project are support of F2 Associates development activities for their laser-based coating removal system in the following three areas:

- On-line sensors for cleaning optimization and waste assay

- Surface-cleaning cost model for comparison of competing technologies

- Engineering design handbook for easy decontamination of equipment

The focus of the work in the first year will be on developing strategies for on-line sensors and providing preliminary work on the cost analysis model. Work on the engineering design handbook will take place in the second year.

\subsection{On-line Sensors}

There are two major objectives of adding on-line sensors to the laser surface cleaning system, both of which will reduce the cost of applying this technology. On-line sensors will be used to optimize the cleaning process by allowing a smaller number of iterations on the survey-clean cycle typically employed in the removal of contaminated coatings from floors and walls in DOE facilities. On-line sensors also offer the possibility for performing chemical analysis in-situ during removal of coatings, resulting in reduced costs of assay for the materials collected by the VAC-PAC system.

The on-line sensors under consideration will be used to ensure that coatings are removed as completely as possible and to determine whether radioactive materials have been removed with the coatings. As mentioned, a by-product of this work will be the possibility of assay of removed materials.

The goal of developing the methods necessary to in-situ measurement of inorganic species (heavy metals) and the detection of radioactive materials during D\&D of equipment will call for special attention to the measurement environment. Specification of the analytical requirements will be developed in cooperation with F2 Associates. A detailed listing of the objectives and 
specifications for the analytical methods will be prepared. From the analytical specifications, a list of applicable detection techniques will be compiled. Detection schemes will be critically evaluated in terms of overall measurement objectives. Candidate detection schemes will be selected from the list, and commercially available instrumentation will be sought for their implementation. Commercially available instruments will be evaluated in terms of the measurement objectives and specifications. Modifications to these instruments will be devised for their application to in-situ measurements. Sample-conditioning hardware will be devised if necessary, to condition the sample stream for the selected instrumentation.

\subsection{Coating Removal Cost Analysis}

The initial work to be performed on cost analysis will be limited to a survey of existing economic models available for application to D\&D operations and to the development of a plan for enhancing the existing models or for creating new algorithms. An effective model for assessing the economics of $\mathrm{D} \& \mathrm{D}$ operations can be a valuable tool for determining the optimal method of cleanup at least cost. Current models are designed for specific technologies and are not sufficiently general to be used for comparison of different technologies. The algorithm to be developed in the second year will be capable of comparing the cost and performance of many different $\mathrm{D} \& \mathrm{D}$ operations.

\subsection{ACCOMPLISHMENTS}

Work during the first two quarters has focused on understanding and definition of the measurement problem associated with application of on-line sensors to the laser-based surfacecleaning system.

\subsection{Literature Search}

To obtain background on spectroscopic analysis of laser-induced plasmas and radiation detectors, a literature search was done, and pertinent publications have been identified. A list of the literature database used in this project is given in Appendix A.

\subsection{Development of On-line Sensor Specifications}

A meeting was held between F2 Associates and EERC personnel at the F2 facility in Albuquerque, New Mexico. The purpose of this meeting was to develop a detailed description of the measurement objectives, determine what priority F2 Associates places on various sensor applications, and discuss possible solutions. As a result of this meeting we have compiled the following list of applicable technologies:

- Residual gas analyzer (RGA) - DOE has supplied F2 with a RGA for application to analysis of the effluent to the VAC-PAC. Two sampling points are currently in the system, one just after the scanner and one just prior to the VAC-PAC. The RGA is expected to provide analysis of organics in the stream going from the scanner to the VAC-PAC. 
- Radiation detection - Radiation detection will be used to optimize surface cleaning, aid in detection of migration of radionuclides from the coating to the underlying surface, and provide information for waste assay.

- Laser-induced plasma analysis (LIP) - To investigate the applicability of spectroscopic analysis of the LIP generated by the laser ablation process, it is planned to employ research-grade equipment for the initial tests. This will serve to identify usable spectral lines for lead, uranium, and plutonium to be used in monitoring cleaning efficiency.

- Laser-induced breakdown spectroscopy (LIBS) - LIBS detects analytes in the same way as the LIP analysis above. LIBS uses its own source of atomic excitation in the form of a laser.

- Inductively coupled plasma-atomic emission spectroscopy (ICP-AES) - ICP-ACS analysis of the ablated material may be applied to the aerosol transmitted from the scanner head to the VAC-PAC.

- Molecular spectroscopy for organic analysis - Some painted surfaces may be contaminated with polychlorinated biphenyls (PCBs) or other organic compounds; thus a need exists for molecular spectroscopy to detect the formation of partial combustion products. Organic species may be analyzed by Fourier transform infrared spectroscopy (FT-IR) to provide information for assay of the waste generated during the cleaning process. Another potential use for FT-IR is monitoring water vapor in the gas stream. This is important for use of the laser cleaning system in high-humidity environments, since oxidation of radionuclides can cause plugging of the filters on the VAC-PAC.

\subsubsection{General Sensor Criteria}

The ICP-AES, FT-IR, and other analyses that are applicable to the particle-laden gas stream will be applied at both ends of the waste stream transfer tube between the scanner and the VAC-PAC. The objective is to provide as complete an analysis of the contents of the waste drum as possible. The following items will be considered in any application of sensors to the laser cleaning system:

- Region around the LIP has high electromagnetic radiation, which may interfere with electronics.

- Region around the scanner nozzle has a high gas flow (vacuum, $\sim 500 \mathrm{cfm}$ ).

- Particle size in the sample stream will vary.

- The entire system may be operated in high-humidity environments.

- Try to use off-the-shelf instruments and components.

- Keep cost to a minimum.

- Maximize efficiency of the cleaning process. 


\subsubsection{On-line Sensor Priority Items}

F2 and the EERC have identified two focus areas for the necessary sensors: spectroscopic analysis of the LIP and radiation detection. Spectroscopic analysis of the LIP will be used to optimize the surface cleaning and to provide information for waste assay. Radiation detection will be used to optimize surface cleaning, aid in detection of migration of radionuclides from the coating to the underlying surface, and provide information for waste assay.

\subsubsection{Spectroscopic Analysis of LIP}

F2 Associates has an agreement with Dr. David Cremers of Los Alamos National Laboratory (LANL) to work with him on the initial LIP spectroscopic analysis tests. Dr. Cremers has obtained internal funding from LANL for the initial suite of tests to identify usable spectral lines for monitoring cleaning of lead-based paint from concrete. The initial tests will be carried out at the F2 Associates laboratory using lead-based paint without contamination by radionuclides. During this testing, a side-by-side comparison may be done between the research-grade instrumentation and a lead-monitoring system developed by Physical Sciences Incorporated (PSI) for air-monitoring applications. The objective here will be to identify the best spectral lines for lead and to provide a preliminary evaluation of the PSI unit. EERC involvement in these tests will be to set up airmonitoring equipment for collection of emissions from the laser cleaning system. The EERC will monitor for metals and organic compounds to determine the level of fugitive emissions from the tests. This data will be useful to determine the requirements for worker protection in areas where the laser cleaning equipment is operated.

\subsubsection{Radiation Detectors}

Real-time detection of radiation during removal of contaminated coatings from floors has proven to be technically feasible when scabbling is applied [1]. This concept may also be applied to radiation monitoring during laser-based coating removal.

The idea is to equip the scanner head for the laser cleaning system with two radiation detectors, which will function as pre- and postcleaning detectors to monitor the efficiency of the cleaning process, thus reducing the need for repeated survey-clean cycles. The radiation detectors employed will be standard off-the-shelf detectors equipped with the appropriate radiation monitor. The radiation monitor will provide signal conditioning to the detector signals, enabling the data to be passed to the laser cleaning system master control computer. The radiation detector data will be used as feedback to the scanner to optimize surface cleaning. The application will be demonstrated by using standard radiation sources embedded in concrete coupons. The scanner control algorithm will be developed by moving the scanner head across the concrete coupon without the laser operating to determine whether the temporal response of the radiation detectors will be adequate for the laser cleaning operation. The algorithm will be adjusted to optimize the rate of cleaning while still getting meaningful signals from the radiation detectors.

Various means of radiation detection are being examined to determine their applicability to the laser cleaning system. The types of detectors under consideration are as follows: 
- Gas proportional counters

- Long-range alpha detectors

- Surface-barrier detectors

- Phoswitch scintillation detectors

The two technologies that offer the most promise for radiation detection on the laser cleaning system are gas proportional counters and phoswitch detectors. Gas proportional counters have been applied with scabbling at a DOE facility for on-line sensing of radiation during floor cleaning operations. This application has shown that gas proportional counters are sensitive, rugged, and generally reliable enough for application to on-line monitoring.

Recently, phoswitch detectors have been applied to work at LANL in an automated system used to separate low-level mixed wastes. Phoswitch detectors are scintillation detectors made up in this case of NaI/CsI layers that produce light detectable by a photomultiplier tube. New signal conditioning electronics developed at LANL have greatly reduced the size and complexity of the support electronics needed to apply phoswitch detectors. Additionally, these detectors can be gated on submicrosecond scales, can acquire data at high speed, and can be built to minimize the effects of background radiation sources (cosmic events, environmental background radiation, etc.). All these attributes make phoswitch detectors very attractive for application with the laser cleaning system.

\subsubsection{Laser-Induced Breakdown Spectroscopy}

LIBS is a useful analytical tool for the determination of many elements. In this technique, a laser pulse is focused on a target of interest where the analyte is vaporized and a plasma is formed. Spectral and temporal isolation of plasma emission can be used for the determination of elements of interest in the target material. Light emitted from the laser spark can be measured in the 180- to $600-\mathrm{nm}$ range for the determination of a number of elements. This technique is useful for the determination of analytes of interest in solids, liquids, and gases. In the high-temperature plasma, material is broken down to elemental form and emits light. LIBS has recently been applied to direct determination of lead in paint [2]. LIBS can be done over optical fibers, allowing remote location of the laser, spectrograph and associated support electronics. Complete portable LIBS systems have been demonstrated for field applications [3]. For these reasons, LIBS offers an attractive means to monitor paint removal using laser-based or other technologies. In the case of the laser cleaning system, one might employ a monitoring scheme such as that suggested for the radiation detectors in Section 3.2.2.2.

The idea is to use pre- and postcleaning sampling by optical fibers for LIBS of the surface before and after cleaning. The two sampling points may be multiplexed to a single LIBS spectrometer using fiber optics. The system would be designed to alternately sample before or after cleaning during operation of the laser cleaning system. The possible drawback to this approach as compared to the LIP analysis above is the additional cost of the laser and associated hardware in the LIBS system. The costs for the spectroscopic systems for both LIBS and emission spectroscopy of the LIP should be comparable, since essentially the same hardware is required for both. In the case of LIBS however, additional equipment (laser, power supply, etc.) will be required to provide the excitation for the atomic emissions, whereas the LIP is created by the laser cleaning process so no additional laser hardware is needed. Addition of the laser for LIBS results in added cost for the 
system, but the additional cost is small ( $\sim \$ 10 \mathrm{~K}$ ) compared to the cost of the entire laser cleaning apparatus. An advantage of employing LIBS rather than direct spectroscopic analysis of the LIP from the cleaning process is that the spectrum obtained from LIBS may be less complicated (contain lower continuum emissions, reduced number of ionized states, lower-temperature plasma, etc.) allowing simplified spectral interpretation.

A practical LIBS system consists of three sub-components:

- Laser - A source of excitation energy, the laser, which for most of the small portable or lab instruments is a solid-state laser, usually a Nd:YAG laser although any laser source of sufficient intensity and suitable wavelength could be used.

Recent developments in miniature solid-state lasers have led to the availability of instruments that require only a 115-volt AC source. Prior to the development of these miniature devices, $\mathrm{Nd}$ :YAG lasers normally required a circulating cooler as well as a power supply, which was usually bulky and often required 220 volts for operation. Compact benchtop Nd:YAG lasers operating with a nominal power range of from 15 to $50 \mathrm{~mJ}$ and a repetition rate of between 10 and $20 \mathrm{~Hz}$ are now readily available. These lasers emit a strong line at $1064 \mathrm{~nm}$, although weaker lines are available at 266,355 , and $532 \mathrm{~nm}$. Usually only the 1064 line is used because of possible spectral interferences at the lower-wavelength emission lines. If a time-resolved measurement system is employed, measurement of emission radiation is made between laser pulses, thus laser radiation is not a problem.

- Transfer optics - A method for delivery of energy to the sample, which can consist of normal optical components such as lenses and mirrors or can be fiber optic systems using quartz fibers to transmit light in the UV range down to $180 \mathrm{~nm}$ and can incorporate graded index lenses.

Although conventional optics based on lenses and mirrors can be used, the availability of relatively efficient fiber optic components has led to the development of numerous systems and instrument configurations based on optical fibers for delivery of the excitation pulse as well as collection of the emission signal. Besides offering flexibility in delivering laser light and collection of the emission signal, fiber optics, for the most part, eliminate the need for difficult-to-align optical components that can easily become misaligned if instruments are moved or bumped. Numerous fiber configurations have been employed, ranging from single fibers to bifurcated or formatted fiber bundles. Fiber bundles incorporating formatting from circular delivery of excitation energy and collection of emission energy to a line configuration for delivery of excitation energy to the slit of a monochromator or spectrograph offer increased efficiency and greatly simplify the optics required. Normally either conventional or graded index lenses are used for both delivery and collection of light as well as for coupling the fiber optics to the laser.

- Spectrometer - A means of collecting and measuring of emission energy at the wavelengths of interest. Normally this is a spectroscope or monochrometer employing either single-wavelength detection or multichannel measurement capability.

Measurement of excitation energy can be accomplished using systems based on optical filters, monochromators, and spectrographs. Monochromators normally use a photodiode or 
photomultiplier tube (PMT) for detection of emission light at a single wavelength. Spectrographs can be configured for multichannel detection using either a photodiode array (PDA) or chargecoupled device (CCD). The various configurations are determined by need and budget, with the cost of a monochromator and PMT system falling at the low end $(\$ 3000$ to $\$ 5000)$ and spectrographs fitted with CCDs costing considerably more, ranging from $\$ 11,000$ to over $\$ 55,000$. A spectrograph with a CCD can offer high-speed multichannel detection and over 100 times the sensitivity of a PDA, thus allowing for simultaneous measurement of multiple elements with background correction. A multichannel instrument also provides the option for simultaneous laser diagnostics as measurements are being made. A monochromator with PMT detection offers comparable sensitivity while sacrificing multichannel detection, which may be adequate for detection of select elements or some research applications; however, detection at a single wavelength precludes the use of simultaneous background correction, which can be important in the measurement of emission radiation in the presence of multiple emission lines as well as scattered continuum radiation. The signal from a PMT or photodiode detector can be processed either through an oscilloscope or boxcar averager. Multichannel systems employing a PDA or CCD are normally coupled to a computerized data-handling station.

The subcomponent choices making up a working analytical system depend on considerations of necessary capability, flexibility, and cost. Single-wavelength systems are generally less expensive than multichannel systems, but can lack capabilities, including background correction, which is necessary for practical measurement in complex samples encountered in real applications.

\subsubsection{Inductively Coupled Plasma-Atomic Emission Spectropscopy}

Inductively coupled argon plasma (ICAP) spectroscopy is a commonly used analytical tool for the determination of numerous elements in environmental samples. It may be possible to apply ICAP or an analogous plasma emission technique such as microwave-induced plasma (MIP) spectroscopy for the analysis of aerosol, transmitted from the scanner head to an analytical system. The sample will be transported as an aerosol with air as the carrier gas. Since the introduction of air into a conventional ICAP would normally extinguish the plasma, either a modified system or limited-volume sample introduction will likely be required. Air plasma spectrometers are in the development stage and would be ideal for this application. If a conventional ICAP is to be used, it will be necessary to determine what sample volume of air will be acceptable and from this determine what implications this has with respect to detection limits.

\subsection{FUTURE WORK}

Work will continue to evaluate the applicability of radiation detection and spectroscopic analysis to the laser cleaning system. A recommended set of equipment, along with the analytical methods will be compiled.

The preliminary cost analysis will be initiated during the third quarter of this project and will be completed by the end of the contract.

Modifications to the project plan are being considered to expand the current work to include one of the following activities: 
- Initial work on the equipment design handbook that was scheduled to take place in Year-2.

- Construction of a LIBS spectrometer

- Expanded work on the cost comparison between laser cleaning and other coating removal techniques.

The expanded program is being considered as a result of suggestions by $\mathrm{F} 2$ Associates. F2 Associates and the EERC feel that work in these areas will benefit not only the laser cleaning project but also competing coating removal techniques, as well as other D\&D activities.

\subsection{REFERENCES}

1. "Feasibility Test of Real-Time Radiation Monitoring During Removal of Surface Contamination from Concrete Floors," 12584-236, pp. 1-12, 1995, U.S. Department of Energy.

2. Marquardt, B.J.; Goode, S.R.; Angel, S.M. "In Situ Determination of Lead in Paint by LaserInduced Breakdown Spectroscopy Using a Fiber-Optic Probe," Analytical Chemistry 1996, 96, 977-981.

3. Yamamoto, K.Y.; Cremers, D.A.; Ferris, M.J.; Foster, L.E: "Detection of Metals in the Environment Using a Portable Laser-Induced Breakdown Spectroscopy Instrument, " Applied Spectroscopy 1996, 50 (2), 222-232. 
APPENDIX A

LITERATURE DATABASE 


\section{LITERATURE DATABASE}

1. DeOliveira, W.A.; Matias, F.A.A.; Moschim, E. "A Comparison of Detectors for Portable Optical Sensors," IEEE Transactions on Instrumentation and Measurement 1996, 45, 326-328.

2. Fernandez, A.; Mao, X.L.; Shannon, M.A.; Russo, R.E. "Correlation of Spectral Emission Intensity in the Inductively Coupled Plasma and Laser-Induced Plasma During Laser Ablation of Solid Samples," Analytical Chemistry 1996, 67 (14), 2444-2450.

3. Kaelin, A.B. "Properly Engineer Lead Paint Removal Projects," Chemical Engineering Progress 1996, 50-55.

4. Marquardt, B.J.; Goode, S.R.; Angel, S.M. "In Situ Determination of Lead in Paint by Laser-Induced Breakdown Spectroscopy Using a Fiber-Optic Probe," Analytical Chemistry 1996, 96, 977-981.

5. Sanford, C.L.; Thomas, S. E.; Jones, B.T. "Portable, Battery-Powered, Tungsten Coil Atomic Absorption Spectrometer for Lead Determinations," Applied Spectroscopy 1996, 50, 174-181.

6. Yamamoto, K.Y.; Cremers, D.A.; Ferris, M.J.; Foster, L.E. "Detection of Metals in the Environment Using a Portable Laser-Induced Breakdown Spectroscopy Instrument," Applied Spectroscopy 1996, 50 (2), 222-232.

7. U.S. Department of Energy. "Feasibility Test of Real-Time Radiation Monitoring During Removal of Surface Contamination from Concrete Floors," DOE 12584-236; 1995, pp 1-12

8. Baird, W.; Nogar, N. S. "Compact, Self-Contained Optical Spectrometer," Applied Spectroscopy 1995, 49, 1699-1704.

9. Baldwin, D.P.; Zamzow, D.S.; D'Silva, A.P. "Detection Limits for Hazardous and Radioactive Elements in Airborne Aerosols Using Inductively Coupled Air Plasma- Atomic Emission Spectrometry," J. Air \& Waste Manage. Assoc. 1995, 45, 789-791.

10. Bounds, J.A. "Technology Information Profile: Long-Range Alpha Detector (LRAD)," U.S. Department of Energy DE95006448; 1995, NM.

11. Cromwell, E.F.; Arrowsmith, P. "Fractionation Effects in Laser Ablation Inductively Coupled Plasma Mass Spectrometry,” Applied Spectroscopy 1995, 49,1652-1660.

12. Geohegan, D.B.; Puretzky, A.A. "Laser Ablation Plume Thermalization Dynamics in Background Gases Studied by Time-Resolved Imaging, Spectroscopic, and Ion Probe Diagnostics," U.S. Department of Energy DE95010277; 1995, San Jose, CA. 
13. Gonzalez, A.; Ortiz, M.; Campos, J. "Determination of Sulfur Content in Steel by LaserProduced Plasma Atomic Emission Spectroscopy," Applied Spectroscopy 1995, 49, 1632-1635.

14. Helmig, D.; Vierling, L. "Water Adsorption Capacity of the Solid Adsorbents Tenax TA, Tenax GR, Carbotrap, Carbotrap C, Carbosieve SIII, and Carboxen 569 and Water Management Techniques for the Atmospheric Sampling of Volatile Organic Trace Gases," Analytical Chemistry 1995, 67, 4380-4386.

15. Hofstetter, K.J.; Hayes, D.W.; Eakle, R. F. "Portable Radiation Detector and Mapping System,” U.S. Department of Energy DE95017475; 1995, Aiken, SC.

16. Jing, T. "High Spatial Resolution Radiation Detectors Based on Hydrogenated Amorphous Silicon and Scintillator," U.S. Department of Energy DE95016441; 1995, CA.

17. Johnson, J.D.; Bond, A.W.; Bounds, J.A.; Hanson, S.W.; MacArthur, D.W.; Moss, W.D.; Rawool-Sullivan, M.W.; Sprouse, L.L. "A Real-Time Alpha Monitoring System for Radioactive Liquid Waste," U.S. Department of Energy DE95006286; 1995, NM.

18. Knobloch, T.; Engewalk, W. "Sampling and Gas Chromatographic Analysis of Volatile Organic Compounds in Hot and Extremely Humid Emissions," J. High Res Chromatography 1995, 18, 635-642.

19. MacArthur, D. "Alpha Detection for Decontamination and Decommissioning: Results and Possibilities," U.S. Department of Energy DE95016792; 1995, NM.

20. McClenny, W.A.; Oliver, K.D.; Daughtrey, E.H., Jr. "Analysis of VOCs in Ambient Air Using Multisorbent Packings for VOC Accumulation and Sample Drying," J. Air \& Waste Manage. Assoc. 1995, 45, 792-800.

21. Reed, S.E.; Berthold, J.W. "Lightguide-Coupled Sensor for In-Situ Radiation Monitoring," U.S. Department of Energy DE95012313; 1995, Alliance, OH.

22. Reisch, M.S. "Paints and Coatings," $C \& E N$ 1995, 30-31.

23. Russo, R.E. "Laser Ablation," Applied Spectroscopy 1995, 49 (9), 14A-28A.

24. Russo, R.E.; Mao, X.L.; Chan, W.T.; Bryant, M.F.; Kinard, W.F. "Laser Ablation Sampling with Inductively Coupled Plasma Atomic Emission Spectrometry for the Analysis of Prototypical Glasses," J. Analytical Atomic Spectrometry 1995, 10, 295-301. 
25. Shannon, M.A.; Mao, X.L.; Fernandez, A.; Chan, W.; Russo, R.E. "Laser Ablation Mass Removal Versus Incident Power Density During Solid Sampling for Inductively Coupled Plasma Atomic Emission Spectroscopy," Analytical Chemistry 1995, 67 (24), 4522-4529.

26. Ward, P.P.; Dybwad, G.L. "Plasma Technology Directory," U.S. Department of Energy DE95011577; 1995, Albuquerque, NM.

27. Ward, P P. "Automated Plasma Control with Optical Emission Spectroscopy," U.S. Department of Energy DE95016753; 1995, Albuquerque, NM.

28. "Position Paper-Continuous Air Monitor (CAM) Acquisition Recommendation," U.S. Department of Energy DE95006598; 1995, Richland, WA.

29. Barnett, J.M.; Kane, J E. "Radioactive Check Sources for Alpha and Beta Sensitive Radiological Instrumentation," U.S. Department of Energy DE94016477; 1994, Richland, WA.

30. Bolton, R.D. "Radon Monitoring Using Long-Range Alpha Detector-Based Technology," U.S. Department of Energy DE95002729; 1994, NM.

31. Bounds, J.A.; Bolton, R.B.; Garner, S.E.; Johnson, J.D.; Johnson, J.P.; MacArthur, D.W.; Sprouse, L.L; Walters, S.G.; Allander, K.S. "Practical Alpha Detectors for Site Characterization," U.S. Department of Energy DE94016292; 1994, NM.

32. Caress, R.W.; Allander, K.S.; Bounds, J.A.; Catlett, M.M.; Garner, S.E.; Johnson, J.D.; Johnson, J.P.; Rutherford, D.A.; MacArthur, D.W. "LRAD-Based Airflow Monitors," U.S. Department of Energy DE94007727; 1994, NM.

33. Johnson, J.P.; Allander, K.S.; Arnone, G.; Bolton, R.D.; Garner, S.E.; MacArthur, D.W.; Sprouse, L.L ; Walters, S.G. "Design Advances in Long-Range Alpha Detection," U.S. Department of Energy DE94012901; 1994, NM.

34. Koster, J.E.; Johnson, J.P.; MacArthur, D.W.; Walters, S.G. “Alpha Detection as a Probe for Counter Proliferation," U.S. Department of Energy DE94014435; 1994, NM.

35. Lin, Z.; Booksh, K.S.; Burgess, L.W.; Kowalski, B.R. "Second-Order Fiber Optic Heavy Metal Sensor Employing Second-Order Tensorial Calibration," Analytical Chemistry 1994, $66,2552-2560$.

36. MacArthur, D.W.; Allander, K.S.; Bolton, R.D.; Koster; J.; Rawool-Sullivan, M.; Rojas, S.; Sprouse, L. "Alpha Detection for Characterization of D\&D Site," U.S. Department of Energy DE95002730; 1994, NM. 
37. Mason, C F.V.; Allander, K.S.; Bounds, J.A.; Garner, S.E. "The Use of the Long-Range Alpha Detector (LRAD) for Alpha Emission Surveys at Active and Inactive Firing Sites," U.S. Department of Energy DE94007526; 1994, NM.

38. Meyer, K E.; Gammage, R.B.; Dudney, C S. "Field Demonstrations of Passive Detectors for Screening of Alpha Contaminated Soils," U.S. Department of Energy DE94011467; 1994, TN.

39. Monts, D.L.; Bauman, L.E.; Lengel, R.K.; Wang, W.; Lin, J.; Cook, R.L.; Shepard, W.S. "Use of Emission Spectroscopy as a Tool for Optimization of Plasma Hearth Operation for Hazardous Waste Thermal Treatment," U.S. Department of Energy DE95006479; 1994, DOE.

40. Rawool-Sullivan, M.W.; Allander, K.S.; Bounds, J.A.; Koster, J.E.; MacArthur, D.W.; Sprouse, L.L.; Stout, D.; Vaccarella, J.A.; Vu, T.Q. "Field Study of Alpha Characterization of a D\&D Site Using Long-Range Alpha Detectors," U.S. Department of Energy DE95002731; 1994, NM.

41. Tsai, C.C.; Nelson, W.D.; Haselton, H.H; .Schechter, D.E.; Thompson, L.M.; Campbell, V.B.; Glover, A.L.; Googin, J.M. "Plasma Surface Cleaning in a Microwave Plasma Source,".U.S. Department of Energy DE94009837; 1994.

42. Vu, T.Q.; Bolton, R.D.; Bounds, J.A.; Garner, S.E.; Johnson, J.D.; Johnson, J P.; MacArthur, D.W.; Allander, K.S. "Applications of the Long-Range Alpha Detector for SiteCharacterization Technology," U.S. Department of Energy DE94006147; 1994, NM.

43. Bhattacharjie, A.; Quam, W. "New Radiation Detectors for Field Measurements," U.S. Department of Energy DE94013565; 1993, Goleta,CA.

44. Boulmer-Leborgne, C.; Hermann, J.; Dubreuil, B. "Plasma Formation Resulting from the Interaction of a Laser Beam with a Solid Metal Target in an Ambient Gas," Plasma Sources Sci. Technol. 1993, 2, 219-226.

45. Darke, S.A.; Tyson, J.F. "Interaction of Laser Radiation with Solid Materials and Its Significance to Analytical Spectrometry," J. Analytical Atomic Spectrometry 1993, 8, 145-209.

46. Hareland, W.A.; Buss, R. "Optical Diagnostic Instrument for Monitoring Etch Uniformity During Plasma Etching of Polysilicon in a Chlorine-Helium Plasma," U.S. Department of Energy DE93019582; 1993, pp 3-14, Albuquerque,NM.

47. Hofstetter, K.J. "Gamma Radiation Detector," U.S. Department of Energy DE95009952; 1993, Aiken, SC. 
48. Johnson, J.D.; Bounds, J.A.; Garner, S.E.; Johnson, J.P.; MacArthur, D.W.; Allander, K. S. "Long-Range Alpha Detector (LRAD) Sensitivity to Beta Contamination and Soil Moisture," U.S. Department of Energy DE94003972; 1993, NM.

49. Johnson, M.L. "Evaluation of the Eberline TCM-2 Tool Contamination Monitor," U.S. Department of Energy DE94003142; 1993, Richland, WA.

50. Moenke-Blankenburg, L. "Laser-ICP-Spectrometry," Spectrochimica Acta 1993, 15, 1-37.

51. Sigg, R.A. “Apparatus and Method for Detecting Gamma Radiation," U.S. Department of Energy DE95015047; 1993, Aiken, SC.

52. Lee, Y.I.; Sawan, S.P.; Thiem, T.L.; Teng, Y.Y.; Sneddon, J. "Interaction of a Laser Beam with Metals. Part II: Space-Resolved Studies of Laser-Ablated Plasma Emission," Applied Spectroscopy 1992, 46, 436-441.

53. Majidi, V.; Joseph, M.R. "Spectroscopic Applications of Laser-Induced Plasmas," Critical Reviews in Analytical Chemistry 1992, 23, 143-162.

54. Odell, D.M.C. “Audible Radiation Monitor,” U.S. Department of Energy DE94007336; 1992, Aiken, SC.

55. Chan, W.T.; Russo, R.E. "Study of Laser-Material Interactions Using Inductively Coupled Plasma-Atomic Emission Spectrometry,” Spectrochimica Acta 1991, 46B, 1471-1486.

56. Grant, K.J.; Paul, G.L.; O'Neill, J.A. "Quantitative Elemental Analysis of Iron Ore by Laser-Induced Breakdown Spectroscopy," Applied Spectroscopy 1991, 45, 701-705.

57. Olesik, J.W.; Fister, J.C. III "Incompletely Desolvated Droplets in Argon Inductively Couple Plasmas: Their Number, Original Size and Effect on Emission Intensities," Spectrochimica Acta 1991, 46B, 851-868.

58. Grant, K.J.; Paul, G.L.; O'Neill, J.A. “Time-Resolved Laser-Induced Breakdown Spectroscopy of Iron Ore," Applied Spectroscopy 1990, 44, 1711-1714.

59. Richner, P.; Borer, M.W.; Brushwyler, K.R.; Hieftje, G.M. "Comparison of Different Excitation Sources and Normalization Techniques in Laser-Ablation AES Using a Photodiode-Based Spectrometer," Applied Spectroscopy 1990, 44, 1290-1296.

60. American National Standards Institute. "Occupational Airborne Radioactivity Monitoring Instrumentation," In American National Standard Performance Specifications for Health Physics Instrumentation; 1989, Vol. ANSI N42.17B-1989, pp 7-28.

61. Leis, F.; Sdorra, W.; Ko, J.B.; Niemax, K. "Basic Investigations for Laser Microanalysis: I. Optical Emission Spectrometry of Laser-Produced Sample Plumes," Mikrochimica Acta $1989, I I, 185-199$. 
62. Radziemski, L.J.; Cremers, D.A. "Spectrochemical Analysis Using Laser Plasma Excitation," In Laser-Induced Plasmas and Applications; Radziemski, L.J.; Cremers, D. A., Eds.; Marcel Dekker, Inc.: New York, 1989; pp 295-325.

63. Wachter, J.R.; Cremers, D.A. "Determination of Uranium in Solution Using Laser-Induced Breakdown Spectroscopy," Applied Spectroscopy 1987, 41, 1042-1048.

64. Cremers, D.A.; Radziemski, L J.; Loree, T. R. "Spectrochemical Analysis of Liquids Using the Laser Spark," Applied Spectroscopy 1984, 38 (5), 721-729.

65. American National Standards Institute. American National Standard Radiation Protection Instrumentation Test and Calibration; 1977, Vol. ANSI N323-1978, pp 9-23.

66. Beverly, R.E., III; Walters, C.T. "Measurement of $\mathrm{CO}_{2}$-Laser-Induced Shock Pressures Above and Below LSD-Wave Thresholds," J. Appl. Phys. 1976, 47, 3485-3495. 


\section{Program/Project Identification No. DE-FC21-94MC31388 \\ 2. Program/Project Title \\ EM Task 12-Laser Cleaning of Contaminated Painted Surfaces}

4. Name and Address Energy \& Environmental Research Center University of North Dakota

PO Box 9018, Grand Forks, ND 58202-9018

(701) $777-5000$
3. Reporting Period

1-1-96 through 3-31-96

5. Program/Project Start Date 9-30-94

6. Completion Date 9-29-99

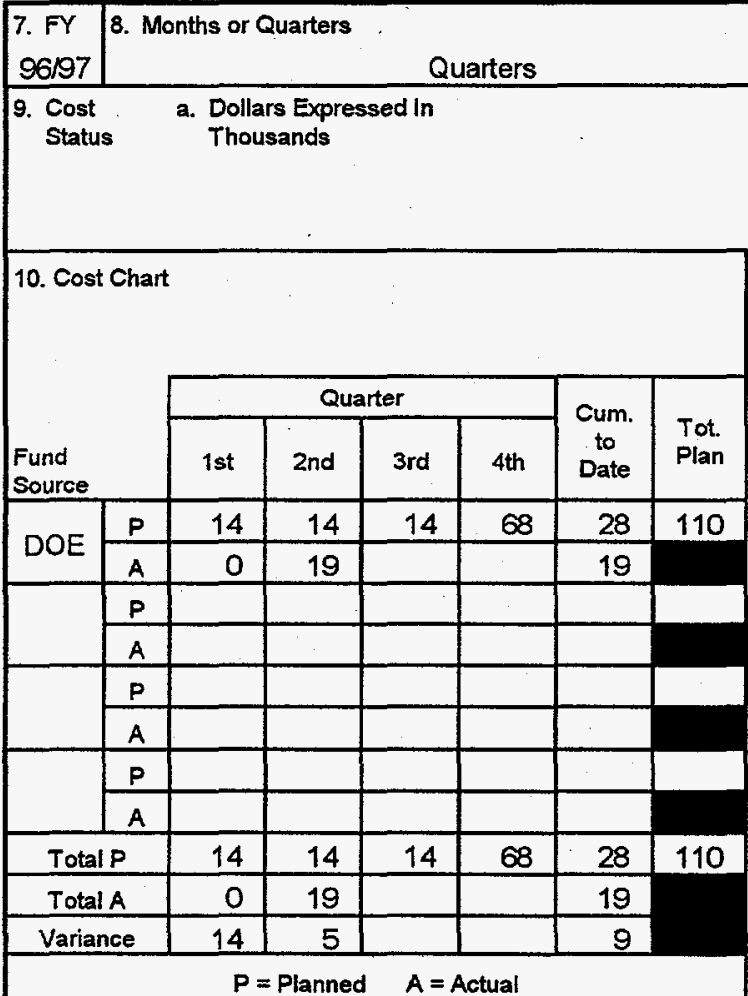

Total Planned Costs for Program/Project

$\$ 110$ b. Dollar Scale
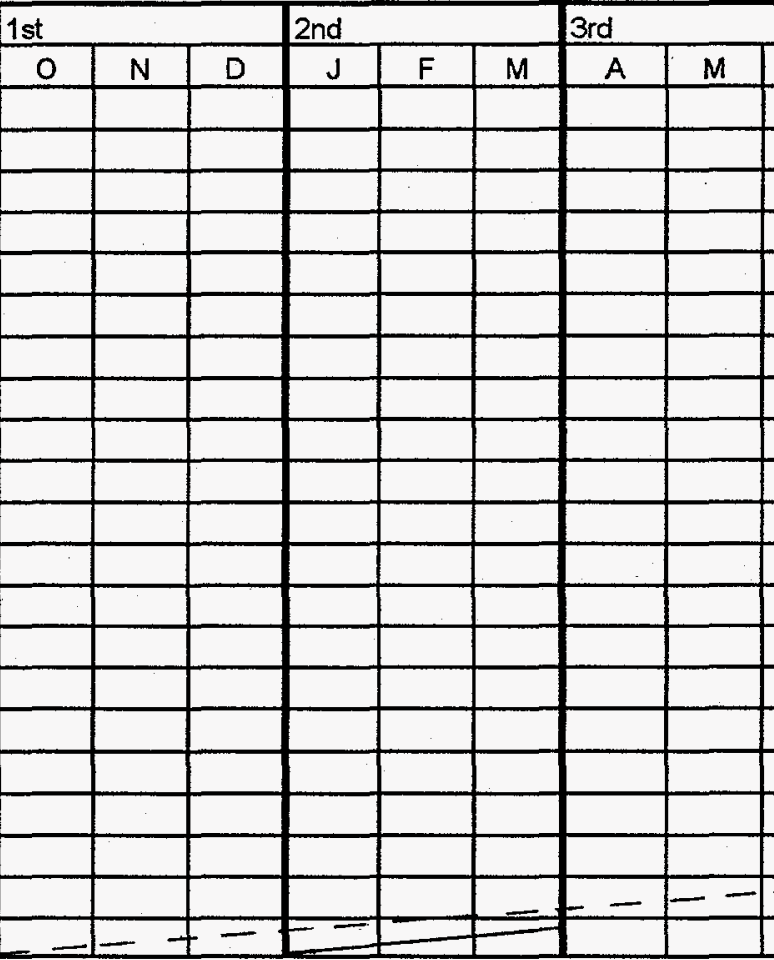

\section{4th}

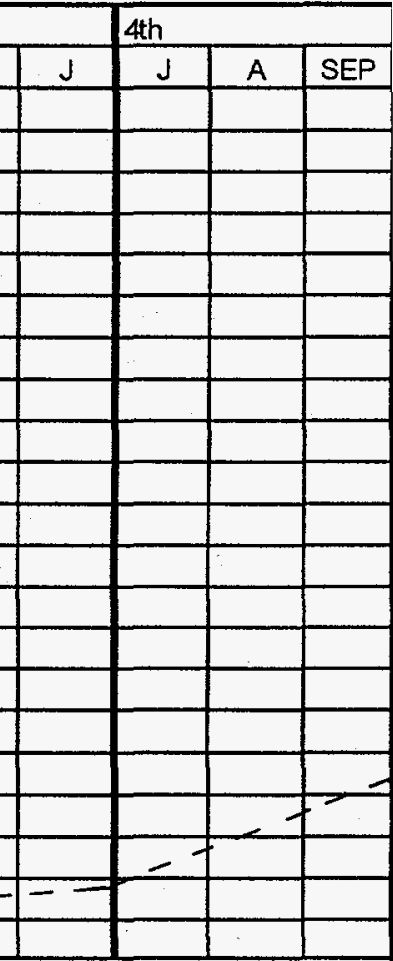

c. Cumulative Accrued Costs

\begin{tabular}{|l|r|r|r|r|r|r|r|}
\hline Planned & & & 14 & & & 28 \\
\hline Actual & & & 0 & & & 19 \\
\hline Variance & & & 14 & & & 9 & \\
\hline
\end{tabular}

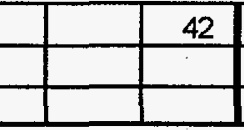

11. Major Milestone Status

Units Planned

Units Complete

Subtask 12.1 In Situ Analytical Instrumentation for Characterization of Hazardous Materials

$P$

Subtask 12.2 Economical Analysis of Laser Cleanup Operations

$P$

P

P

P

P

P

C

P

$P$

p c

c

c

c

c

c

c

c

12. Remarks

13. Signature of Recipient and Date 